Check for updates

Cite this: Mater. Chem. Front. 2020, 4, 1954

Received 31st March 2020,

Accepted 4th May 2020

DOI: $10.1039 / \mathrm{d} 0 \mathrm{qm} 00186 \mathrm{~d}$

rsc.li/frontiers-materials

\section{Opportunities and critical factors of porous metal-organic frameworks for industrial light olefins separation}

\author{
Tianhao Lan, ${ }^{a}$ Libo Li, (D) *ab Yang Chen, (D) ${ }^{a}$ Xiaoqing Wang, ${ }^{a}$ Jiangfeng Yang (D) ${ }^{a}$ \\ and Jinping $\mathrm{Li}\left(\mathbb{D D}^{\mathrm{ab}}\right.$
}

\begin{abstract}
Light olefins (ethylene, propylene, and 1,3-butadiene) are widely used as building blocks in the petrochemical industry and for the fabrication of everyday products. Developing energy cost-efficient porous materials for the separation of light olefins is fundamentally and industrially important. Metal-organic frameworks (MOFs), representing a novel class of porous materials, possess unique pore structures, endowing them with exceptional porosity, tunable pore sizes, and facile functionalization. These features permit distinct host-guest interactions and/or sieving effects, allowing the separation of molecules in an energy-efficient manner. However, some critical factors, such as large-scale production and fabrication into shaped forms need to be addressed for real industrial separations. To solve these issues, many novel approaches for synthesizing and shaping MOFs have recently been developed. In this review, we summarize and highlight recent advances in the realm of gas separation using MOFs as adsorbents, covering the progress made in improving the key features of MOFs that are necessary for their real-world applications, and opening a broader perspective on the current status of this field and its challenges.
\end{abstract}

${ }^{a}$ College of Chemistry and Chemical Engineering, Shanxi Key Laboratory of Gas Energy Efficient and Clean Utilization, Taiyuan University of Technology, Taiyuan,030024, Shanxi, P. R. China. E-mail: lilibo908@hotmail.com; Tel: +8615635105908

${ }^{b}$ State Key Laboratory of Coal Conversion, Institute of Coal Chemistry, Chinese Academy of Sciences, Taiyuan 030024, Shanxi, P. R. China

\section{Introduction}

Light olefins (C2-C4) are important constituents of many products that we rely upon in our daily lives, and are currently produced from fossil-derived feedstocks such as naphtha and light paraffins. Nowadays, most of the machinery present in a generic industrial installation (e.g., oil refinery or polymer factory) consumes vast amounts of energy with the aim of purifying these products.

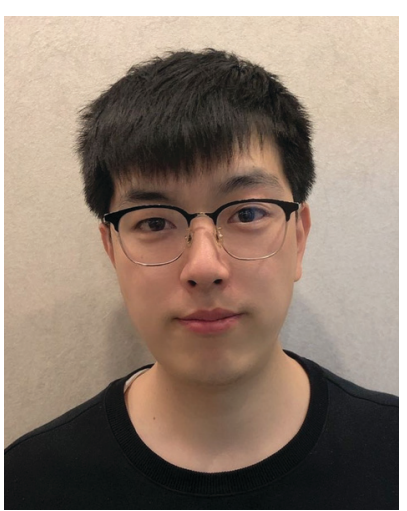

Tianhao Lan
Tianhao Lan obtained his BS degree in Process Equipment and Control Engineering from Taiyuan University of Technology in 2018. In the same year, he joined the group of Prof. Libo Li as a MS student at Taiyuan University of Technology. His main interests are in the fields of metal-organic frameworks for efficient light hydrocarbons separation.

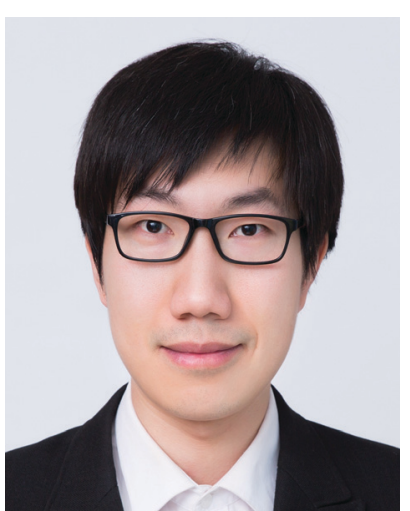

Libo Li
Libo Li received his PhD degree in Chemistry Engineering from Taiyuan University of Technology in 2015. From 2016 to 2018, he worked in Prof. Banglin Chen's group at the University of Texas at San Antonio as a postdoctoral fellow. In December 2018, he came back to China and promoted as Professor of Chemistry and Chemical Engineering at Taiyuan University of Technology. His current research focuses on the metal-organic frameworks for efficient light hydrocarbons separation. 


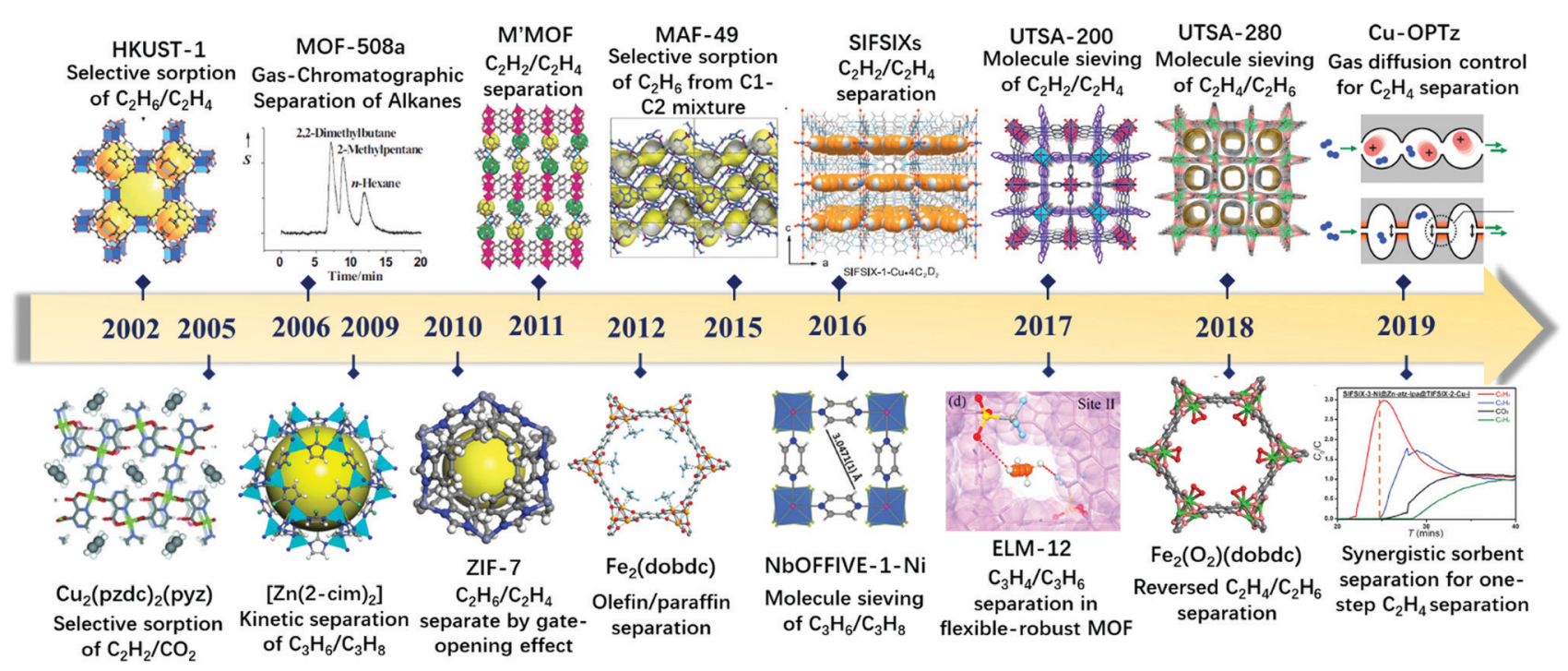

Scheme 1 Timeline of important breakthroughs in the use of MOFs for the separation of light olefins.

Distillation remains the most commonly applied separation process. Specifically, this technology constitutes around $90-95 \%$ of all separations in the light-olefin and petroleum refining industries. ${ }^{1}$ However, the separation and purification process is also inefficient, and the aforementioned energy consumption accounts for around $40 \%$ of all energy input in the current chemical industry. ${ }^{2}$ The recent rise in energy security concerns and demands further emphasizes the relevance of this problem.

In this regard, tremendous energy savings can be expected by applying advanced adsorptive separation and/or membrane-based processes by employing porous materials as separating agents. ${ }^{3}$ Notable research efforts have been devoted to the design and synthesis of efficient separation materials, such as carbon-based materials, ${ }^{4}$ zeolites, ${ }^{5}$ and metal-organic frameworks (MOFs) ${ }^{6}$ for the adsorptive separation of light olefins. Compared with classical adsorbents, such as zeolites and carbon-based materials, the new generation of MOFs (also called porous coordination polymers) offer great potential for addressing the above challenges by virtue of their

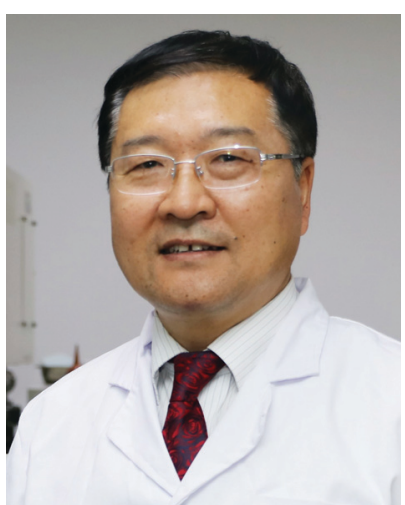

Jinping Li
Jinping Li obtained the PhD degrees from Taiyuan University of Technology in 2007, under the supervision of Prof. Ke-Chang. Xie. Since 2008, he has been a full professor at Taiyuan University of Technology. He now serves as the director of Shanxi Key Laboratory of Gas Energy Efficient and Clean Utilization and Collaborative Innovation Center for Efficient Exploitation and Utilization of Coal bed methane. His current research focuses on the new materials for efficient and clean utilization of gas energy. customizable pore channels and propensity for fine-tuning of the pore system (pore aperture size, shape, and functionality). ${ }^{7-11}$ That's why MOFs can be applied to numerous fields such as gas storage ${ }^{12-16}$ gas separations, ${ }^{17-20}$ chemical sensing, ${ }^{21-25}$ catalysis, ${ }^{26-31}$ molecular recognition $^{32-35}$ and environmental remediation. ${ }^{36-38}$ For the chemistry and materials science communities, MOFs have been demonstrated to be promising for addressing some traditional technological problems (Scheme 1). ${ }^{39-42}$

Although a good deal of progress has been made, several steps are still required to scale-up MOF materials from studies of their basic science to the realm of applications. Looking forward, a future direction would be to focus on scaled-up syntheses, ${ }^{43-46}$ while still satisfying multiple criteria, such as longterm stability ${ }^{47-53}$ high performance, and processability, ${ }^{54-56}$ all within a viable cost envelope.

Herein, we intend to give an overview on: (I) recent important scientific developments on MOFs for their potential industrial applications in the selected area of light-olefin separation, and correlations between their structural/chemical features and their adsorption or separation performances; (II) producing as well as shaping MOFs in a simple, easy, green, and low-cost way, and in sufficient amounts to meet the needs for such applications; (III) the state-of-the-art preparation of MOF-based devices for industrial implementation, including the many efforts of industry to patent and commercialize these compounds. This review aims to chart the path from the basic academia laboratory to the practical application of MOF materials in real separations, showing that these compounds can indeed be much more than intellectual exercises of an educated mind. The final goal, in any case, would be market implementation.

\section{Pore chemistry and size control in MOFs for the separation of light olefins}

Light olefins are among the most important feedstocks in the petrochemical industry, with a global production capacity of 
more than 420 million tons [ethylene $\left(\mathrm{C}_{2} \mathrm{H}_{4}\right) 170$ million, propylene $\left(\mathrm{C}_{3} \mathrm{H}_{6}\right) 130$ million, and 1,3-butadiene $\left(\mathrm{C}_{4} \mathrm{H}_{6}\right) 120$ million] in 2018. Today, due to increased worldwide demand for plastic products, there is tremendous interest in the development of new separation technologies and separation materials for the efficient isolation of light olefins from their mixtures. Moreover, some petrochemical industry purge gases or refinery gases are potentially significant sources of light olefins, with contents of up to 20-30\%. About 6 million cubic meters of release gas is generated by oil refineries in China each year, and a high proportion of this gas resource is not well gathered, with some being directly burned and vented to the atmosphere. It is a great waste of energy and a source of significant $\mathrm{CO}_{2}$ emissions.

Porous materials can be used to separate olefins from these mixtures through pressure-swing adsorption or vacuum-swing adsorption. Qualitatively, the effectiveness of a particular porous material depends on how well it adsorbs olefins at the higher pressure and then how easily it releases them at the lower pressure. ${ }^{57-61}$

\section{$2.1 \mathrm{C}_{2} \mathrm{H}_{4}-\mathrm{C}_{2} \mathrm{H}_{6}$ separation}

The separation of olefin-paraffin mixtures, such as $\mathrm{C}_{2} \mathrm{H}_{4}-\mathrm{C}_{2} \mathrm{H}_{6}$, is a very important process because polymer-grade $\mathrm{C}_{2} \mathrm{H}_{4}$ products with purity $\geq 99.5 \%$ is the prime raw material in the chemical industry and the feedstock for $30 \%$ of all petrochemicals, such as polyethylene, polyvinyl chloride, cellulose acetate, and polyvinyl acetate polymer. ${ }^{1}$ Traditional olefin/paraffin separations have primarily relied on energy-intensive cryogenic distillation, which represents one of the most energy-intensive processes in industry. ${ }^{62}$ Adsorbent-based separations have been considered as being among the most energy-efficient alternatives. Studies of a number of MOFs have revealed that their excellent separations mainly rely on one or more of the following mechanisms: (1) an equilibrium-based mechanism; (2) a kinetic-based mechanism; (3) a gate-opening effect; and (4) a molecular sieving effect. Depending on whether $\mathrm{C}_{2} \mathrm{H}_{4}$ or $\mathrm{C}_{2} \mathrm{H}_{6}$ is captured, MOF materials can be categorized into $\mathrm{C}_{2} \mathrm{H}_{4}$ - or $\mathrm{C}_{2} \mathrm{H}_{6}$-selective adsorbents, as detailed below.

2.1.1 $\mathrm{C}_{2} \mathrm{H}_{4}$-selective adsorbent. $\mathrm{C}_{2} \mathrm{H}_{4}$-selective adsorbents extract $\mathrm{C}_{2} \mathrm{H}_{4}$ from $\mathrm{C}_{2} \mathrm{H}_{4} / \mathrm{C}_{2} \mathrm{H}_{6}$ mixtures, primarily owing to stronger framework- $\mathrm{C}_{2} \mathrm{H}_{4}$ interactions and the smaller molecular size of $\mathrm{C}_{2} \mathrm{H}_{4}$.

In the view of commercial adsorbent, researchers have made great efforts on zeolites for selective separation of $\mathrm{C}_{2} \mathrm{H}_{4}$ with molecule sieving effect. In 2012, Aguado et al. prepared a silver zeolite A (AgA) from NaX by ion-exchange. ${ }^{63}$ Compared with $\mathrm{NaX}$, the pore size of AgA decreased from 4.24 and $4.84 \AA$ to 4.35 and $4.36 \AA$, falling just between the kinetic diameters of ethane and ethylene. The gas mixture can be separated effectively by molecular sieving and $\pi$-complexation between $\mathrm{Ag}^{+}$ and ethylene. In 2017, Bereciartua et al. described the synthesis and structural determination of a flexible pure silica zeolite (ITQ-55). ${ }^{64}$ This material can dynamically separate ethylene from ethane with an unprecedented selectivity of close to 100 .

The first example of an MOF material used to separate olefin/ alkane mixtures was Cu-BTC ${ }^{65}$ (BTC = benzene-1,3,5-tricarboxylate).
The double bond of the olefin can form a strong $\pi$-complex with the unsaturated $\mathrm{Cu}$ (II) ions in the MOF under low pressure, resulting in strong selective adsorption. The adsorption capacity of ethylene is thus larger than that of ethane, achieving the purpose of their separation. Wang et al.'s simulation results for singlecomponent adsorption of ethylene yielded a value in excess of $6 \mathrm{mmol} \mathrm{g}{ }^{-1}{ }^{66}$ At $298 \mathrm{~K}$ and $100 \mathrm{kPa}$, Grand Canonical Monte Carlo (GCMC) calculations predict a separation selectivity for this material of more than 2 .

In 2011, Bao et al. reported Mg-MOF-74, ${ }^{67}$ which has a high density of unsaturated metal sites for the separation of olefin/ alkane mixtures. Mg-MOF-74 has one-dimensional hexagonal channels with five-coordinate $\mathrm{Mg}$ (II) ions decorating their edges (Fig. 1a), and gas molecules are mainly adsorbed at the unsaturated metal sites. The results of gas adsorption experiments (Fig. 1b and c) showed that the material had good adsorption capacities for ethylene and ethane, and the amounts adsorbed at $298 \mathrm{~K}$ and $100 \mathrm{kPa}$ in Mg-MOF-74 were measured as 6.9 and $7.2 \mathrm{mmol} \mathrm{g}^{-1}$, respectively. The ideal separation ability and high $\mathrm{C}_{2} \mathrm{H}_{4} / \mathrm{C}_{2} \mathrm{H}_{6}$ selectivity (13.9) of Mg-MOF-74 proves that it is feasible to separate such mixtures in a vacuum-swing adsorption process using this MOF as an adsorbent.

To enhance interactions between ethylene and unsaturated metal sites in an MOF adsorbent, in 2012, Bloch et al. applied $\mathrm{Fe}_{2}$ (dobdc) (dobdc ${ }^{4-}=2,5$-dioxido-benzenedicarboxylate) in the separation of $\mathrm{C}_{2} \mathrm{H}_{4} / \mathrm{C}_{2} \mathrm{H}_{6} \cdot{ }^{68}$ Their adsorption experiments showed that $\mathrm{Fe}_{2}$ (dobdc) exhibits a strong affinity for unsaturated

a
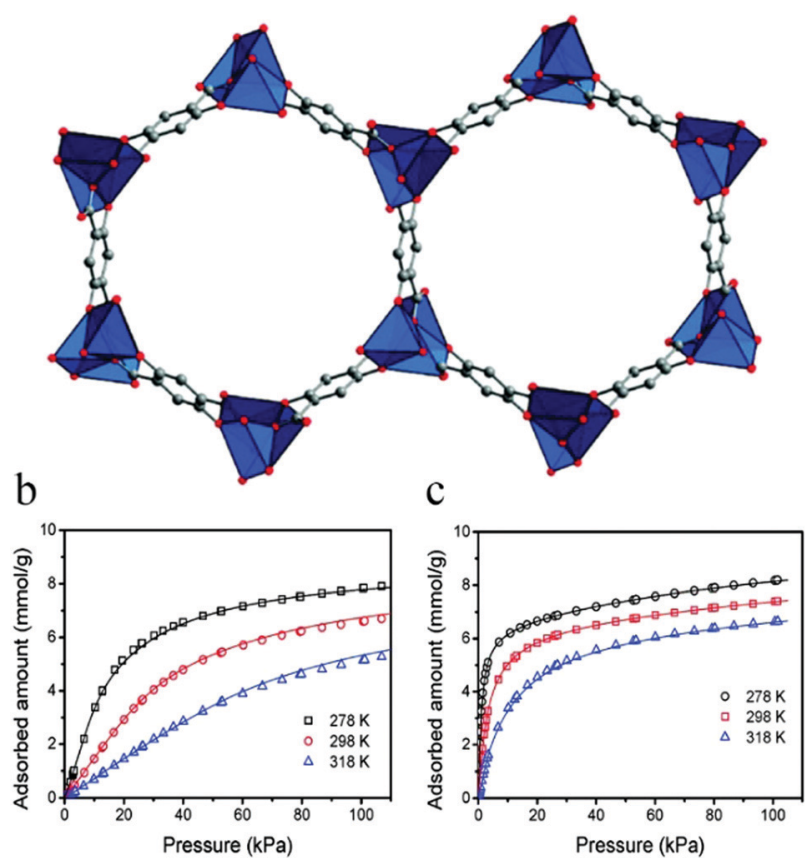

Fig. 1 (a) Crystal structure of Mg-MOF-74 viewed along the $c$-axis direction. The open metal ions bonded by five oxygen atoms are located in the center of a square-pyramidal coordination environment $(\mathrm{O}$, red; $\mathrm{C}$, gray; $\mathrm{H}$ atoms omitted for clarity). Adsorption equilibrium isotherms of ethane (b) and ethylene (c) on Mg-MOF-74 at 278, 298, and $318 \mathrm{~K}$. Solid lines represent the dual-site Sips model fits. 
light hydrocarbons, including $\mathrm{C}_{2} \mathrm{H}_{2}, \mathrm{C}_{2} \mathrm{H}_{4}$, and $\mathrm{C}_{3} \mathrm{H}_{6}$. Neutron powder diffraction studies indicated that the adsorption site of unsaturated light hydrocarbons lay within the $\mathrm{Fe}_{2}$ (dobdc) channel, with Fe-C distances in the range 2.42-2.60 $\AA$ (Fig. 2). The interactions of $\mathrm{C}_{2} \mathrm{H}_{6}$ and $\mathrm{CH}_{4}$ with the metal cations in $\mathrm{Fe}_{2}$ (dobdc) were seen to be weaker, as suggested by elongated Fe-C distances of around $3 \AA$. The $\mathrm{C}_{2} \mathrm{H}_{4} / \mathrm{C}_{2} \mathrm{H}_{6}$ selectivity was calculated to be 13-18 for an equimolar mixture at $318 \mathrm{~K}$ on the basis of ideal adsorbed solution theory (IAST), which is significantly higher than those of zeolite NaX or isostructural metalorganic framework $\mathrm{Mg}_{2}$ (dobdc). Breakthrough experiments also proved that $\mathrm{Fe}_{2}$ (dobdc) could separate an equimolar mixture of $\mathrm{C}_{2} \mathrm{H}_{4}$ and $\mathrm{C}_{2} \mathrm{H}_{6}$ into the pure component gases of $99.0-99.5 \%$ purity at $318 \mathrm{~K}$ and $100 \mathrm{kPa}$. This work represents a good example to illustrate the role of unsaturated metal sites in $\mathrm{C}_{2} \mathrm{H}_{4} / \mathrm{C}_{2} \mathrm{H}_{6}$ separation.

Subsequently, in 2014, Yang et al. adopted hydroxylfunctionalized porous MOF NOTT-300 (NOTT represent for University of Nottingham) to achieve high-capacity adsorption and separation of light hydrocarbons through multiple synergistic supramolecular interactions. ${ }^{69}$ The amounts of $\mathrm{C}_{2} \mathrm{H}_{4}$ and $\mathrm{C}_{2} \mathrm{H}_{6}$ adsorbed at $293 \mathrm{~K}$ and 1 bar in NOTT-300 were measured as 4.28 and $0.85 \mathrm{mmol} \mathrm{g}^{-1}$, respectively, giving rise to a notable uptake difference of $3.43 \mathrm{mmol} \mathrm{g}^{-1}$, which was greater than that of any MOF reported prior to this 2014 study. The selectivity for $\mathrm{C}_{2} \mathrm{H}_{4} / \mathrm{C}_{2} \mathrm{H}_{6}$ by IAST in NOTT-300 was calculated as 48.7, significantly higher than those of the previously reported
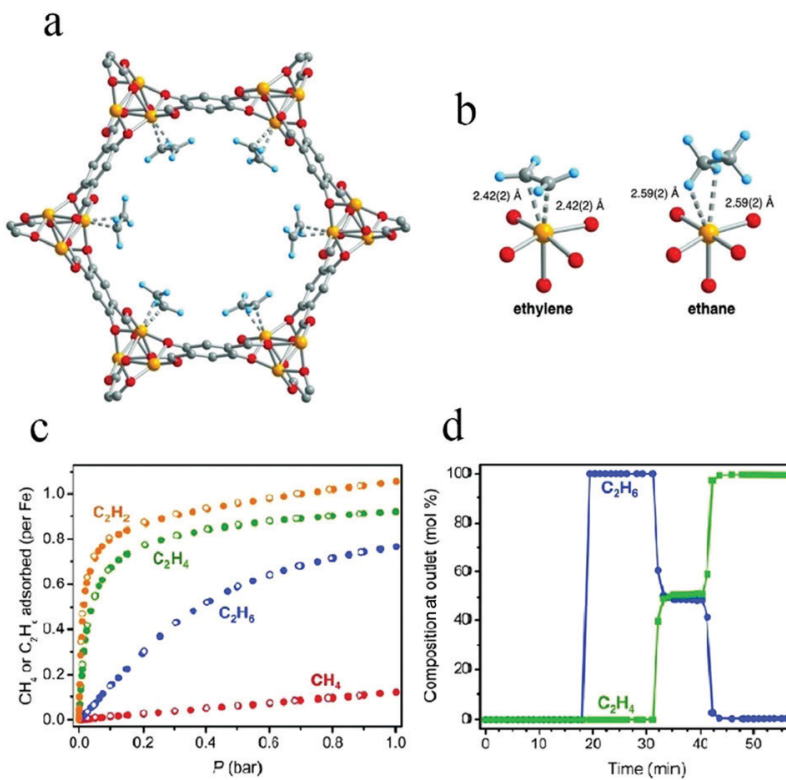

d

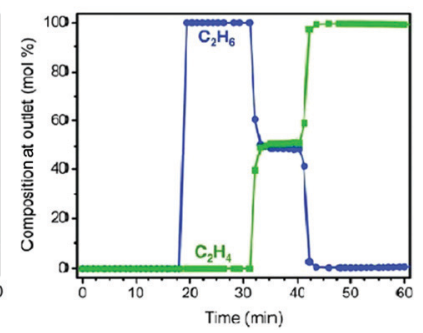

Fig. 2 (a) A portion of the solid-state structure of $\mathrm{Fe}_{2}(\mathrm{dobdc}) \cdot 2 \mathrm{C}_{2} \mathrm{D}_{4}$ determined from neutron powder diffraction analysis. Orange, red, gray, and blue spheres represent $\mathrm{Fe}, \mathrm{O}, \mathrm{C}$, and $\mathrm{D}$ atoms, respectively. (b) $\mathrm{H}_{4}$ (dobdc) ligand and the first coordination spheres about the Fe center upon dosing $\mathrm{Fe}_{2}$ (dobdc) with $\mathrm{C}_{2} \mathrm{H}_{4}$ or $\mathrm{C}_{2} \mathrm{H}_{6}$. (c) Gas adsorption isotherms for methane, ethane, ethylene, and acetylene on $\mathrm{Fe}_{2}$ (dobdc) at $318 \mathrm{~K}$. Filled and open circles represent adsorption and desorption data, respectively. (d) Experimental breakthrough curves for the adsorption of equimolar ethane/ethylene mixtures flowing through a $1.5 \mathrm{~mL}$ bed of $\mathrm{Fe}_{2}$ (dobdc) at $318 \mathrm{~K}$ with a total gas flow of $2 \mathrm{~mL} \mathrm{~min}^{-1}$ at atmospheric pressure. materials, including Cu-BTC (4.0), Co-MOF-74 (6.0), Fe-MOF-74 (13.6), and PAF-1-SO ${ }_{3} \mathrm{Ag}$ (26.9). In situ synchrotron X-ray and neutron powder diffraction experiments revealed that the $\mathrm{M}-\mathrm{OH}$ groups, aromatic - $\mathrm{CH}$ groups, and phenyl rings in NOTT-300 introduced weak, additive, supramolecular interactions with the adsorbed $\mathrm{C}_{2} \mathrm{H}_{4}$ molecules, with the $\mathrm{C} \cdot \mathrm{HO}$ distance between the $\mathrm{C}_{2} \mathrm{H}_{4}$ molecule and the hydroxyl group being about $4.62 \AA$. However, $\mathrm{C}_{2} \mathrm{H}_{6}$ was seen to reside at a much longer distance from the $-\mathrm{OH}$ group $(\mathrm{C} \cdots \mathrm{O}=5.07 \AA)$, indicative of weaker interactions with the NOTT-300 host. Consequently, the material showed excellent adsorption and separation performance.

In 2017, Bachman et al. built upon previous work by modifying the organic ligands of $\mathrm{Fe}_{2}$ (dobdc), thereby synthesizing a series of MOFs of the type $\mathrm{M}_{2}(m$-dobdc) $(\mathrm{M}=\mathrm{Mg}, \mathrm{Mn}, \mathrm{Fe}$, Co, Ni; $m$-dobdc ${ }^{4-}=4,6$-dioxido-1,3-benzenedicarboxylate) by employing a meta-substituted $\mathrm{H}_{4}\left(m\right.$-dobdc) ligand. ${ }^{70} \mathrm{Fe}_{2}(m$-dobdc $)$ displayed the highest ethylene/ethane $(>25)$ and propylene/ propane $(>55)$ selectivities at $298 \mathrm{~K}$ and $1 \mathrm{bar}$, together with olefin capacities exceeding $7 \mathrm{mmol} \mathrm{g}^{-1}$. In situ single-crystal X-ray diffraction analysis revealed that the vast improvement in selectivity arises from enhanced metal-olefin interactions induced by increased charge density at the metal sites. As a precondition of its selectivity, the material also shows fast adsorption kinetics because of its hexagonal channels of width about $12 \AA$, yielding highly pure olefins without a temperature swing. The excellent olefin/paraffin selectivity, high olefin capacity, rapid adsorption kinetics, and low raw material costs make $\mathrm{Fe}_{2}$ ( $m$-dobdc) a promising material for the separation of light hydrocarbons.

Another powerful strategy for achieving the separation of light hydrocarbons through the use of MOFs is to precisely tune their pore size to permit a molecular sieving effect. This strategy allows the complete separation of one component from others based on a molecular size or shape cut-off, avoids the co-adsorption of impurities without sacrificing the valuable uptake capacity of the porous medium, and enables infinite selectivity.

In 2018, Bao et al. synthesized a series of gallate-based MOF materials, $\mathrm{M}$-gallate $(\mathrm{M}=\mathrm{Ni}, \mathrm{Mg}, \mathrm{Co}),{ }^{71}$ featuring threedimensionally interconnected zigzag channels. The aperture sizes were ideally suited for molecular sieving of ethylene $(3.28 \times$ $4.18 \times 4.84 \AA)$ and ethane $(3.81 \times 4.08 \times 4.82 \AA)$. In breakthrough experiments with equimolar $\mathrm{C}_{2} \mathrm{H}_{4} / \mathrm{C}_{2} \mathrm{H}_{6}$ mixtures, members of the M-gallate series of MOFs all performed well, showing high selectivity for ethylene. In particular, Co-gallate at $298 \mathrm{~K}$ and 1 bar exhibited an unprecedented adsorption selectivity of 52 .

In 2018, Lin et al. synthesized an ultramicroporous MOF $\left[\mathrm{Ca}\left(\mathrm{C}_{4} \mathrm{O}_{4}\right)\left(\mathrm{H}_{2} \mathrm{O}\right)\right]$ (denoted as UTSA-280, UTSA represent for University of Texas USA) from calcium nitrate and squaric acid. $^{72}$ UTSA-280 possesses rigid one-dimensional channels with cross-sectional areas of about $14.4 \AA^{2}$ (Fig. 3), which falls between the sizes of $\mathrm{C}_{2} \mathrm{H}_{4}\left(13.7 \AA^{2}\right)$ and $\mathrm{C}_{2} \mathrm{H}_{6}\left(15.5 \AA^{2}\right)$, suggesting great size/shape sieving potential for their separation. At $298 \mathrm{~K}$ and 1 bar, the $\mathrm{C}_{2} \mathrm{H}_{4}$ uptake in UTSA-280 reaches $2.5 \mathrm{mmol} \mathrm{g}^{-1}$, whereas it adsorbs a negligible amount of $\mathrm{C}_{2} \mathrm{H}_{6}$ (0.098 $\left.\mathrm{mmol} \mathrm{g}^{-1}\right)$. Breakthrough experiments validated the efficacy of this material for separating $\mathrm{C}_{2} \mathrm{H}_{4} / \mathrm{C}_{2} \mathrm{H}_{6}$ mixtures with 
a

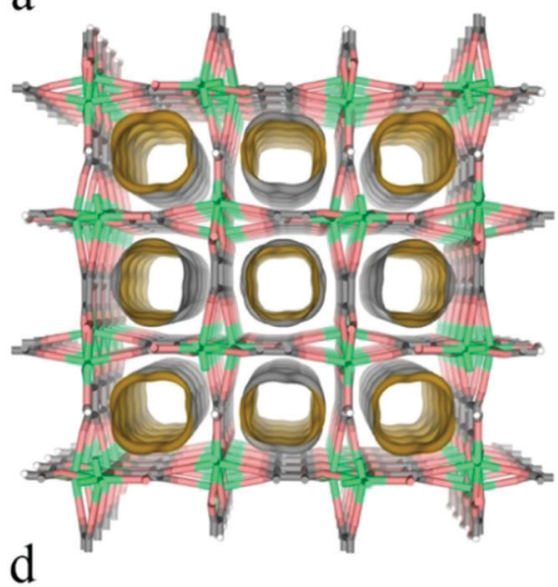

b

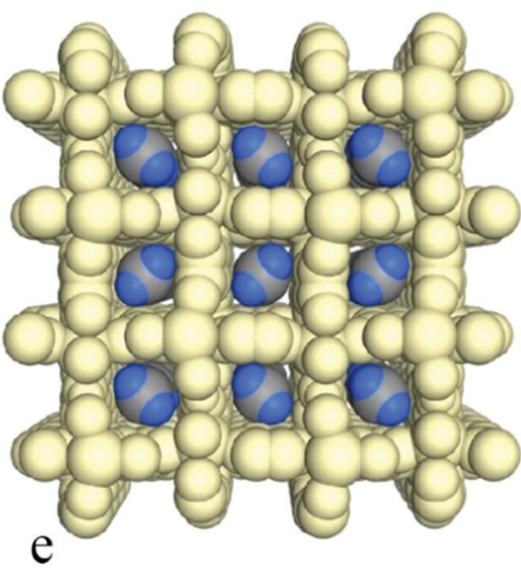

C
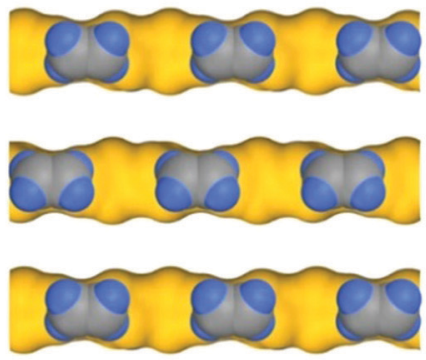

$\mathrm{f}$
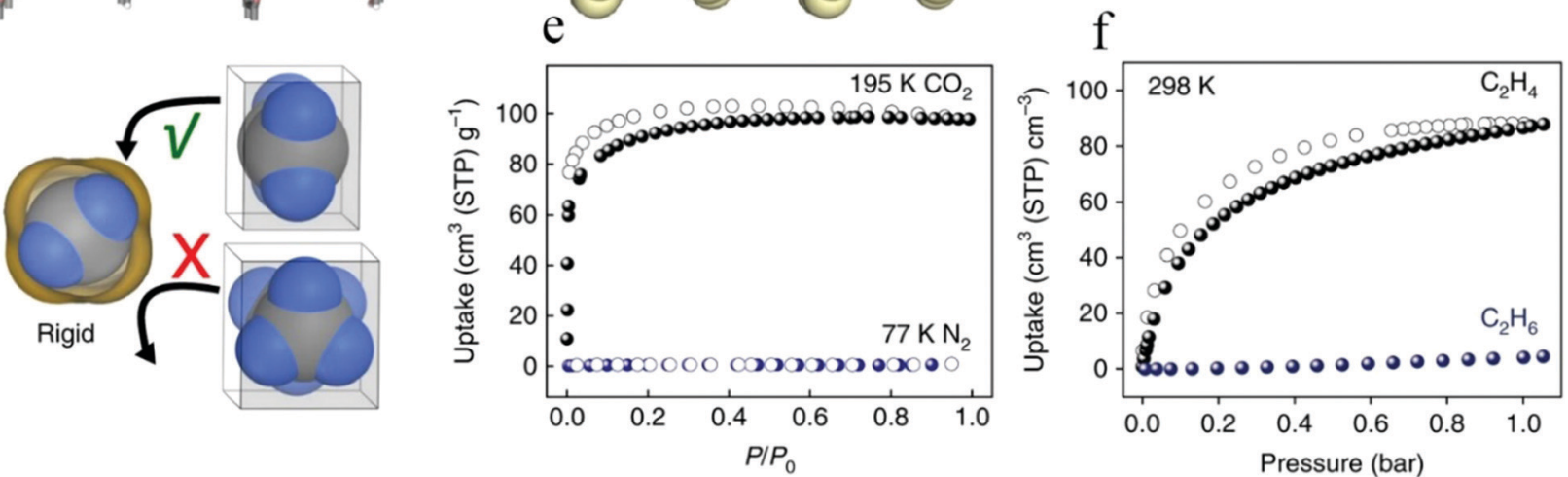

Fig. 3 (a) Crystal structure of guest-free UTSA-280 determined by single-crystal X-ray diffraction analysis, showing one-dimensional channels viewed along the [001] direction. Green, light-coral, and gray nodes represent $\mathrm{Ca}$, $\mathrm{O}$, and $\mathrm{C}$ atoms, respectively. (b and $\mathrm{c}$ ) Top and side views of the packing diagram of the $\mathrm{C}_{2} \mathrm{H}_{4}$-adsorbed structure. The framework and pore surface are shown in pale-gold and orange, respectively. The light-blue and gray spheres represent $\mathrm{H}$ and $\mathrm{C}$ atoms, respectively, of $\mathrm{C}_{2} \mathrm{H}_{4}$ molecules. (d) Schematic diagram of the size/shape sieving based on the minimum crosssectional areas of $\mathrm{C}_{2} \mathrm{H}_{4}$ and $\mathrm{C}_{2} \mathrm{H}_{6}$ molecules. (e and f) Single-component sorption isotherms of carbon dioxide (black) at $195 \mathrm{~K}$ and nitrogen (blue) at $77 \mathrm{~K}$ (e) and of ethylene (black) and ethane (indigo) at $298 \mathrm{~K}$ (f) for UTSA-280.

high $\mathrm{C}_{2} \mathrm{H}_{4}$ productivity at $298 \mathrm{~K}$ and 1 bar. Furthermore, the material not only showed strong water stability, but could also be easily synthesized on a kilogram scale using environmentally friendly methods, making it possible to be applied in industry.

Although the molecular sieving strategy can achieve very high selectivity, small pore aperture will lead to lower adsorption capacity and kinetic diffusion rate, which will eventually affect the separation efficiency.

A large number of studies have indicated that transition metal cations, such as $\mathrm{Cu}(\mathrm{I}), \operatorname{Ag}(\mathrm{I})$, and $\mathrm{Pt}(\mathrm{I})$, show strong $\pi$-complexation with compounds containing double bonds, and exhibit a strong selective adsorption capacity. Therefore, introducing metal ions into MOFs is also a good strategy for improving selectivity and adsorption capacity for olefins.

In 2014, Li et al. introduced Ag(I) ions into PAF-1 for the first time and synthesized PAF-1- $\mathrm{SO}_{3} \mathrm{Ag} .{ }^{73} \mathrm{Ag}(\mathrm{I})$ ions can form $\pi$-complexes with the carbon-carbon double bonds of olefin molecules, thus increasing the adsorption affinity towards propylene and permitting the separation of propylene and alkanes. At $296 \mathrm{~K}$ and 1 bar, the amount of ethylene taken up by PAF-1-SO $\mathrm{SO}_{3} \mathrm{Ag}$ was about $4.1 \mathrm{mmol} \mathrm{g}^{-1}$. Although this is only a moderate level, those MOFs with higher adsorption capacities [such as MgMOF-74 (7.2 $\mathrm{mmol} \mathrm{g}^{-1}$ ), Cu-BTC (7.2 $\mathrm{mmol} \mathrm{g}^{-1}$ ), and NOTT-102 $\left.\left(5.8 \mathrm{mmol} \mathrm{g}^{-1}\right)\right]$ are invariably characterized by poor stability. They commonly undergo partial framework degradation after exposure to moisture, inevitably leading to drastic decreases in ethylene uptake capacity upon reuse, but this is avoided by the high stability of PAF-1-SO $\mathrm{Ag}$. For an equimolar mixture of ethylene and ethane at $296 \mathrm{~K}$, the adsorption selectivity obtained for $\mathrm{PAF}-1-\mathrm{SO}_{3} \mathrm{Ag}$ at $100 \mathrm{kPa}$ was evaluated as 27, higher than those of all MOF materials reported prior to that time. Breakthrough experiments confirmed that PAF-1-SO $\mathrm{SO}_{3} \mathrm{Ag}$ could effectively separate an equimolar mixture of ethylene and ethane into the pure component gases with purity greater than $99 \%$.

In 2019, Mohamed et al. introduced Cu(I) ions into MFU-4l, replacing $\mathrm{Zn}$ (II) in the MOF by cation-exchange to synthesize $\mathrm{Cu}(\mathrm{I})$-MFU- $4 . .^{74}$ These authors studied the amounts of olefins and alkanes adsorbed on $\mathrm{Cu}(\mathrm{I})$-MFU- $4 l$ with different $\mathrm{Cu} / \mathrm{Zn}$ ratios. Ethylene and ethane adsorption isotherms showed the ethylene adsorption capacities of all variants of $\mathrm{Cu}(\mathrm{I})-\mathrm{MFU}-4 l$ to be larger than that of MFU-4l. A steep increase in ethylene uptake was observed at very low pressures, which was attributed to its binding to the unsaturated $\mathrm{Cu}(\mathrm{I})$ active sites and subsequent uptake by physisorption. Continuous-wave electron paramagnetic resonance spectroscopy revealed the presence of 
partially saturated $\mathrm{Cu}(\mathrm{II})$ in the activated materials. As such sites would not coordinate olefins, their adsorption capacities were not as high as expected. The potential of these materials to separate olefins/paraffins at $296 \mathrm{~K}$ and 1 bar was investigated by breakthrough experiments with equimolar olefin/paraffin mixtures. High-grade propylene and ethylene (>99.999\%) could be generated through temperature-concentration swing recycling from a $\mathrm{Cu}(\mathrm{I})-\mathrm{MFU}-4 l$ packed column with no measurable paraffin breakthrough.

In 2019, Zhang et al. selected the UiO-66 (UiO represent for University of Oslo) family for studies of $\mathrm{C}_{2} \mathrm{H}_{4} / \mathrm{C}_{2} \mathrm{H}_{6}$ separation. ${ }^{75}$ They synthesized two different MOFs [denoted as $\mathrm{UiO}-66-\mathrm{COOH}$ and $\left.\mathrm{UiO}-66-(\mathrm{COOH})_{2}\right]$ by using two organic linkers with different numbers of carboxyl groups, namely benzene-1,2,4-tricarboxylic acid (1,2,4-BTC) and benzene-1,2,4,5tetracarboxylic acid (1,2,4,5-BTEC) (Fig. 4a). The pore window size could be systematically modulated through judicious choice of the organic linkers. These authors not only finely tuned the pore size, but also immobilized copper(I) ions on the framework. The obtained microporous $\mathrm{Cu}^{\mathrm{I}}$ @UiO-66- $(\mathrm{COOH})_{2}$ showed excellent performance for the separation of $\mathrm{C}_{2} \mathrm{H}_{4} / \mathrm{C}_{2} \mathrm{H}_{6}$, with a selectivity of 80.8 , by virtue of its optimal pore size along with $\pi$-complexation ability (Fig. $4 \mathrm{~b}$ and d). This type of material usually shows a strong interaction with ethylene, as manifested in a high heat of adsorption $\left(Q_{\mathrm{st}}\right)$ (Fig. $4 \mathrm{c}$ ), which will lead to a large desorption energy.

In $2019, \mathrm{Gu}$ et al. proposed a strategy to achieve temperaturecontrolled regulation of guest molecule diffusion process based on the flipped molecular motion of ligand groups. ${ }^{76}$ They synthesized $\mathrm{Cu}$-based porous coordination polymer $\mathrm{Cu}(\mathrm{OPTz})$ with butterfly-type ligand (Optz-ipa) containing isophthalic acid and phenothiazine-5,5-dioxide (OPTz). The OPTz group shows effective local motion with low rotation and flipping energies, therefore, the size of its cavity can be adjusted according to the variation of temperature. In gas adsorption experiment, the $\mathrm{C}_{2} \mathrm{H}_{4}$ adsorption of $\mathrm{Cu}(\mathrm{OPTz})$ was increased from 9 to $62 \mathrm{~mL} \mathrm{~g}^{-1}$ with the temperature changed from 180 to $320 \mathrm{~K}$. In the temperature range of $200-370 \mathrm{~K}, \mathrm{C}_{2} \mathrm{H}_{4}$ is more easily adsorbed than $\mathrm{C}_{2} \mathrm{H}_{6}$ and the maximum adsorption ratio of $\mathrm{C}_{2} \mathrm{H}_{4} / \mathrm{C}_{2} \mathrm{H}_{6}$ is 6.0 with the selectivity of $\mathrm{C}_{2} \mathrm{H}_{4} / \mathrm{C}_{2} \mathrm{H}_{6}$ about 75 .

2.1.2 $\mathrm{C}_{2} \mathrm{H}_{6}$-selective adsorbent. Traditionally, MOF materials preferentially adsorb $\mathrm{C}_{2} \mathrm{H}_{4}$ over $\mathrm{C}_{2} \mathrm{H}_{6}$, because the former typically exhibits stronger binding affinity with the MOF structure due to its $\pi-\pi$ interactions and smaller molecular size. The desired $\mathrm{C}_{2} \mathrm{H}_{4}$ product is thus captured from gas mixtures and later released from the adsorbent. However, during this process, some co-adsorption of $\mathrm{C}_{2} \mathrm{H}_{6}$ is inevitable, which is an undesirable contaminant in the $\mathrm{C}_{2} \mathrm{H}_{4}$ product. To obtain highly pure $\mathrm{C}_{2} \mathrm{H}_{4}$ through an energy-economic approach, efforts have been devoted to seeking adsorbents that selectively remove the $\mathrm{C}_{2} \mathrm{H}_{6}$ impurity from such mixtures.

Some traditional porous materials (zeolite and porous carbon-based material) also exhibit preferential adsorption of $\mathrm{C}_{2} \mathrm{H}_{6}$, in general they are not satisfactory in separation processes due to low capacity and poor adsorption selectivity (normally lower than 3). ${ }^{77,78}$

As for MOFs, in 2010, Gücüyener et al. reported zeolite imidazolate framework ZIF-7 with unique gate-opening behavior, which was formed by connecting $\mathrm{Zn}$ metal clusters through benzimidazole linkers. ${ }^{79}$ The adsorption isotherms of several hydrocarbons were seen to increase rapidly with increasing pressure in the relevant range, but the adsorption capacity
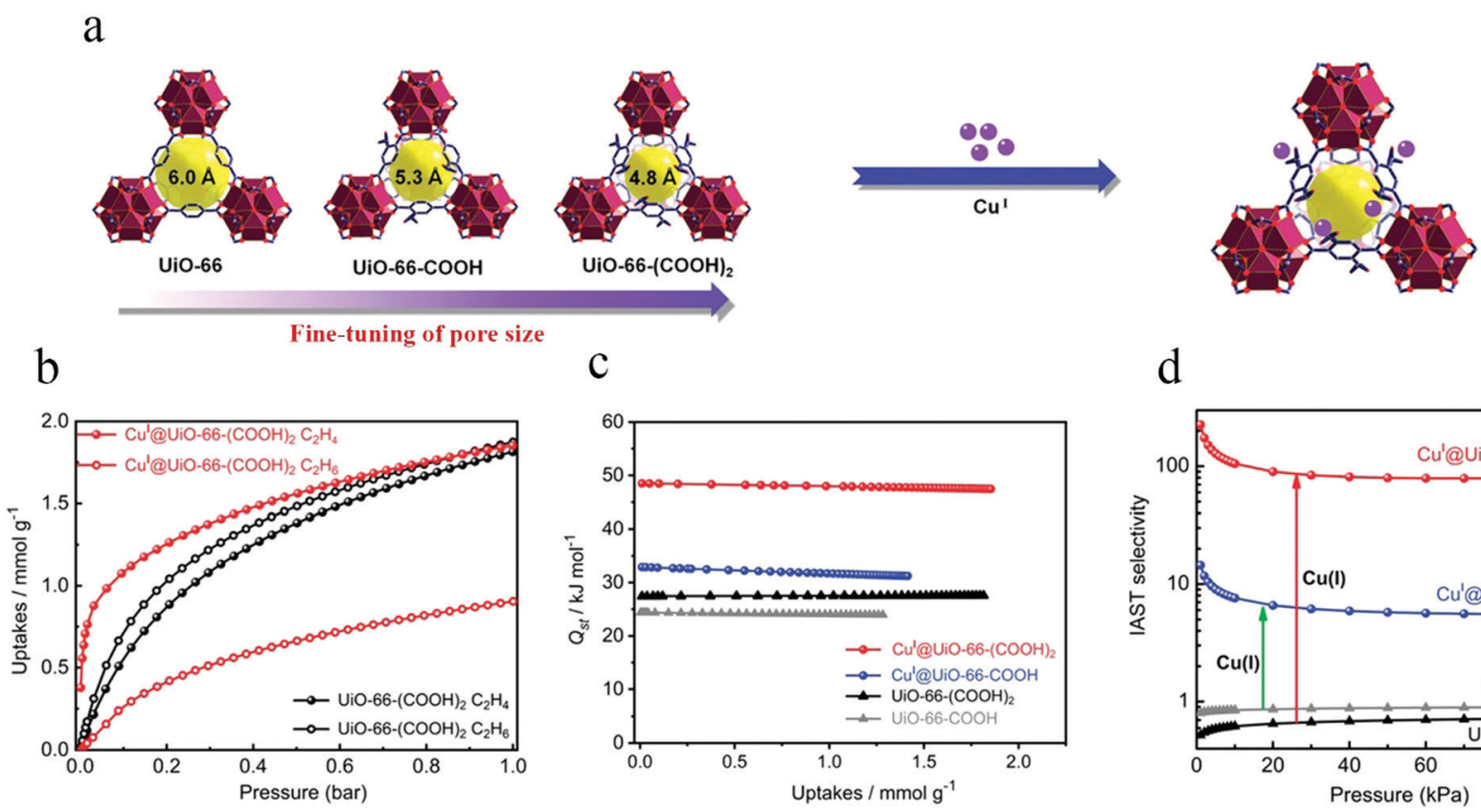

C

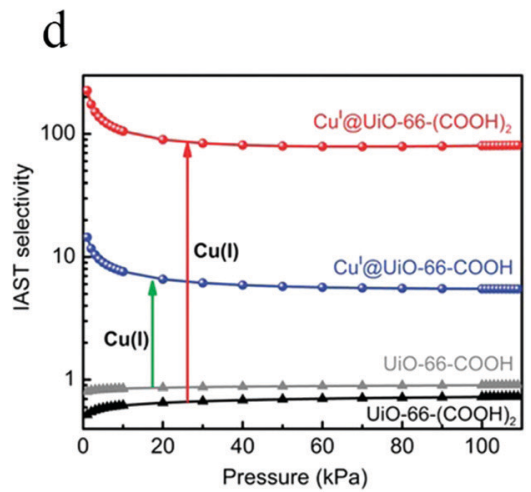

Fig. 4 (a) Single-crystal X-ray structures of UiO-66-type MOFs. (b) Single-component adsorption isotherms for $\mathrm{C}_{2} \mathrm{H}_{4}$ and $\mathrm{C}_{2} \mathrm{H}_{6}$ on $\mathrm{UiO}$-66-(COOH $)_{2}$ and Cul (aUiO-66- $(\mathrm{COOH})_{2}$ at $298 \mathrm{~K}$. (c) Isosteric heat $\left(Q_{\mathrm{st}}\right)$ of $\mathrm{C}_{2} \mathrm{H}_{4}$ adsorption on the UiO-66-type MOFs. (d) IAST calculations of activated UiO-66-type MOFs for $\mathrm{C}_{2} \mathrm{H}_{4} / \mathrm{C}_{2} \mathrm{H}_{6}$ separation at $298 \mathrm{~K}$. 
increased much more slowly in high and low pressure ranges. This type of adsorption isotherm is attributed to a specific mechanism involving gate opening, whereby specific threshold pressures control the uptake and release of individual molecules. This is a unique property of flexible MOFs. The main cavity of ZIF-7 can enlarge or contract depending on pressure variations because the linkers have some freedom to rotate through a certain angle. Because of the symmetry of the methyl structure, ZIF-7 has a lower opening pressure to $\mathrm{C}_{2} \mathrm{H}_{6}$. Consequently, there is a pressure range in which ZIF-7 can selectively adsorb $\mathrm{C}_{2} \mathrm{H}_{6}$ and not $\mathrm{C}_{2} \mathrm{H}_{4}$, suggesting that it might be possible to realize the reverse adsorption of $\mathrm{C}_{2} \mathrm{H}_{6} / \mathrm{C}_{2} \mathrm{H}_{4}$. Breakthrough experiments were carried out to evaluate the separation performance of ZIF-7 for $\mathrm{C}_{2} \mathrm{H}_{6} / \mathrm{C}_{2} \mathrm{H}_{4}$. The authors introduced a mixed gas of $\mathrm{C}_{2} \mathrm{H}_{6} / \mathrm{C}_{2} \mathrm{H}_{4} / \mathrm{H}_{2}(40: 40: 20)$ into an adsorption column packed with ZIF-7. In breakthrough experiments, $\mathrm{C}_{2} \mathrm{H}_{4}$ passed through the adsorption bed first, and could thus be obtained in high purity. This was the first report of the selective adsorption of $\mathrm{C}_{2} \mathrm{H}_{6}$ from $\mathrm{C}_{2} \mathrm{H}_{6} / \mathrm{C}_{2} \mathrm{H}_{4}$ mixtures. However, the lack of $\mathrm{C}_{2} \mathrm{H}_{6}$ adsorption sites in $\mathrm{ZIF}-7$ and the smaller pressure range between $\mathrm{C}_{2} \mathrm{H}_{6}$ and $\mathrm{C}_{2} \mathrm{H}_{4}$ led to lower separation efficiency.

In 2014, Pires et al. reported the MOF IRMOF-8 (IR represent for Isoreticular), which adsorbed greater amounts of ethane than of ethylene over a wide pressure range. ${ }^{80}$ Selectivity values between 3.4 and 1.6 were obtained, depending on the temperature and pressure. To explore the interaction of gas molecules with the surface of IRMOF-8, density functional theory (DFT) methods were applied to simulate the adsorption sites of the respective gases. Both experimental and computational results showed that, due to the difference in interaction energies of ethane and ethylene in IRMOF-8, this material preferentially adsorbs the former. The primary reason for this is that IRMOF8 has neither unsaturated metal centers nor acid groups, so it does not have strong interactions with $\mathrm{C}_{2} \mathrm{H}_{4}$. The presence of two adjacent aromatic rings is an additional important factor affecting the separation performance, allowing for strong $\mathrm{C}-\mathrm{H} \cdots \pi$ interactions between the IRMOF-8 and $\mathrm{C}_{2} \mathrm{H}_{6}$.

Because the polarity of ethylene is greater than that of ethane, MOFs with active metal sites are not suitable for selective adsorption of the latter. Instead, adsorbents with inert pore surfaces (e.g., bearing aromatic or aliphatic moieties) should be selected. In 2018, Lin et al. proposed a feasible strategy for the design of MOF materials that preferentially adsorb $\mathrm{C}_{2} \mathrm{H}_{6}{ }^{81}$ They found that increasing the effective contact area or the number of interactions between $\mathrm{C}_{2} \mathrm{H}_{6}$ molecules and the host framework can strengthen the binding affinity and lead to higher $\mathrm{C}_{2} \mathrm{H}_{6} / \mathrm{C}_{2} \mathrm{H}_{4}$ selectivities. They used $\mathrm{Cu}(\mathrm{Qc})_{2}$ (HQc = quinoline-5-carboxylic acid) as the adsorbent, the pore surface of which bears aromatic rings of low polarity, which can preferentially combine with $\mathrm{C}_{2} \mathrm{H}_{6}$, and the suitable pore size of $\mathrm{Cu}(\mathrm{Qc})_{2}$ provides a variety of interaction possibilities for the host and guest. Moreover, the larger quinoline moieties in $\mathrm{Cu}(\mathrm{Qc})_{2}$ dramatically lower its uptake capacity for $\mathrm{C}_{2} \mathrm{H}_{4}$. The calculated $\mathrm{C}_{2} \mathrm{H}_{6} / \mathrm{C}_{2} \mathrm{H}_{4}$ selectivity of $\mathrm{Cu}(\mathrm{Qc})_{2}$ for the corresponding binary equimolar mixture was up to 3.4 at $298 \mathrm{~K}$ and $100 \mathrm{kPa}$, which was higher than those of the other top-performing ethane-selective MOF materials at the time of this report. Neutron powder diffraction studies clearly revealed that $\mathrm{Cu}(\mathrm{Qc})_{2}$ displays self-adaptive sorption behavior towards $\mathrm{C}_{2} \mathrm{H}_{6}$, which enables continuous maintenance of close van der Waals contacts with $\mathrm{C}_{2} \mathrm{H}_{6}$ molecules in its optimized pore structure, and thus the preferential binding of $\mathrm{C}_{2} \mathrm{H}_{6}$ over $\mathrm{C}_{2} \mathrm{H}_{4}$. The same phenomenon can also be observed in NUM-7a which reported by $\mathrm{Hu}$ et al. in $2020 .^{82}$

According to some previous research, the $\mathrm{C}_{2} \mathrm{H}_{6}$ molecule may interact more strongly with the framework of a material than $\mathrm{C}_{2} \mathrm{H}_{4}$ by virtue of the fact that it has more $\mathrm{C}-\mathrm{H}$ bonds. If some polar functional groups are precisely introduced into an MOF, it may be possible to design a material with optimized pore size/shape and surface electrostatic distribution that can bind $\mathrm{C}_{2} \mathrm{H}_{6}$ much more strongly than $\mathrm{C}_{2} \mathrm{H}_{4}$. In 2015, Liao et al. reported the construction of a $\mathrm{Zn}$-azolate MOF [Zn(batz)] [ $\mathrm{H}_{2}$ batz $=$ bis(5-amino-1H-1,2,4-triazol-3-yl)methane $],{ }^{83}$ denoted as MAF-49, for rare selective adsorption of $\mathrm{C}_{2} \mathrm{H}_{6}$ over $\mathrm{C}_{2} \mathrm{H}_{4}$ (Fig. $5 \mathrm{a}$ and b). The pore surface of MAF-49 is rich with precisely arranged electronegative nitrogen atoms. Computational simulations indicated that the $\mathrm{C}_{2} \mathrm{H}_{6}$ molecule should form three strong $\mathrm{C}-\mathrm{H} \cdots \mathrm{N}$ hydrogen bonds and three weak $\mathrm{C}-\mathrm{H} \cdots \mathrm{N}$ electrostatic interactions with MAF-49. In contrast, for the $\mathrm{C}_{2} \mathrm{H}_{4}$ molecule, only two less strong $\mathrm{C}-\mathrm{H} \cdots \mathrm{N}$ hydrogen bonds and two very weak $\mathrm{C}-\mathrm{H} \cdots \mathrm{N}$ electrostatic interactions should be formed, because there is significant steric hindrance and electrostatic repulsion between the two $\mathrm{C}-\mathrm{H}$ moieties of the two methylene groups and the neck of the host channel, which will push $\mathrm{C}_{2} \mathrm{H}_{4}$ into a position that is not conducive to the formation of strong hydrogen bonds. Gas adsorption isotherms showed that MAF-49 had a higher $\mathrm{C}_{2} \mathrm{H}_{6}$ uptake than that of $\mathrm{C}_{2} \mathrm{H}_{4}$ under low pressure at $316 \mathrm{~K}$ (Fig. 5c). Breakthrough experiments, injecting a $15: 1 \mathrm{C}_{2} \mathrm{H}_{4} / \mathrm{C}_{2} \mathrm{H}_{6}$ mixture, were carried out, which showed that $\mathrm{C}_{2} \mathrm{H}_{4}$ could be obtained with $99.995 \%$ purity.

Li et al. also studied $\mathrm{C}_{2} \mathrm{H}_{6}$-selective adsorbents, and reported two kinds of MOFs, Ni(bdc)(ted) ${ }_{0.5}{ }^{84}$ in 2016 and PCN-250 ${ }^{85}$ in 2017. The surface area and total pore volume of $\mathrm{Ni}(\mathrm{bdc})(\mathrm{ted})_{0.5}$ were evaluated as $1701 \mathrm{~m}^{2} \mathrm{~g}^{-1}$ and $0.79 \mathrm{~cm}^{3} \mathrm{~g}^{-1}$, respectively, with an average pore diameter of $7.94 \AA$. The adsorption capacity of $\mathrm{C}_{2} \mathrm{H}_{6}$ at $100 \mathrm{kPa}$ was measured as $6.93 \mathrm{mmol} \mathrm{g}^{-1}$, and the IAST $\mathrm{C}_{2} \mathrm{H}_{6} / \mathrm{C}_{2} \mathrm{H}_{4}$ selectivity was about 2 at $100 \mathrm{kPa}$. The main reason for selective adsorption of $\mathrm{C}_{2} \mathrm{H}_{6}$ over $\mathrm{C}_{2} \mathrm{H}_{4}$ in $\mathrm{Ni}(\mathrm{bdc})(\text { ted })_{0.5}$ is the favored host-guest interactions between its $-\mathrm{CH}_{3}$ groups and the framework. PCN-250 (PCN represent for porous coordination network) is an Fe-based MOF material, which has excellent water and chemical stability. Its $\mathrm{C}_{2} \mathrm{H}_{6} / \mathrm{C}_{2} \mathrm{H}_{4}$ (1:15 and $1: 1$ ) selectivity was found to be in the range 1.9-4.0. At $100 \mathrm{kPa}$ and $298 \mathrm{~K}$, the adsorption capacities of PCN-250 for $\mathrm{C}_{2} \mathrm{H}_{6}$ and $\mathrm{C}_{2} \mathrm{H}_{4}$ were evaluated as 5.21 and $4.22 \mathrm{mmol} \mathrm{g}^{-1}$, respectively. It was found by a GCMC method that $\mathrm{C}_{2} \mathrm{H}_{6}$ and $\mathrm{C}_{2} \mathrm{H}_{4}$ have good adsorption positions around the four corners of benzene rings and the $\mathrm{N}$ atom of PCN-250. The influence of pore size and the difference in van der Waals adsorption energies are the reasons for the preferential adsorption of $\mathrm{C}_{2} \mathrm{H}_{6}$. 
a

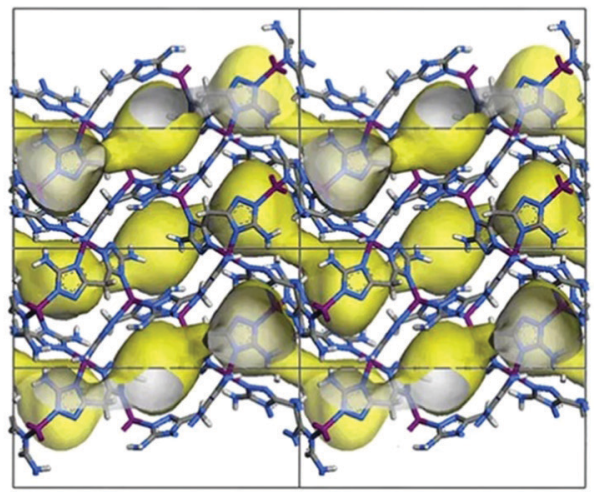

b

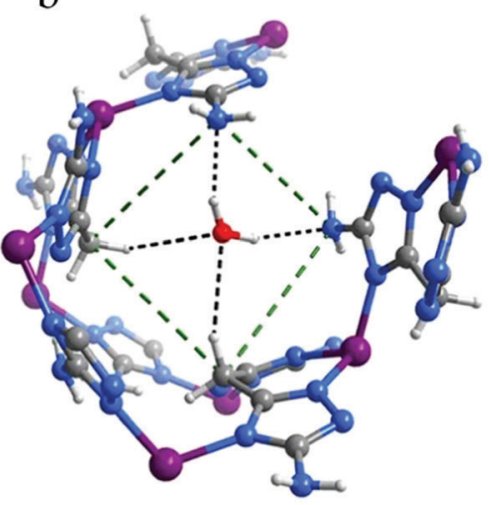

$\mathrm{c}$

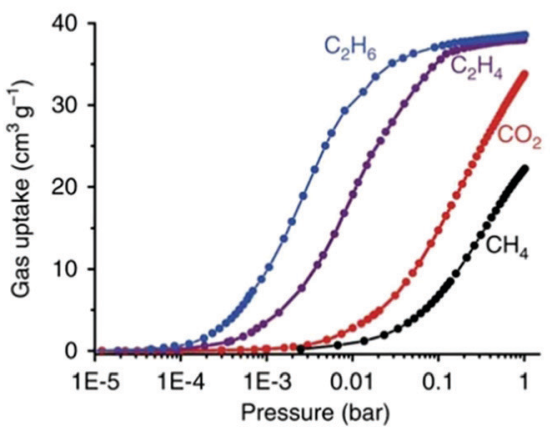

Fig. 5 X-ray crystal structure of MAF-49. $\mathrm{H}_{2} \mathrm{O}$. (a) Framework (Zn purple, $\mathrm{C}$ dark-gray, $\mathrm{H}$ light-gray, N blue) and pore surface (yellow/gray curved surface) structures. Guest molecules are omitted for clarity. (b) Local environment and hydrogen-bonding interactions of the narrowest channel neck (highlighted by green dashed lines). (c) Gas adsorption isotherms for $\mathrm{C}_{2} \mathrm{H}_{6}, \mathrm{C}_{2} \mathrm{H}_{4}, \mathrm{CO}_{2}$, and $\mathrm{CH}_{4}$ in MAF-49 at $316 \mathrm{~K}$.

The reported MOFs capable of preferentially adsorbing $\mathrm{C}_{2} \mathrm{H}_{6}$ have typically lacked specific research objectives. Unsaturated metal sites are very common in MOFs. If the unsaturated metal sites in MOF materials can be modified, the resulting materials may exhibit stronger binding affinity with alkanes than alkenes, and might thus be utilized for the selective separation of $\mathrm{C}_{2} \mathrm{H}_{6}$ from $\mathrm{C}_{2} \mathrm{H}_{6} / \mathrm{C}_{2} \mathrm{H}_{4}$ mixtures. Inspired by natural metalloenzymes and some active catalytic intermediates for the synthesis of alkanes, Li et al. reported an MOF material with iron-peroxo sites, $\mathrm{Fe}_{2}\left(\mathrm{O}_{2}\right)$ (dobdc), in $2018^{6}$ (Fig. 6). Its $\mathrm{C}_{2} \mathrm{H}_{6}$ binding affinity was evident from single-component sorption isotherms at $298 \mathrm{~K}$, which showed a much higher adsorption capacity for $\mathrm{C}_{2} \mathrm{H}_{6}\left(74.3 \mathrm{~cm}^{3} \mathrm{~g}^{-1}\right.$ ) than for $\mathrm{C}_{2} \mathrm{H}_{4}$ (around $57 \mathrm{~cm}^{3} \mathrm{~g}^{-1}$ ) at 1 bar. High-resolution neutron powder diffraction experiments were conducted on $\mathrm{C}_{2} \mathrm{D}_{6}$-loaded and $\mathrm{C}_{2} \mathrm{D}_{4}$-loaded $\mathrm{Fe}_{2}\left(\mathrm{O}_{2}\right)$ (dobdc) samples. The preferential binding of $\mathrm{C}_{2} \mathrm{H}_{6}$ at peroxo sites was established through C-D $\cdots \mathrm{O}$ deuterium bonding ( $\cdots \cdots \mathrm{O} 2.17-$ $2.22 \AA)$, with a $\mathrm{D} \cdots \mathrm{O}$ distance much shorter than the sum of the van der Waals radii of oxygen $(1.52 \AA)$ and deuterium $(1.20 \AA)$. $\mathrm{Fe}_{2}\left(\mathrm{O}_{2}\right)$ (dobdc) exhibits an IAST selectivity of 4.4 for $\mathrm{C}_{2} \mathrm{H}_{6} / \mathrm{C}_{2} \mathrm{H}_{4}$ (50:50), which sets a new benchmark. The clean and sharp separation in column breakthrough experiments performed with a $\mathrm{C}_{2} \mathrm{H}_{6} / \mathrm{C}_{2} \mathrm{H}_{4} \quad(50: 50)$ mixture further demonstrates that $\mathrm{Fe}_{2}\left(\mathrm{O}_{2}\right)\left(\right.$ dobdc) can readily produce high-purity $\mathrm{C}_{2} \mathrm{H}_{4}$ ( $\geq 99.99 \%$ ) from $\mathrm{C}_{2} \mathrm{H}_{6} / \mathrm{C}_{2} \mathrm{H}_{4}$ mixtures.

The same strategy can also be applied to other MOFs. Yang et al. reported "reversed $\mathrm{C}_{2} \mathrm{H}_{6} / \mathrm{C}_{2} \mathrm{H}_{4}$ adsorption" in $\mathrm{Cr}$ BTC through the introduction of oxygen at its unsaturated metal sites in $2019 .{ }^{86}$ The oxidized $\mathrm{Cr}-\mathrm{BTC}\left(\mathrm{O}_{2}\right)\left[\mathrm{Cr}_{3}(1,3,5\right.$-benzenetricarboxylate $\left.)_{2}\left(\mathrm{O}_{2}\right)_{3}\right]$ was found to bind $\mathrm{C}_{2} \mathrm{H}_{6}$ over $\mathrm{C}_{2} \mathrm{H}_{4}$ through its active Cr-superoxo sites. The $\mathrm{C}_{2} \mathrm{H}_{6} / \mathrm{C}_{2} \mathrm{H}_{4}(50: 50$, v/v) selectivity of $\mathrm{Cr}-\mathrm{BTC}\left(\mathrm{O}_{2}\right)$ calculated by IAST was over 3 in the low-pressure region, suggesting a universality of this strategy. However, strong interaction between the $\mathrm{C}_{2} \mathrm{H}_{6}$ molecule and the active iron-peroxo site results in a high heat of adsorption $\left(Q_{\mathrm{st}}=-66.8 \mathrm{~kJ} \mathrm{~mol}^{-1}\right)$, which necessitates increased energy consumption during the regeneration process. Decoration of the $\mathrm{C}_{2} \mathrm{H}_{6}$ preferential binding sites with ligands would allow for a significant reduction in the associated heat of adsorption, but would require the construction of a favorable pore environment for the selective binding of $\mathrm{C}_{2} \mathrm{H}_{6}$.

Large nanopores lead to a low selectivity, whereas high selectivity is invariably accompanied by very limited $\mathrm{C}_{2} \mathrm{H}_{6}$ uptake. In 2019, Qazvini et al. reported an MOF material showing a near-optimal trade-off in $\mathrm{C}_{2} \mathrm{H}_{6} / \mathrm{C}_{2} \mathrm{H}_{4}$ separations, named MUF-15 (MUF represent for Massey University Framework) ${ }^{87}$ (Fig. 7c). The $\mathrm{C}_{2} \mathrm{H}_{6}$ uptake capacity of MUF-15 at $1 \mathrm{bar}\left(4.69 \mathrm{mmol} \mathrm{g}^{-1}\right)$ is notably higher than those of some $\mathrm{C}_{2} \mathrm{H}_{6}$-selective adsorbents, namely $\mathrm{Cu}(\mathrm{Qc})_{2}\left(1.85 \mathrm{mmol} \mathrm{g}^{-1}\right)$, ZIF-7 $\left(1.85 \mathrm{mmol} \mathrm{g}^{-1}\right)$, and MAF-49 $\left(1.73 \mathrm{mmol} \mathrm{g}^{-1}\right)$. This may be attributed to its large pore volume $\left(0.51 \mathrm{~cm}^{3} \mathrm{~g}^{-1}\right)$. The adsorption selectivity of $\mathrm{C}_{2} \mathrm{H}_{6} / \mathrm{C}_{2} \mathrm{H}_{4}$ mixtures was predicted on the basis of IAST using a range of starting compositions $(50: 50,25: 75$, and 10:90 $\left.\mathrm{C}_{2} \mathrm{H}_{6} / \mathrm{C}_{2} \mathrm{H}_{4}\right)$. MUF-15 exhibited a $\mathrm{C}_{2} \mathrm{H}_{6} / \mathrm{C}_{2} \mathrm{H}_{4}$ selectivity of around 2 for all three mixtures. Based on DFT calculations, the $\mathrm{C}_{2} \mathrm{H}_{6}$ molecules are bound in a pocket defined by four phenyl rings. There are $\mathrm{C}-\mathrm{H} \cdots \pi$ interactions between all six hydrogen atoms of $\mathrm{C}_{2} \mathrm{H}_{6}$ and three adjacent phenyl rings (Fig. 7a). In contrast, the $\mathrm{C}_{2} \mathrm{H}_{4}$ molecule only shows short contacts with two parallel edges of the cavity (Fig. 7b), which explains its high selectivity for $\mathrm{C}_{2} \mathrm{H}_{6}$. Furthermore, MUF-15 has excellent properties, such as low synthesis cost, robustness, and easy regeneration, which make it a promising MOF for industrial applications.

A similar pore surface decoration strategy has recently reported by Yang et al. ${ }^{88}$ They reported a series of MOF materials, namely M-PNMI ( $\mathrm{M}=\mathrm{Mn}, \mathrm{Zn}, \mathrm{Cd})$, which were synthesized using $N, N^{\prime}$-di(4-pyridyl)-1,4,5,8-naphthalenetetracarboxydiimide. In this work, ligands with polar binding sites were introduced on the pore surfaces of the investigated MOFs, which was shown to effectively facilitate the binding of $\mathrm{C}_{2} \mathrm{H}_{6}$ molecules. The pore structure in these materials can provide a suitable preferential binding environment for $\mathrm{C}_{2} \mathrm{H}_{6}$, resulting in a higher binding affinity for $\mathrm{C}_{2} \mathrm{H}_{6}$ over $\mathrm{C}_{2} \mathrm{H}_{4}$. Based on this mechanism, M-PNMI can efficiently remove $\mathrm{C}_{2} \mathrm{H}_{6}$ from $\mathrm{C}_{2} \mathrm{H}_{6} / \mathrm{C}_{2} \mathrm{H}_{4}(1: 9$ and $1: 15, \mathrm{v} / \mathrm{v})$ mixtures to directly produce highly pure $\mathrm{C}_{2} \mathrm{H}_{4}(>99.99 \%)$ under ambient conditions.

It is worth mentioning that to separate ethylene from industrial gases, apart from ethane, trace amounts impurities 

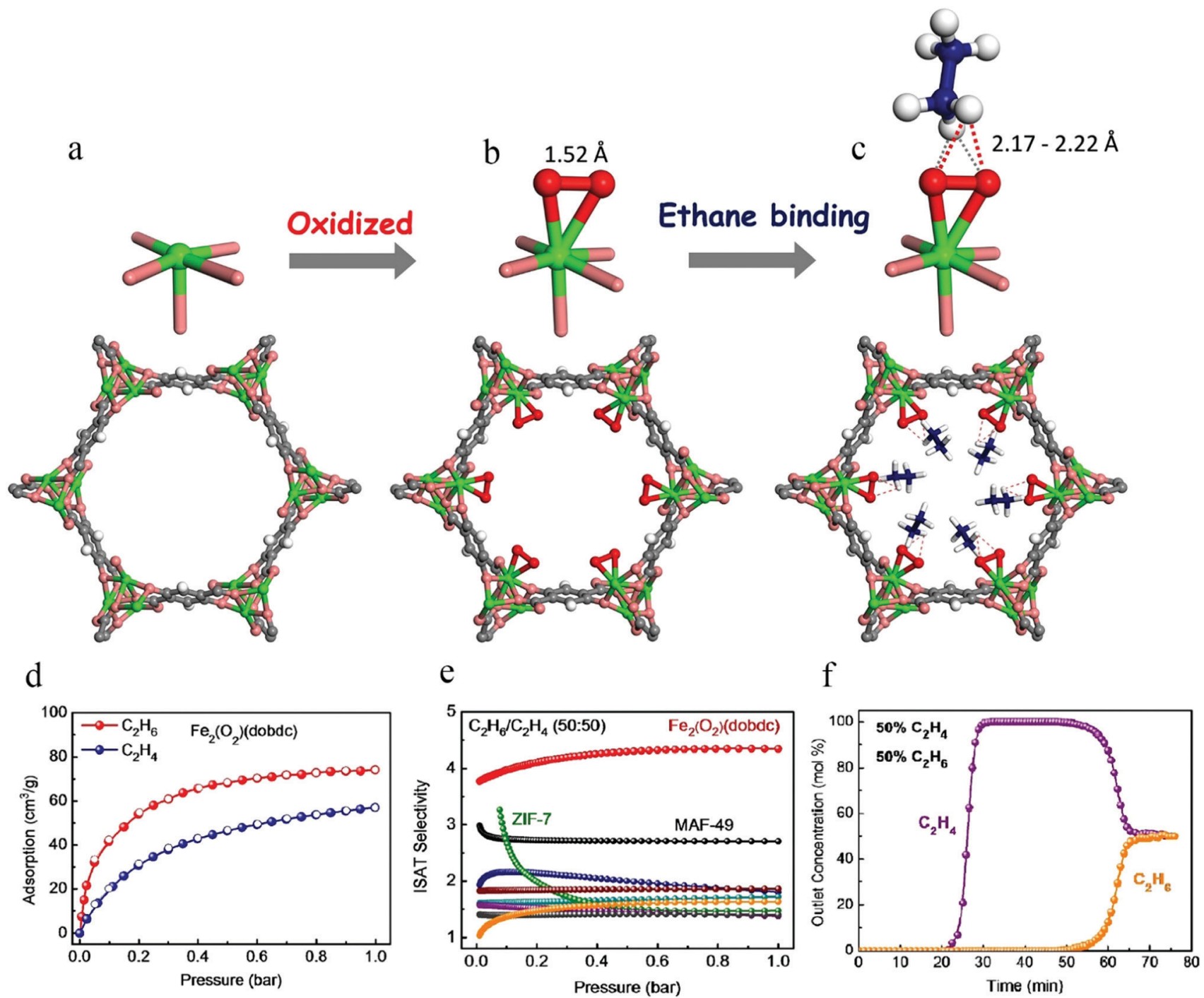

Fig. 6 Structures of (a) $\mathrm{Fe}_{2}$ (dobdc), (b) $\mathrm{Fe}_{2}\left(\mathrm{O}_{2}\right)$ (dobdc), and (c) $\mathrm{Fe}_{2}\left(\mathrm{O}_{2}\right)$ (dobdc) $\supset \mathrm{C}_{2} \mathrm{D}_{6}$ at $7 \mathrm{~K}$. Note the change from the unsaturated Fe(॥) site to the Fe( $(I I)-$ peroxo site for the preferential binding of $\mathrm{C}_{2} \mathrm{H}_{6}$. Fe, green; $\mathrm{C}$, dark-gray; $\mathrm{O}$, pink; $\mathrm{O}_{2}{ }^{2-}$, red; $\mathrm{H}$ or $\mathrm{D}$, white; $\mathrm{C}$ in $\mathrm{C}_{2} \mathrm{D}_{6}$, blue. (d) Adsorption (solid) and desorption (open) isotherms of $\mathrm{C}_{2} \mathrm{H}_{6}$ (red circles) and $\mathrm{C}_{2} \mathrm{H}_{4}$ (blue circles) in $\mathrm{Fe}_{2}\left(\mathrm{O}_{2}\right)$ (dobdc) at $298 \mathrm{~K}$. (e) Comparison of the IAST selectivities of $\mathrm{Fe}_{2}\left(\mathrm{O}_{2}\right)$ (dobdc) with those of previously reported best-performing materials for $\mathrm{C}_{2} \mathrm{H}_{6} / \mathrm{C}_{2} \mathrm{H}_{4}(50: 50)$ mixtures. (f) Experimental column breakthrough curves for a $\mathrm{C}_{2} \mathrm{H}_{6} / \mathrm{C}_{2} \mathrm{H}_{4}(50: 50)$ mixture in an absorber bed packed with $\mathrm{Fe}_{2}\left(\mathrm{O}_{2}\right)($ dobdc) at $298 \mathrm{~K}$ and 1.01 bar.

of acetylene and $\mathrm{CO}_{2}$ also should be considered. In 2019, Chen et al. solved this challenge perfectly by developing synergistic sorbent separation technology. ${ }^{89}$ They put three physisorbents in a packed-bed geometry. Among them, TIFSIX-2-Cu-i (TIFSIX $=\mathrm{TiF}_{6}{ }^{2-}, 2=4,4^{\prime}$-dipyridylacetylene, $\mathrm{i}=$ interpenetrated) is used to remove acetylene, $\mathrm{Zn}$-atz-ipa (atz $=3$-amino-1,2,4triazolate; ipa = isophthalate) is for capture of $\mathrm{C}_{2} \mathrm{H}_{6}$ and $\mathrm{CO}_{2}$ can be selective removed by SIFSIX-3-Ni (SIFSIX $=\operatorname{SiF}_{6}{ }^{2-}, 3=$ pyrazine). By using the packing sequence of SIFSIX-3-Ni@ Zn-atz-ipa@TIFSIX-2-Cu-i, directly separation of quaternary gas mixture $\left(\mathrm{C}_{2} \mathrm{H}_{2}-\mathrm{C}_{2} \mathrm{H}_{4}-\mathrm{C}_{2} \mathrm{H}_{6}-\mathrm{CO}_{2}\right)$ to product high-purity ethylene is achieved in one step.

\section{$2.2 \quad \mathrm{C}_{3} \mathrm{H}_{6}-\mathrm{C}_{3} \mathrm{H}_{8}$ separation}

Adsorptive separation of $\mathrm{C}_{3} \mathrm{H}_{6} / \mathrm{C}_{3} \mathrm{H}_{8}$ based on porous materials holds great promise for enabling a possible revolution from traditional energy-intensive cryogenic distillation to energyefficient adsorbent-based separation. Like $\mathrm{C}_{2} \mathrm{H}_{4} / \mathrm{C}_{2} \mathrm{H}_{6}$ separation, $\mathrm{C}_{3} \mathrm{H}_{6} / \mathrm{C}_{3} \mathrm{H}_{8}$ separation is also dominated by one or more of the four mechanisms (equilibrium-based mechanism, kineticbased mechanism, gate-opening effect, and molecular sieving effect) in MOFs. A high purity $\mathrm{C}_{3} \mathrm{H}_{6}$ with $99.5 \%$ minimum is required as the raw material of polypropylene. Although it is a daunting challenge to design ideal porous materials for the target separation task, immense effort from both academia and industry has been incessant over the past two decades.

2.2.1 $\mathrm{C}_{3} \mathrm{H}_{6}$-selective adsorbent. Due to the formation of a $\pi$-complex between a propylene molecule and an unsaturated metal site in an MOF, many previous efforts to separate propane and propylene have relied on this strategy. In 2009, Lamia et al. ${ }^{90}$ used the property that unsaturated $\mathrm{Cu}(\mathrm{II})$ sites in HKUST-1 (HKUST represent for Hong Kong University of 
a

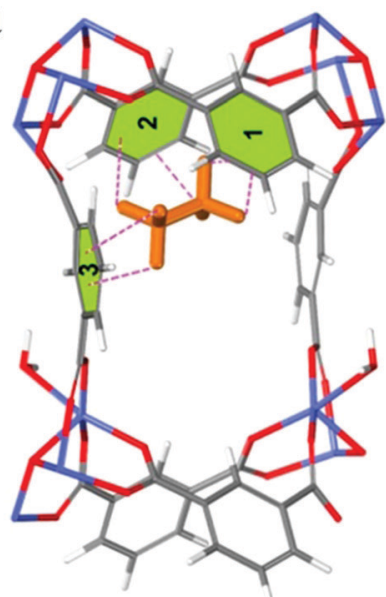

b

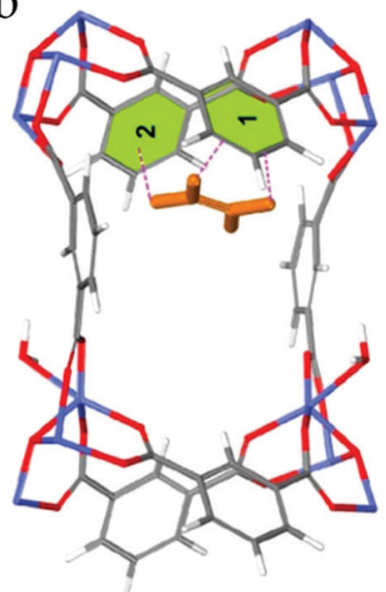

c

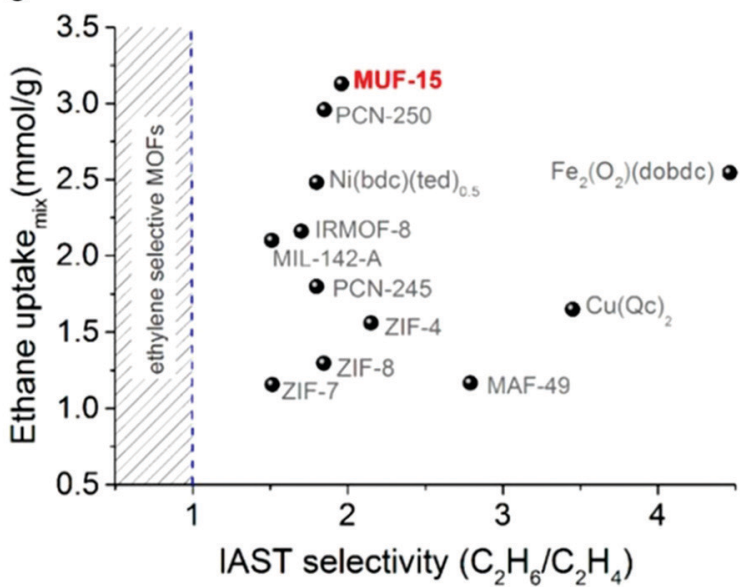

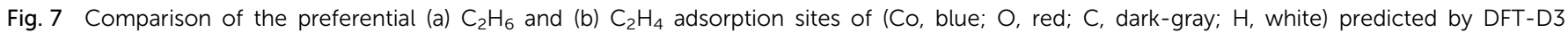

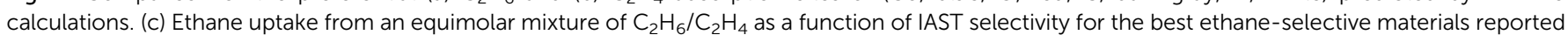
to date.

Science and Technology) preferentially combine with propylene to achieve $\mathrm{C}_{3} \mathrm{H}_{6} / \mathrm{C}_{3} \mathrm{H}_{8}$ separation. MIL-100 (Fe) (MIL represent for Materials of Institute Lavoisier) constructed by Yoon et al. ${ }^{91}$ contained large amounts of $\mathrm{Fe}(\mathrm{II})$ and $\mathrm{Fe}(\mathrm{III})$, which greatly improved the interaction between this MOF and propylene under low pressure, giving a $\mathrm{C}_{3} \mathrm{H}_{6} / \mathrm{C}_{3} \mathrm{H}_{8}$ selectivity of 27 . However, this value was measured at a low pressure of 0.0025 bar, and the selectivity will decrease significantly with increasing pressure. In 2012, Bae et al. examined the selective adsorption of $\mathrm{C}_{3} \mathrm{H}_{6}$ over $\mathrm{C}_{3} \mathrm{H}_{8}$ in M-MOF-74 materials $(\mathrm{M}=\mathrm{Co}, \mathrm{Mn}$, and $\mathrm{Mg}$ ), a series of MOFs characterized by a high density of unsaturated metal sites. ${ }^{92}$ Among them, Co-MOF-74 exhibited the highest thermodynamic $\mathrm{C}_{3} \mathrm{H}_{6} / \mathrm{C}_{3} \mathrm{H}_{8}$ selectivity of 46 due to strong $\pi$-complexation between its unsaturated $\mathrm{Co}$ (II) sites and the $\mathrm{C}_{3} \mathrm{H}_{6}$ molecules. Interestingly, its selectivity increased with increasing pressure, because $\mathrm{C}_{3} \mathrm{H}_{6}$ molecules exhibit a higher van der Waals force at higher pressure after all of the metal sites are occupied.

As mentioned above, $\mathbf{M}_{2}$ ( $m$-dobdc) is a structural isomer of M-MOF-74. However, its ability to separate $\mathrm{C}_{3} \mathrm{H}_{6} / \mathrm{C}_{3} \mathrm{H}_{8}$ is better than that of M-MOF-74 due to an increase in charge density at its metal sites. In 2017, Bachman et al. evaluated the $\mathrm{C}_{3} \mathrm{H}_{6} / \mathrm{C}_{3} \mathrm{H}_{8}$ separation ability of $\mathrm{M}_{2}(m$-dobdc $)(\mathrm{M}=\mathrm{Mn}, \mathrm{Fe}, \mathrm{Co}, \mathrm{Ni}$; $m$-dobdc ${ }^{4-}=4,6$-dioxido-1,3-benzenedicarboxylate) ${ }^{70}$ Among these systems, $\mathrm{Fe}_{2}(m$-dobdc) showed the best selectivity $(>55)$ for $\mathrm{C}_{3} \mathrm{H}_{6} / \mathrm{C}_{3} \mathrm{H}_{8}$ (50:50) under ambient conditions, and the adsorption capacity for $\mathrm{C}_{3} \mathrm{H}_{6}$ exceeded $7 \mathrm{mmol} \mathrm{g}^{-1}$.

While equilibrium-based separations are achieved by the preferential equilibrated uptake of one component over the other, kinetic separations are accomplished by a difference in diffusion rates of adsorbates in and out of the adsorbent. Consequently, kinetic separation can efficiently prevent the generation of high heat of adsorption during the separation process.

In 2009, Li et al. realized the first study illustrating the kinetic separation of $\mathrm{C}_{3} \mathrm{H}_{6} / \mathrm{C}_{3} \mathrm{H}_{8}$ on ZIFs $\left[\mathrm{Zn}(2 \text {-cim })_{2}\right.$, $\mathrm{Zn}(2 \text {-bim })_{2}$, ZIF-8]. ${ }^{93}$ Under equilibrium conditions, $\mathrm{C}_{3} \mathrm{H}_{6}$ and
$\mathrm{C}_{3} \mathrm{H}_{8}$ adsorption measurements on these three ZIFs revealed similar adsorption capacities for both molecules, implying that thermodynamic separation would be impractical. However, $\mathrm{C}_{3} \mathrm{H}_{6}$ and $\mathrm{C}_{3} \mathrm{H}_{8}$ exhibit remarkably different diffusion rates in ZIF-8 (Fig. 8a and b), suggesting that this material has great potential for the separation of these two very similar molecules.

In 2011, Lee et al. reported a series of isostructural, noncatenated, zinc-pillared, paddlewheel MOF materials, including materials designated as DTO, TO, DBTO, and BTO ${ }^{94}$ Compared with DTO and TO, the pore sizes of DBTO and BTO are made suitably smaller by the introduction of $\mathrm{Br}$ atoms. The results of gas separation experiments showed that DBTO and BTO bearing $\mathrm{Br}$ atoms display higher kinetic selectivity for propylene and propane than DTO and TO with larger pore size.

In 2017, Peng et al. reported another example of the kinetic separation of $\mathrm{C}_{3} \mathrm{H}_{6}$ and $\mathrm{C}_{3} \mathrm{H}_{8}$ by employing the MOF $\mathrm{Zn}(\mathrm{ox})_{0.5}(\mathrm{trz})(\mathrm{ox}=\text { oxalate, trz }=1,2,4 \text {-triazole) })^{95}$ Because of its zigzag-shaped ultramicroporous $1 \mathrm{D}$ channels with matching pore apertures, $\mathrm{Zn}(\mathrm{ox})_{0.5}(\mathrm{trz})$ showed good $\mathrm{C}_{3} \mathrm{H}_{6}$ uptake, and very high kinetic selectivity values were achieved for $\mathrm{C}_{3} \mathrm{H}_{6} / \mathrm{C}_{3} \mathrm{H}_{8}$ mixtures over a wide temperature range between 303 and $363 \mathrm{~K}$. At $323 \mathrm{~K}$, the kinetic separation coefficient of $\mathrm{Zn}(\mathrm{ox})_{0.5}(\mathrm{trz})$ reached the highest value at the time of this report (1565).
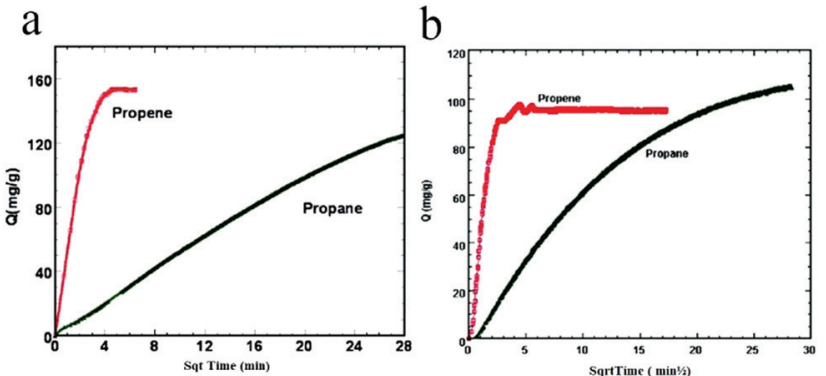

Fig. 8 Propene and propane uptakes by ZIF-8 (a) and Zn(2-cim) $)_{2}$ (b) as a function of the square root of time. 
a

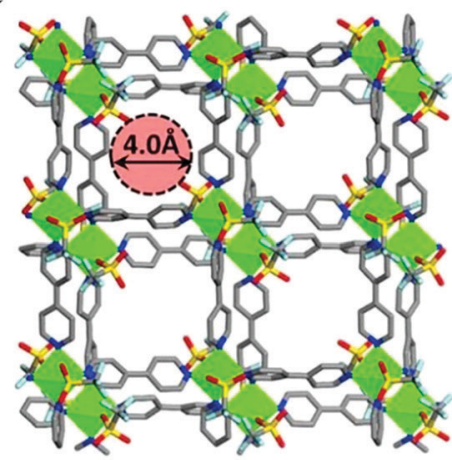

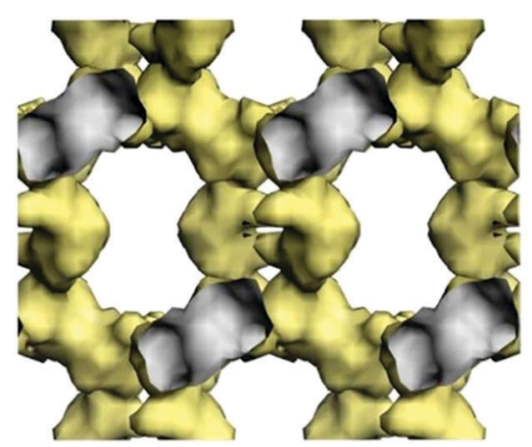

$\mathrm{b}$

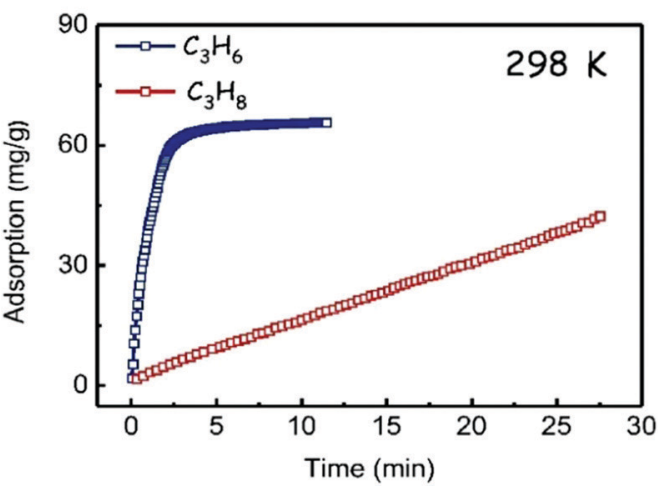

Fig. 9 (a) Illustration of the crystal structure and two-dimensional zigzag channels in ELM-12, with the inner surface of the channels shown in gray. Hydrogen atoms omitted for clarity ( $\mathrm{Cu}$, green; $\mathrm{O}$, red; $\mathrm{F}$, light-blue; $\mathrm{S}$, yellow; $\mathrm{N}$, blue; $\mathrm{C}$, gray). (b) Kinetic adsorption profiles of $\mathrm{C}_{3} \mathrm{H}_{6}$ and $\mathrm{C}_{3} \mathrm{H}_{8}$ on $\mathrm{ELM}_{-}$ 12 at $298 \mathrm{~K}$.

Similarly, ELM-12, reported by Li et al. in 2018, with appropriate channels (Fig. 9a) also achieved the desired kinetic separation performance. ${ }^{96}$ The kinetic $\mathrm{C}_{3} \mathrm{H}_{6} / \mathrm{C}_{3} \mathrm{H}_{8}$ selectivity was up to 204 at $298 \mathrm{~K}$ and 971 at $308 \mathrm{~K}$ (Fig. 9b). This high kinetic selectivity was manifested in real separation performance; a $\mathrm{C}_{3} \mathrm{H}_{6} / \mathrm{C}_{3} \mathrm{H}_{8}(50: 50, \mathrm{v} / \mathrm{v})$ mixture could be efficiently separated by passage through a column loaded with ELM-12, and concentrated $\mathrm{C}_{3} \mathrm{H}_{6}(>82 \%)$ could be quickly recovered during the regeneration step. Moreover, ELM-12 can be easily regenerated and synthesized on a large scale. Gas adsorption and powder X-ray diffraction (PXRD) measurements showed that ELM-12 maintained its structural integrity and gas uptake capacity over 3 years of storage under ambient conditions, suggesting that it should be favorable for practical industrial applications.

Although the above materials exhibit excellent separation performances, it is inevitable that a small amount of propane will be co-adsorbed during the separation process. However, the molecular sieving strategy can effectively block the co-adsorption of propane so as to obtain highly pure propylene. In 2016, Cadiau et al. made important progress in the separation of propylene and propane. ${ }^{97}$ Through precise control of the pore size of MOF materials, complete exclusion of propane was achieved, so as to effectively separate propylene/propane gas mixtures based on molecular sieving (Fig. 10). NbOFFIVE-1-Ni is isostructural to SIFSIX-3-Ni, and is built from Ni(II)-pyrazine square-grid layers and $\mathrm{NbOF}_{5}{ }^{2-}$ pillars. The rational use of $\mathrm{NbOF}_{5}{ }^{2-}$ rather than $\mathrm{SiF}_{6}{ }^{2-}$ gives rise to a longer metalfluorine distance $(1.95 \AA)$ and a concomitant tilting of the pyrazine moieties. Consequently, NbOFFIVE-1-Ni shows a smaller pore aperture size $(3.0471 \AA)$ than SIFSIX-3-Ni (4.965 ̊). Molecular-sieving-based $\mathrm{C}_{3} \mathrm{H}_{6} / \mathrm{C}_{3} \mathrm{H}_{8}$ separation was further confirmed by breakthrough experiments with a $50: 50 \mathrm{C}_{3} \mathrm{H}_{6} / \mathrm{C}_{3} \mathrm{H}_{8}$ mixture, resulting in a $\mathrm{C}_{3} \mathrm{H}_{6}$ productivity of $0.6 \mathrm{mmol} \mathrm{g}^{-1}$ for a given cycle.

In 2018, similar molecular sieving of propane/propylene was achieved in a tailor-made rare-earth-based MOF. ${ }^{98}$ Wang et al. reported the synthesis of $\mathrm{Y}_{6}(\mathrm{OH})_{8}(\mathrm{abtc})_{3}\left(\mathrm{H}_{2} \mathrm{O}\right)_{6}(\mathrm{DMA})_{2}$ (denoted as Y-abtc; abtc $=3,3,5,5$-azobenzene-tetracarboxylate; DMA = dimethylammonium). This MOF was rationally designed through topology-guided replacement of inorganic building units, which involved precise tuning of its pore apertures by judicious selection of structure topology, inorganic nodes, and organic linkers. The resultant Y-abtc has optimal pore window size $(4.72 \AA)$, which falls between the kinetic diameters of $\mathrm{C}_{3} \mathrm{H}_{6}$ (4.68 $\AA$ ) and $\mathrm{C}_{3} \mathrm{H}_{8}(5.1 \AA)$. Therefore, this material can effectively separate propane and propylene through a molecular sieving mechanism. Multicomponent breakthrough experiments indicated that polymer-grade $\mathrm{C}_{3} \mathrm{H}_{6}(99.5 \%)$ could be obtained from a typical cracking product mixture composition. Moreover, Y-abtc exhibits high thermal and hydrothermal stability due to its hexanuclear $\mathrm{Y}_{6}$ clusters, which indicates that this MOF has potential for efficient separation of $\mathrm{C}_{3} \mathrm{H}_{8} / \mathrm{C}_{3} \mathrm{H}_{6}$ mixtures.

As a unique phenomenon in flexible MOFs, gate-opening effect also plays a positive role in gas separation. In 2018, Wang et al. utilized NJU-bai8 (constructed by $\mathrm{Cu}$ and 5-(pyrimidin-5yl)isophthalate acid) for separation of $\mathrm{C}_{3} \mathrm{H}_{6} / \mathrm{C}_{3} \mathrm{H}_{8}$ mixture. ${ }^{99}$ Single-component adsorption isotherms of $\mathrm{C}_{3} \mathrm{H}_{6}$ and $\mathrm{C}_{3} \mathrm{H}_{8}$ shows that this material has an obvious gate-opening effect on both gases at $298 \mathrm{~K}$. When the pressure rises to a certain value, their adsorption capacity rises sharply. In $348 \mathrm{~K}$, this material can only adsorb $\mathrm{C}_{3} \mathrm{H}_{6}$ (gate-opening pressure as $49.0 \mathrm{kPa}$ ) below 1 bar, thus exhibits extremely high selectivity for $\mathrm{C}_{3} \mathrm{H}_{6} / \mathrm{C}_{3} \mathrm{H}_{8}$. According to the breakthrough experiments, NJU-bai8 shows good separation performance for $\mathrm{C}_{3} \mathrm{H}_{6} / \mathrm{C}_{3} \mathrm{H}_{8}$ mixtures in a wide temperature rage (298-348 K). The difference in adsorption capacity of NJU-bai8 toward the two gases can be attributed to the flat pore size and strong acid-base interaction between $\mathrm{C}_{3} \mathrm{H}_{6}$ and the framework.

In 2019, Yu et al. synthesized a flexible MOF $\{\mathrm{Cu}-(\mathrm{FPBDC})$. $\mathrm{DMF}_{n}$ (NKU-FlexMOF-1) $\left(\mathrm{H}_{2} \mathrm{FPBDC}=5\right.$-(5-fluoropyridin-3-yl)1,3-benzenedicarboxylic acid). ${ }^{100}$ This material can be induced structural transformation by different guest molecules, thus showing unique adsorption behavior for $\mathrm{C}_{2} \mathrm{H}_{6}, \mathrm{C}_{3} \mathrm{H}_{6}$ and $\mathrm{C}_{3} \mathrm{H}_{8}$. In different temperature ranges, the adsorption capacity increases with the increase of temperature. Based on this characteristic, 

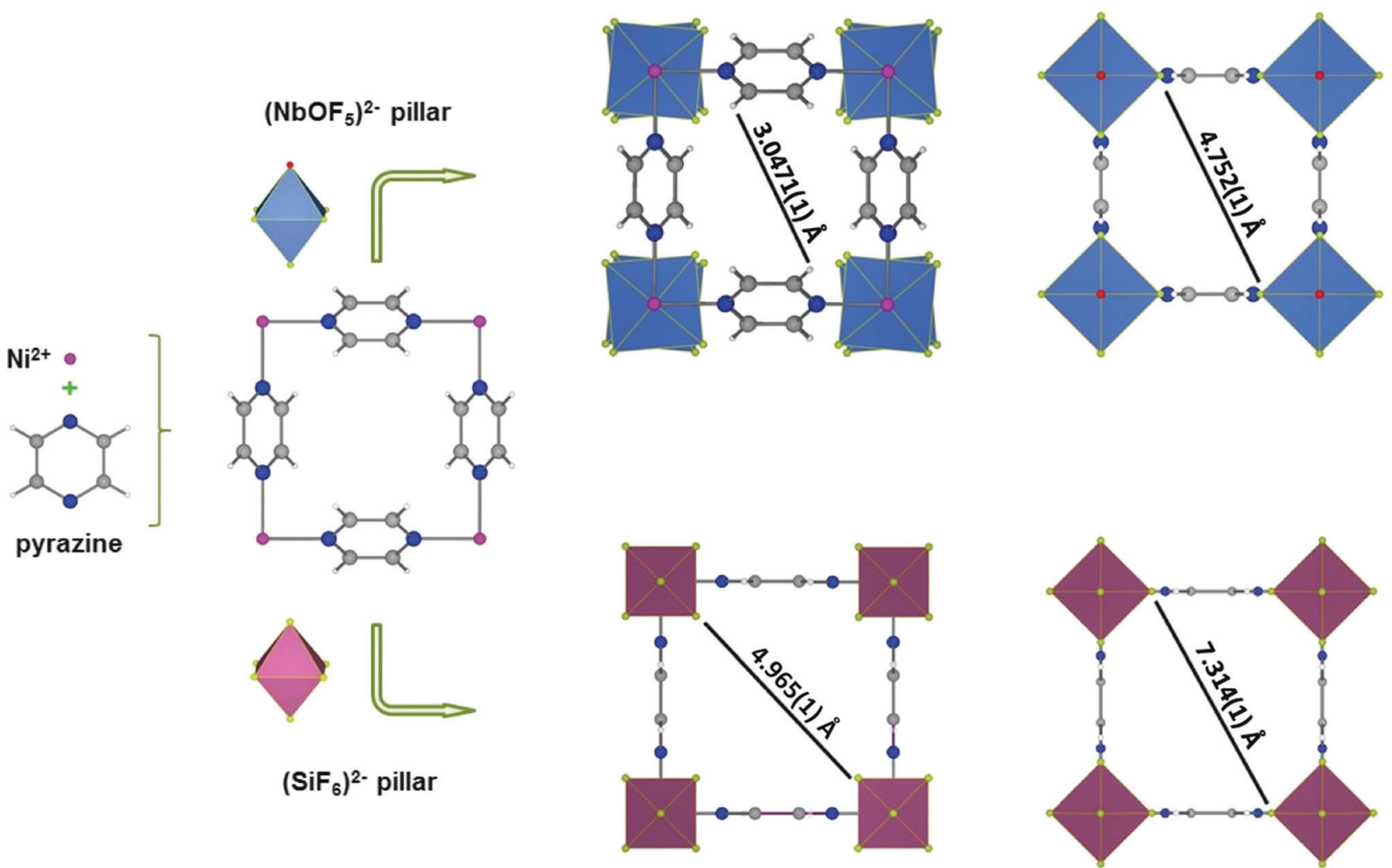

Fig. 10 Structural description of NbOFFIVE-1-Ni highlighting the arrangement of building blocks, and comparison with the parent SIFSIX-3-Ni.

NKU-FlexMOF-1 shows excellent ability to separate $\mathrm{C}_{3} \mathrm{H}_{6} / \mathrm{C}_{3} \mathrm{H}_{8}$ at 273 and $298 \mathrm{~K}$. In addition, the thermal stability of NKUFlexMOF-1 reaches approximately $613 \mathrm{~K}$, and this material also remains stable in solutions with a $\mathrm{pH}$ of $3-11$, demonstrating its potential for industrial separation.

2.2.2 $\mathrm{C}_{3} \mathrm{H}_{8}$-selective adsorbent. In the separation of $\mathrm{C}_{3} \mathrm{H}_{8} /$ $\mathrm{C}_{3} \mathrm{H}_{6}$, high purity $\mathrm{C}_{3} \mathrm{H}_{6}$ is the target product. Most of the work carried out to date has been focused on the priority adsorption of $\mathrm{C}_{3} \mathrm{H}_{6}$. It would be more favorable if $\mathrm{C}_{3} \mathrm{H}_{8}$ could be adsorbed preferentially.

In 2013, Böhme et al. ${ }^{101}$ found that although the pore size of ZIF-8 is only $3.4 \AA$, under certain conditions it can adsorb molecules larger than this, such as $n$-alkanes $(4.3 \AA)$, branched alkanes $(>5.4 \AA)$, and 2,3-dimethylbutane (5.8 $\mathrm{\AA}$ ). From this, it can be inferred that ZIF-8 has a flexible structure like that of ZIF-7. Gas adsorption experiments showed that ZIF-8 adsorbed larger amounts of $\mathrm{C}_{3} \mathrm{H}_{8}$ than of $\mathrm{C}_{3} \mathrm{H}_{6}$ at lower pressures. This phenomenon was attributed to the gate-opening mechanism of ZIF-8.

In 2020, Yang et al. reported the MOF material $\mathrm{Ni}(\mathrm{bpe})_{2}\left(\mathrm{WO}_{4}\right)$ [denoted as WOFOUR-1-Ni; bpe $=1,2$-bis(4-pyridyl)ethylene]. ${ }^{102}$ Its cavity has a cubic shape with a size of $5.6 \AA$, which is close to the kinetic diameter of $\mathrm{C}_{3} \mathrm{H}_{8}$. The aromatic-ring-appended surface of the cage provides more electronegative binding sites relative to the channels (Fig. 11a), so as to realize multiple interactions with the adsorbed molecules. Therefore, its cage may plausibly show preferential adsorption of $\mathrm{C}_{3} \mathrm{H}_{8}$ because of the abundance of a

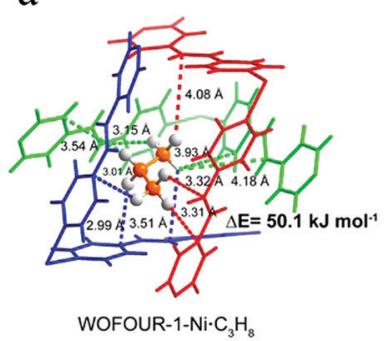

b

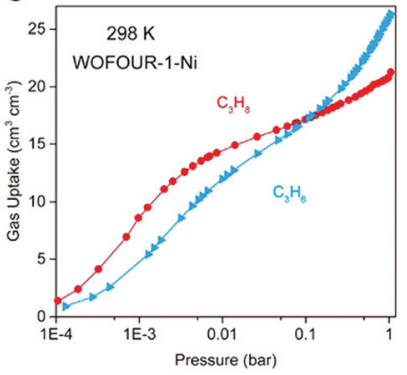

Fig. 11 (a) DFT-simulated configuration of WOFOUR-1-Ni- $\mathrm{C}_{3} \mathrm{H}_{8}$. (b) $\mathrm{C}_{3} \mathrm{H}_{8}$ and $\mathrm{C}_{3} \mathrm{H}_{6}$ adsorption isotherms on WOFOUR-1-Ni at $298 \mathrm{~K}$ and 1 bar.

binding sites $(\mathrm{C}-\mathrm{H})$ and large van der Waals surface of $\mathrm{C}_{3} \mathrm{H}_{8}$. Meanwhile, it exhibits shape-selectivity for $\mathrm{C}_{3} \mathrm{H}_{8}$ because of its better matched shape than for that of $\mathrm{C}_{3} \mathrm{H}_{6}$ with a relatively planar configuration. Based on the above two factors, WOFOUR-1-Ni shows good performance in separating propane/propylene (Fig. 11b), with recorded $\mathrm{C}_{3} \mathrm{H}_{8} / \mathrm{C}_{3} \mathrm{H}_{6}$ selectivities of 1.62-2.75. Through column breakthrough experiments, propylene with a purity of $99.6 \%$ could be obtained without adsorption-desorption cycles, further improving the separation efficiency. This work reveals a novel strategy for designing propane-selective materials. To date, however, the adsorption capacities and selectivities for $\mathrm{C}_{3} \mathrm{H}_{8}$ of $\mathrm{C}_{3} \mathrm{H}_{8}$-selective MOF materials have still been very low, and much effort is needed to develop more efficient materials. 


\subsection{Separation of $\mathrm{C} 4$ olefins}

C4 olefins, including $1,3-\mathrm{C}_{4} \mathrm{H}_{6}, n-\mathrm{C}_{4} \mathrm{H}_{8}$, and $\mathrm{i}-\mathrm{C}_{4} \mathrm{H}_{8}$, are very important feedstocks for the production of synthetic rubbers and other chemical products. Typically, C4 olefins are produced by fluidized catalytic cracking and steam cracking processes, but the $\mathrm{C} 4$ olefins obtained from these techniques generally consist of $30-60 \% 1,3-\mathrm{C}_{4} \mathrm{H}_{6}, 10-20 \% n-\mathrm{C}_{4} \mathrm{H}_{8}$, and $10-30 \%$ i- $\mathrm{C}_{4} \mathrm{H}_{8}$, along with $3-10 \%$ of saturated $\mathrm{C}_{4} \mathrm{H}_{10}$. Due to the similar structures of the $\mathrm{C} 4$ olefins, their separation presents one of the great challenges among hydrocarbon purifications.

In 2017, Zhang et al. reported a series of SIFSIX materials [GeFSIX-2-Cu-i (ZU-32), NbFSIX-2-Cu-i (ZU-52), GeFSIX-14-Cu-i (ZU-33)] capable of selectively recognizing different C4 olefins. ${ }^{103}$ They fine-tuned the cavity size and functional site disposition in the MOFs in increments of $0.2 \AA$ by rationally altering the anion pillars and organic linkers. GeFSIX-14-Cu-i has a pore size of $4.2 \AA$, which is larger than the smallest cross-section of $\mathrm{C}_{4} \mathrm{H}_{6}$ but narrower than those of $n-\mathrm{C}_{4} \mathrm{H}_{8}$ and $\mathrm{i}-\mathrm{C}_{4} \mathrm{H}_{8}$, permitting the size exclusion of these specific $\mathrm{C} 4$ olefins. Dispersion-corrected density functional theory (DFT-D) results showed that after $\mathrm{C}_{4} \mathrm{H}_{6}$ enters into GeFSIX-14-Cu-i, its acidic hydrogen atoms should become strongly bonded with two electronegative $\mathrm{F}$ atoms of the $\mathrm{GeF}_{6}{ }^{2-}$ pillars, with $\mathrm{C}-\mathrm{H} \cdots \mathrm{F}$ distances of $2.09,2.90,2.18$, and $2.30 \AA$, respectively. Based on the molecular sieving effect and the strong interactions between the gas and the MOF surface, GeFSIX-14-Cu-i shows excellent selectivity for $\mathrm{C}_{4} \mathrm{H}_{6}, n-\mathrm{C}_{4} \mathrm{H}_{8}$, and i- $\mathrm{C}_{4} \mathrm{H}_{8}$.

MOFs can often selectively bind $\mathrm{C}_{4} \mathrm{H}_{6}$ at their unsaturated metal sites. However, it is difficult to recover products from the adsorbents because heating is necessary, which induces polymerization. In 2017, Liao et al. reported a hydrophilic MOF $\left[\mathrm{Zn}_{2}(\mathrm{btm})_{2}\right]$, also denoted as $\mathrm{Zn-BTM}\left[\mathrm{H}_{2} \mathrm{btm}=\operatorname{bis}(5-\right.$ methyl-1H-1,2,4-triazol-3-yl)methane], the quasi-discrete pores of which can induce conformational changes in flexible guest molecules ${ }^{104}$ (Fig. 12a). Such a conformational change would be difficult in $\mathrm{C}_{4} \mathrm{H}_{6}$ due to its high binding energy, thus disfavoring its adsorption and realizing the preferential adsorption of $n-\mathrm{C}_{4} \mathrm{H}_{8}$, i- $\mathrm{C}_{4} \mathrm{H}_{8}$, and $\mathrm{C}_{4} \mathrm{H}_{10}$ (Fig. 12b). As shown in the mixture breakthrough curves for $\mathrm{C} 4$ hydrocarbons, Zn-BTM afforded a distinctive elution sequence with quite different breakthrough times in the sequence $\mathrm{C}_{4} \mathrm{H}_{6}<\mathrm{C}_{4} \mathrm{H}_{10}<n-\mathrm{C}_{4} \mathrm{H}_{8}<\mathrm{i}-\mathrm{C}_{4} \mathrm{H}_{8}$ (Fig. 12c), which proves the preferential adsorption of the latter three. It was further demonstrated that Zn-BTM can efficiently purify $\mathrm{C}_{4} \mathrm{H}_{6}$ to the required level $(\geq 99.5 \%)$.

\subsection{Removal of alkyne from alkene}

The separation of acetylene $\left(\mathrm{C}_{2} \mathrm{H}_{2}\right)$ from $\mathrm{C}_{2} \mathrm{H}_{2} / \mathrm{C}_{2} \mathrm{H}_{4}$ and of propyne $\left(\mathrm{C}_{3} \mathrm{H}_{4}\right)$ from $\mathrm{C}_{3} \mathrm{H}_{4} / \mathrm{C}_{3} \mathrm{H}_{6}$ mixtures are important but challenging industrial-scale gas separation tasks. Current commercial technologies include partial hydrogenation and solvent extraction, but these are high-cost and energy-intensive. Adsorption-based porous materials offer great promise for developing cost-effective and energy-efficient separation technologies.

2.4.1 $\mathrm{C}_{2} \mathrm{H}_{2} / \mathrm{C}_{2} \mathrm{H}_{4}$ separation. During the production of ethylene, a small amount of acetylene as an impurity of about $1 \%$ is also generated. It is imperative that the separation of $\mathrm{C}_{2} \mathrm{H}_{2}$ from $\mathrm{C}_{2} \mathrm{H}_{4}$ must meet the requirement of below $40 \mathrm{ppm}$ for $\mathrm{C}_{2} \mathrm{H}_{2}$ in the downstream polymerization reaction.

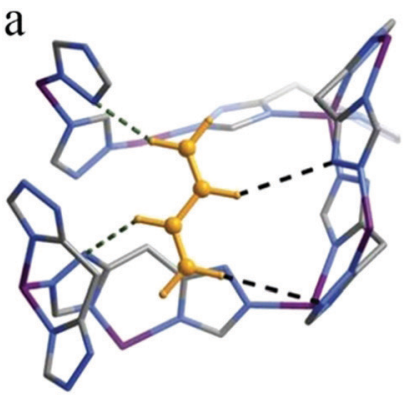

b
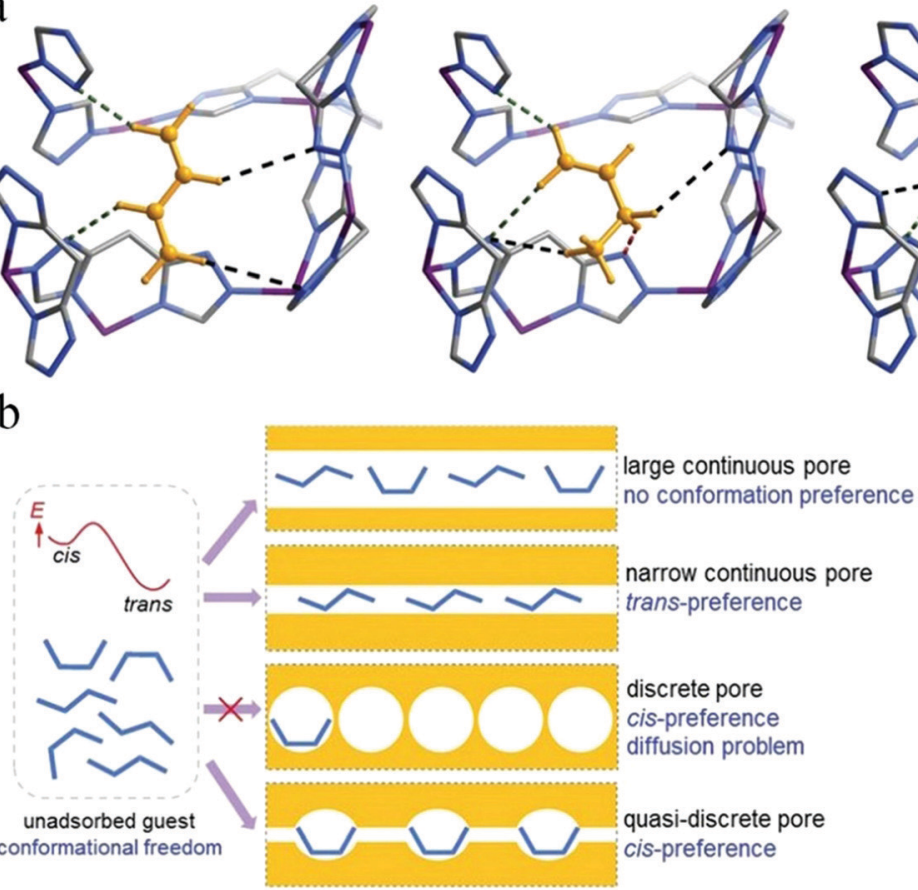
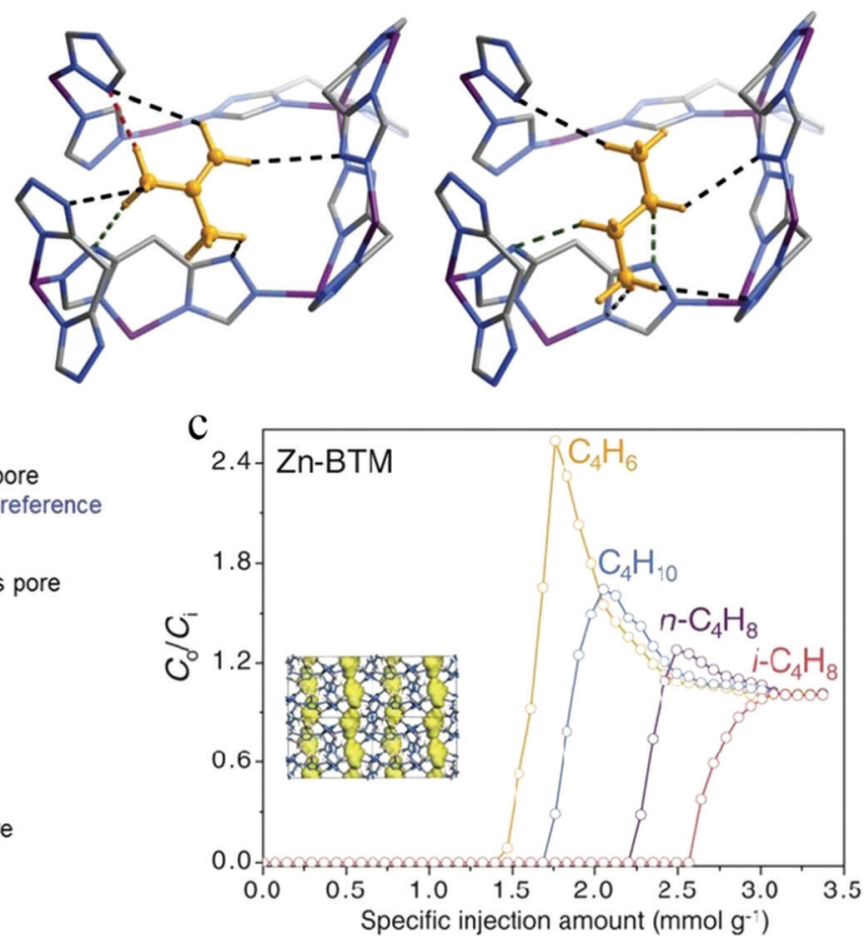

Fig. 12 (a) Single-crystal $\mathrm{X}$-ray structures of host-guest complexes of $\mathrm{C}_{4} \mathrm{H}_{6}, n-\mathrm{C}_{4} \mathrm{H}_{8}, \mathrm{i}-\mathrm{C}_{4} \mathrm{H}_{8}$, and $\mathrm{C}_{4} \mathrm{H}_{10}$. (b) Controlling the guest conformations by variation of the pore size, shape, and dimensionality. (c) Breakthrough curves of $\mathrm{Zn}-\mathrm{BTM}$ for a $5: 2: 2: 1 \mathrm{C}_{4} \mathrm{H}_{6} / n-\mathrm{C}_{4} \mathrm{H}_{8} / \mathrm{i}-\mathrm{C}_{4} \mathrm{H}_{8} / \mathrm{C}_{4} \mathrm{H}_{10}$ mixture. 
In 2011, Xiang et al. reported the first study on MOFs for $\mathrm{C}_{2} \mathrm{H}_{2} / \mathrm{C}_{2} \mathrm{H}_{4}$ separation. ${ }^{105}$ They reported two tunable microporous enantiopure mixed MOFs, M $^{\prime} \mathrm{MOF}-2\left(\mathrm{Zn}_{3}(\mathrm{BDC})_{3}[\mathrm{Cu}(\right.$ SalPycy $\left.)] \cdot(\mathrm{G})_{x}\right)$ and $\mathrm{M}^{\prime} \mathrm{MOF}-3\left(\mathrm{Zn}_{3}(\mathrm{CDC})_{3}[\mathrm{Cu}(\right.$ SalPycy $\left.)] \cdot(\mathrm{G})_{x}\right)$. They found that $M^{\prime}$ MOF-2a could only slightly differentiate $\mathrm{C}_{2} \mathrm{H}_{2}$ from $\mathrm{C}_{2} \mathrm{H}_{4}$, with a low selectivity of 1.6 , whereas $\mathrm{M}^{\prime} \mathrm{MOF}-3 \mathrm{a}$ displayed a significantly higher selectivity of 25.5. This can be attributed to the smaller micropores within $\mathrm{M}^{\prime} \mathrm{MOF}-3 \mathrm{a}$, which favor its higher sizespecific $\mathrm{C}_{2} \mathrm{H}_{2} / \mathrm{C}_{2} \mathrm{H}_{4}$ separation effect. The narrower molecular form of $\mathrm{C}_{2} \mathrm{H}_{2}\left(3.32 \times 3.34 \times 5.70 \AA^{3}\right)$ allows its free entry into the micropores in $\mathrm{M}^{\prime}$ MOF-3a, whereas $\mathrm{C}_{2} \mathrm{H}_{4}$ molecules $(3.28 \times$ $4.18 \times 4.84 \AA^{3}$ ) are basically blocked or the kinetics of their uptake is much slower. Even at room temperature, the $\mathrm{C}_{2} \mathrm{H}_{2} / \mathrm{C}_{2} \mathrm{H}_{4}$ selectivity of $\mathrm{M}^{\prime} \mathrm{MOF}-3 \mathrm{a}$ is $\mathbf{5 . 2}$, which means it has great potential for this separation.

Many new materials have subsequently been developed for the separation of $\mathrm{C}_{2} \mathrm{H}_{2} / \mathrm{C}_{2} \mathrm{H}_{4}$. However, most of these materials are subject to a trade-off between $\mathrm{C}_{2} \mathrm{H}_{2}$ adsorption capacity and $\mathrm{C}_{2} \mathrm{H}_{2} / \mathrm{C}_{2} \mathrm{H}_{4}$ selectivity. Because of the narrow pore space of $\mathrm{M}^{\prime} \mathrm{MOF}-3$, the adsorption capacity of acetylene is only $1.88 \mathrm{~mol} \mathrm{~kg}^{-1}$ at $295 \mathrm{~K}$ and $100 \mathrm{kPa}$. In contrast, although the unsaturated metal sites in Fe-MOF-74 notably enhance its $\mathrm{C}_{2} \mathrm{H}_{2}$ uptake capacity, the large nanopores lead to a low selectivity of 2.08 .
In 2015, Hu et al. synthesized another MOF (UTSA-100) for $\mathrm{C}_{2} \mathrm{H}_{2} / \mathrm{C}_{2} \mathrm{H}_{4}$ separation. ${ }^{106}$ Its single-crystal X-ray structure reveals that it has a three-dimensional framework with rhombic open zigzag nanochannels with amino- and tetrazole-functionalized walls, with narrow windows of $3.3 \AA$ and suitable cages of dimensions $4.0 \AA$ A. The $\mathrm{C}_{2} \mathrm{H}_{2} / \mathrm{C}_{2} \mathrm{H}_{4}$ selectivity is 10.72 because of these structural features. Moreover, the $-\mathrm{NH}_{2}$ groups in the channels can preferentially combine with $\mathrm{C}_{2} \mathrm{H}_{2}$, giving rise to a moderately high $\mathrm{C}_{2} \mathrm{H}_{2}$ uptake of $95.6 \mathrm{~cm}^{3} \mathrm{~g}^{-1}$ at $296 \mathrm{~K}$ and 1 bar.

In 2016, the abovementioned trade-off in $\mathrm{C}_{2} \mathrm{H}_{2} / \mathrm{C}_{2} \mathrm{H}_{4}$ separation was significantly overcome in a series of SIFSIX materials reported by Cui et al. ${ }^{107}$ The channels of SIFSIX series materials are composed of the inorganic anion $\mathrm{SiF}_{6}{ }^{2-}$, and the pore size can be adjusted by changing the length of the organic ligands. The weakly basic nature of the $\mathrm{SiF}_{6}{ }^{2-}$ sites and their geometric disposition enables strong binding with weakly acidic $\mathrm{C}_{2} \mathrm{H}_{2}$ molecules. Therefore, all of these SIFSIX materials display distinctly higher $\mathrm{C}_{2} \mathrm{H}_{2}$ uptake than $\mathrm{C}_{2} \mathrm{H}_{4}$ uptake (Fig. 13a). Among them, SIFSIX-2-Cu-i exhibits a remarkably high $\mathrm{C}_{2} \mathrm{H}_{2}$ adsorption capacity of $2.1 \mathrm{mmol} \mathrm{g}^{-1}$ at $298 \mathrm{~K}$ and $0.025 \mathrm{bar}$, with a $\mathrm{C}_{2} \mathrm{H}_{2} / \mathrm{C}_{2} \mathrm{H}_{4}$ selectivity as high as 39.7-44.8. DFT calculations (Fig. 13c and d) and neutron powder diffraction studies (Fig. 13e and f) predict each $\mathrm{C}_{2} \mathrm{H}_{2}$ molecule to be simultaneously bound by two $\mathrm{F}$ atoms from different nets through
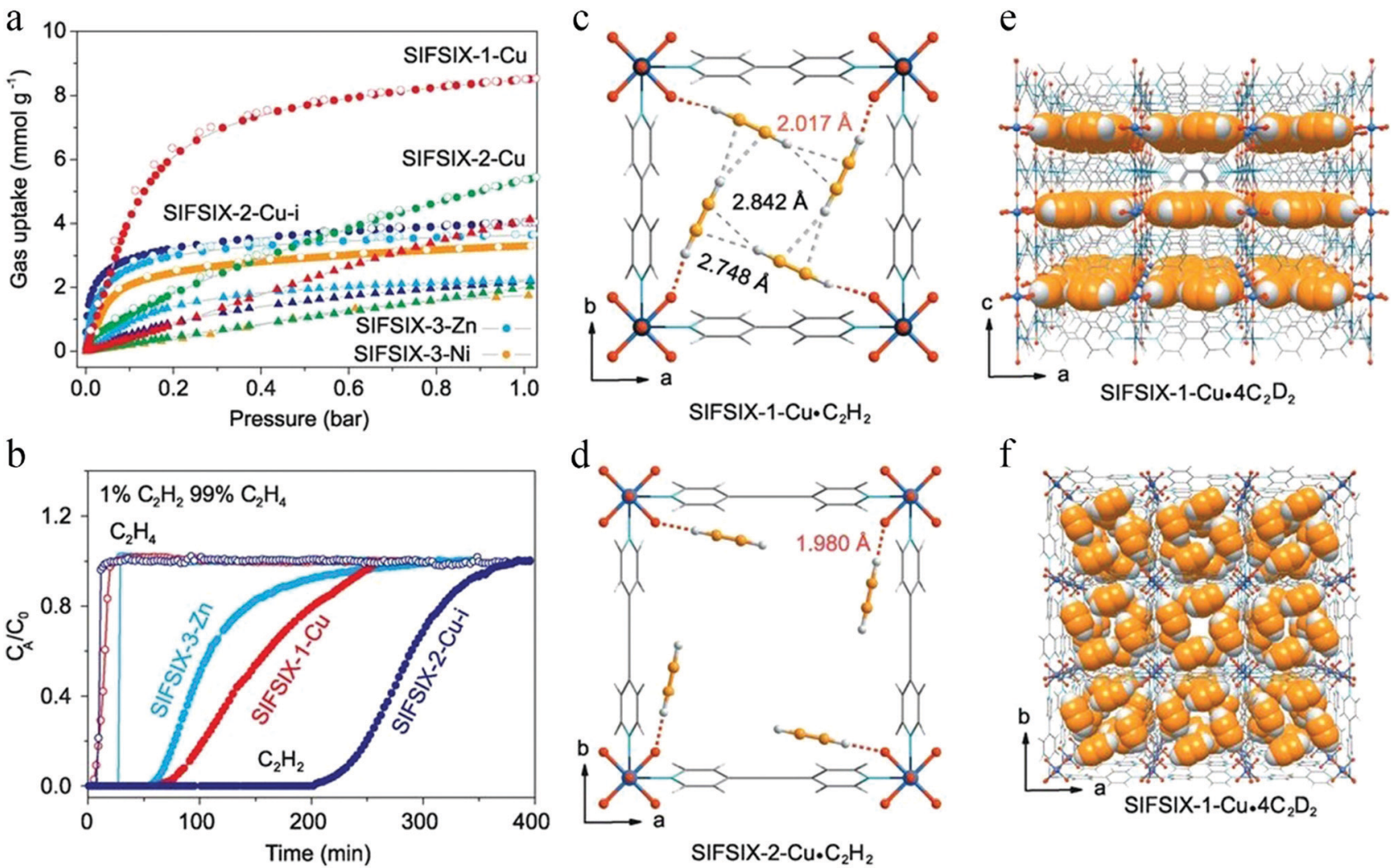

Fig. $13 \mathrm{C}_{2} \mathrm{H}_{2}$ and $\mathrm{C}_{2} \mathrm{H}_{4}$ adsorption isotherms of the MOFs, DFT-D-simulated optimized $\mathrm{C}_{2} \mathrm{H}_{2}$ adsorption sites of the MOFs, and neutron diffraction crystal structure of SIFSIX-1-Cu-4 $4 \mathrm{C}_{2} \mathrm{D}_{2}$. (a) Adsorption isotherms of $\mathrm{C}_{2} \mathrm{H}_{2}$ (filled circles) and $\mathrm{C}_{2} \mathrm{H}_{4}$ (triangles) in SIFSIX-1-Cu (red), SIFSIX-2-Cu (green), SIFSIX-2-Cu-i (blue), SIFSIX-3-Zn (light-blue), and SIFSIX-3-Ni (orange) at $298 \mathrm{~K}$ in the pressure range 0-1.0 bar. (b) Experimental column breakthrough curves for $\mathrm{C}_{2} \mathrm{H}_{2} / \mathrm{C}_{2} \mathrm{H}_{4}\left(1: 99\right.$, v/v) separations with SIFSIX-1-Cu, SIFSIX-2-Cu, and SIFSIX-3-Zn at $298 \mathrm{~K}$ and 1.01 bar. (c and d) DFT-D-calculated $\mathrm{C}_{2} \mathrm{H}_{2}$ adsorption binding sites in SIFSIX-1-Cu (c) and SIFSIX-2-Cu (d). (e and f) Neutron diffraction crystal structure of SIFSIX-1-Cu-4C ${ }_{2} \mathrm{D}_{2}$ at $200 \mathrm{~K}$. 
cooperative $\mathrm{C}-\mathrm{H} \cdots \mathrm{F}$ hydrogen bonding, giving rise to strong interactions with the framework, thus leading to exceptionally high $\mathrm{C}_{2} \mathrm{H}_{2}$ uptake and selectivity. The amount of $\mathrm{C}_{2} \mathrm{H}_{2}$ captured from a 1: 99 mixture by SIFSIX-2-Cu-i was as high as $780 \mathrm{mmol} \mathrm{L}^{-1}$, such that this material can efficiently purify $\mathrm{C}_{2} \mathrm{H}_{4}$ to the desired level (>99.998\%) (Fig. 13b).

In spite of the above results, the pore size of SIFSIX-2-Cu-i is about $4.4 \AA$, larger than the kinetic diameter of $\mathrm{C}_{2} \mathrm{H}_{4}(4.2 \AA)$, which can therefore not be entirely excluded. In 2018, Li et al. synthesized SIFSIX-14-Cu-i (UTSA-200) by replacing 4,4'-dipyridylacetylene (dpa, 9.6 ̊̊) in SIFSIX-2-Cu-i with a shorter organic ligand 4,4'-azopyridine (azpy, 9.0 ̊). ${ }^{108}$ The pore size of SIFSIX14-Cu-i (UTSA-200a) decreased to $3.4 \AA$, between the dimensions of $\mathrm{C}_{2} \mathrm{H}_{4}(4.2 \AA)$ and $\mathrm{C}_{2} \mathrm{H}_{2}(3.2 \AA)$ (Fig. 14). As shown by the adsorption isotherms for $\mathrm{C}_{2} \mathrm{H}_{2}$ and $\mathrm{C}_{2} \mathrm{H}_{4}$, UTSA-200a exhibits a steep and high $\mathrm{C}_{2} \mathrm{H}_{2}$ uptake of $116 \mathrm{~cm}^{3} \mathrm{~cm}^{-3}$ at $298 \mathrm{~K}$ and 1 bar. In contrast, the smaller static pore size of UTSA-200a can completely prevent the entry of $\mathrm{C}_{2} \mathrm{H}_{4}$ molecules below $0.2 \mathrm{bar}$, leading to very little uptake ( $c a .0 .25 \mathrm{mmol} \mathrm{g}^{-1}$ ) at up to $0.7 \mathrm{bar}$ at $298 \mathrm{~K}$, which is dramatically lower than that of SIFSIX-2-Cu-i. Based on neutron powder diffraction studies, the ultra-strong $\mathrm{C}_{2} \mathrm{H}_{2}$ adsorption in UTSA-200 mainly originates from stronger C-D $\cdots$ F deuterium bonding (1.921 $\AA$ ) compared to that in SIFSIX-2-Cu-i (2.015 ̊). UTSA-200a exhibits the record selectivity of over 6000 at $298 \mathrm{~K}$ and 1 bar for a $1: 99 \mathrm{C}_{2} \mathrm{H}_{2} / \mathrm{C}_{2} \mathrm{H}_{4}$ mixture. In breakthrough experiments, UTSA-200a demonstrated a record purification capacity for the removal of trace
$\mathrm{C}_{2} \mathrm{H}_{2}$ from $\mathrm{C}_{2} \mathrm{H}_{4}$, with a $\mathrm{C}_{2} \mathrm{H}_{2}$ uptake capacity of $1.18 \mathrm{mmol} \mathrm{g}^{-1}$ from a 1 : $99 \mathrm{C}_{2} \mathrm{H}_{2} / \mathrm{C}_{2} \mathrm{H}_{4}$ mixture, thereby producing $\mathrm{C}_{2} \mathrm{H}_{4}$ with a purity of $99.9999 \%$. UTSA-200a thus successfully overcomes the trade-off in $\mathrm{C}_{2} \mathrm{H}_{2} / \mathrm{C}_{2} \mathrm{H}_{4}$ separation and sets a new benchmark in terms of both capacity and selectivity.

2.4.2 $\mathbf{C}_{3} \mathbf{H}_{4} / \mathbf{C}_{3} \mathbf{H}_{6}$ separation. As one of the most important chemical products, $\mathrm{C}_{3} \mathrm{H}_{6}$ is produced primarily by steam cracking of hydrocarbons or petroleum distillate and is inevitably mixed with trace $\mathrm{C}_{3} \mathrm{H}_{4}$ in concentrations of $\sim 1000-2000 \mathrm{ppm}$. In order to meet the requirements of polymer-grade $\mathrm{C}_{3} \mathrm{H}_{6}$, the content of $\mathrm{C}_{3} \mathrm{H}_{4}$ must be reduced to $5 \mathrm{ppm}$ or even less than $1 \mathrm{ppm}$.

In $2017, \mathrm{Li}$ et al. reported the first example of the use of a flexible, robust $\mathrm{MOF}\left[\mathrm{Cu}(\mathrm{bpy})_{2}(\mathrm{OTf})_{2}\right]$ (ELM-12; bpy = 4,4-bipyridine, OTf $^{-}=$trifluoromethanesulfonate) to remove the low concentration of $\mathrm{C}_{3} \mathrm{H}_{4}$ from a $\mathrm{C}_{3} \mathrm{H}_{4} / \mathrm{C}_{3} \mathrm{H}_{6}$ mixture $(1: 99, \mathrm{v} / \mathrm{v}) .{ }^{109}$ ELM-12 consists of a rigid square-grid copper bipyridine scaffold with dynamic dangling OTf groups. It has two kinds of cavities, type I cavities are dumbbell-shaped with small pockets $(6.1 \AA \times 4.3 \AA \times 4.3 \AA)$ at each end, which are interconnected through a small aperture $(3.2 \AA \times 4.3 \AA)$. Type II cavities are ellipsoid-shaped with a size of $6.8 \AA \times 4.0 \AA \times 4.2 \AA$ and are separated from type I cavities by dynamic OTf ${ }^{-}$groups (Fig. 15a and b). The size and shape of these cavities matches well with $\mathrm{C}_{3} \mathrm{H}_{4}(6.2 \AA \times 3.8 \AA \times 3.8 \AA)$, as opposed to $\mathrm{C}_{3} \mathrm{H}_{6}$ $(6.5 \AA \times 4.0 \AA \times 3.8 \AA)$, so that the adsorption capacity of the former $\left(1.83 \mathrm{mmol} \mathrm{g}^{-1}\right)$ is much higher than that of the latter $\left(0.67 \mathrm{mmol} \mathrm{g}^{-1}\right)$ at $298 \mathrm{~K}$ and 0.01 bar. Breakthrough experiments

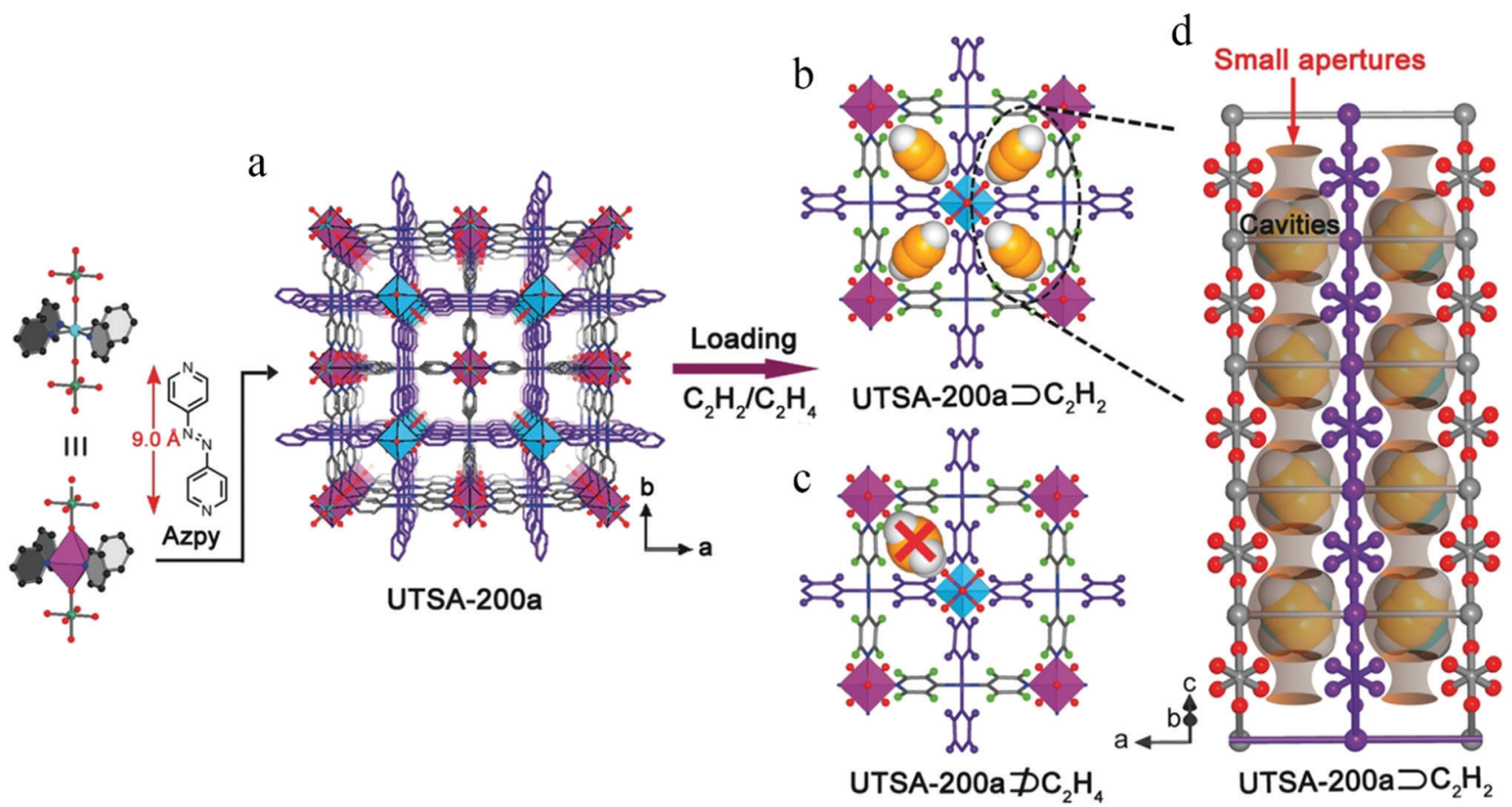

Fig. 14 Structure description of UTSA-200a. (a) The channel structure of UTSA-200a reveals a pores size of $\approx 3.4 \AA$. (b) DFT-D-calculated $\mathrm{C}_{2} \mathrm{H}_{2}$ adsorption models in UTSA-200a, revealing that this pore size enables the passage of $\mathrm{C}_{2} \mathrm{H}_{2}$ molecules. (c) Simulated $\mathrm{C}_{2} \mathrm{H}_{4}$ adsorption in UTSA-200a indicating that the $\mathrm{C}_{2} \mathrm{H}_{4}$ molecule are too large to pass through the pores. (d) Schematic illustration of ideal molecular sieves based on the structure of UTSA-200a $\supset \mathrm{C}_{2} \mathrm{H}_{2}$, in which larger cavities suitable for strongly binding $\mathrm{C}_{2} \mathrm{H}_{2}$ molecules are interconnected by narrow apertures that serve as sieves for $\mathrm{C}_{2} \mathrm{H}_{4}$ but not for $\mathrm{C}_{2} \mathrm{H}_{2}$. The different nets are highlighted in gray and purple for clarity. Colour code: $\mathrm{Cu}$ (turquoise), Si (dark green), $\mathrm{F}$ (red), $\mathrm{N}$ (blue), $\mathrm{C}$ (gray), and $\mathrm{H}$ (green spheres). 

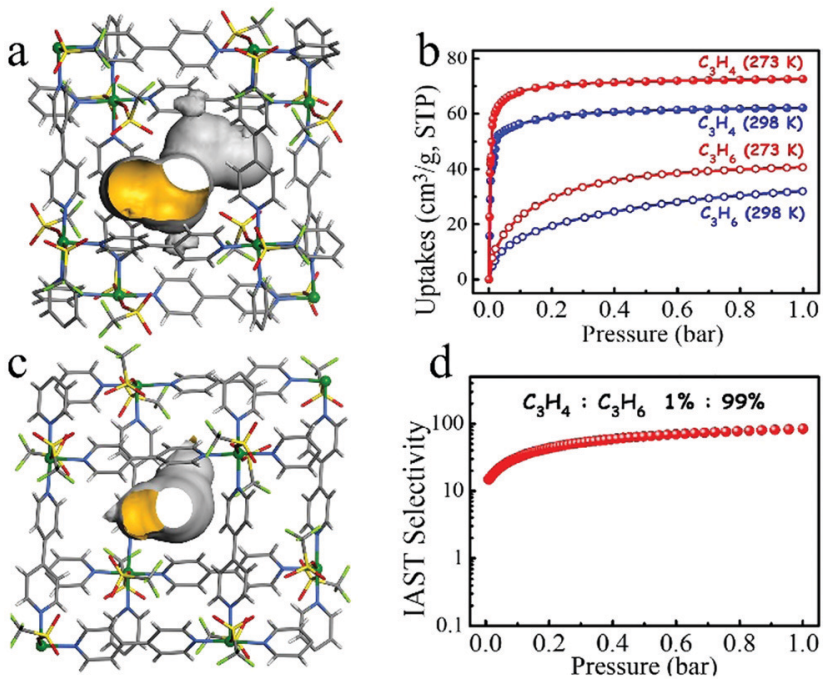

Fig. 15 (a and b) Schematic diagrams of the two types of cavities (I and II) in ELM-12 (Cu, green; $\mathrm{C}$, gray; O, red; $\mathrm{S}$, yellow; $\mathrm{F}$, light-green). (c) $\mathrm{C}_{3} \mathrm{H}_{4}$ and $\mathrm{C}_{3} \mathrm{H}_{6}$ adsorption isotherms of ELM-12. (d) Predicted selectivity of ELM12 for $\mathrm{C}_{3} \mathrm{H}_{4} / \mathrm{C}_{3} \mathrm{H}_{6}(1: 99)$ at $298 \mathrm{~K}$.

revealed that ELM-12 can effectively remove the trace $\mathrm{C}_{3} \mathrm{H}_{4}$ from a $\mathrm{C}_{3} \mathrm{H}_{4} / \mathrm{C}_{3} \mathrm{H}_{6}(1: 99)$ mixture under ambient conditions to produce $\mathrm{C}_{3} \mathrm{H}_{6}$ with a purity of $99.9998 \%$ (Fig. $15 \mathrm{c}$ and d). As expected, ELM-12 exhibits a very high $\mathrm{C}_{3} \mathrm{H}_{4} / \mathrm{C}_{3} \mathrm{H}_{6}$ selectivity of up to 84 for such a $\mathrm{C}_{3} \mathrm{H}_{4} / \mathrm{C}_{3} \mathrm{H}_{6}(1: 99)$ both of which $\mathrm{C}_{3} \mathrm{D}_{4}$ molecules interact with $\mathrm{OTf}^{-}$groups through $\mathrm{C}-\mathrm{D} \cdots \mathrm{O}$ deuterium bonds. Because of its strong binding affinity to $\mathrm{C}_{3} \mathrm{H}_{4}$ and molecular sieving mechanism, ELM-12 offers excellent performance for the separation of $\mathrm{C}_{3} \mathrm{H}_{4} / \mathrm{C}_{3} \mathrm{H}_{6}$.

In order to increase the binding affinity of $\mathrm{C}_{3} \mathrm{H}_{4}$, so as to produce $\mathrm{C}_{3} \mathrm{H}_{6}$ of higher purity, in 2018, Yang et al. investigated a series of hybrid ultramicroporous materials with pillared inorganic anions, including SIFSIX-1-Cu, SIFSIX-2-Cu-i, and SIFSIX-3-Ni, ${ }^{110}$ for $\mathrm{C}_{3} \mathrm{H}_{4}$ removal. All three of these SIFSIX materials displayed steep $\mathrm{C}_{3} \mathrm{H}_{4}$ uptakes in the low-pressure region, and larger adsorption amounts of $\mathrm{C}_{3} \mathrm{H}_{4}$ than of $\mathrm{C}_{3} \mathrm{H}_{6}$ at 1 bar. In particular, SIFSIX-3-Ni shows a near-saturation $\mathrm{C}_{3} \mathrm{H}_{4}$ uptake of $2.65 \mathrm{mmol} \mathrm{g}^{-1}$ at an extremely low pressure $(0.003$ bar), with a $\mathrm{C}_{3} \mathrm{H}_{4} / \mathrm{C}_{3} \mathrm{H}_{6}$ selectivity of over 250 . PXRD experimental results showed that one unit cell of SIFSIX-3-Ni traps one $\mathrm{C}_{3} \mathrm{H}_{4}$ molecule, and that all of the hydrogen atoms of $\mathrm{C}_{3} \mathrm{H}_{4}$ are engaged in strong interactions with $\mathrm{SiF}_{6}{ }^{2-}$ anions through multiple hydrogen-bonding or dipole-dipole interactions $\left(\mathrm{C} \equiv \mathrm{H}^{\delta}+\cdots \mathrm{F}^{\delta-}, \mathrm{C}-\mathrm{H}^{\delta+} \cdots \mathrm{F}^{\delta-}\right)$. Breakthrough experiments further confirmed that SIFSIX-3-Ni can remove trace $\mathrm{C}_{3} \mathrm{H}_{4}$ from $\mathrm{C}_{3} \mathrm{H}_{6}$ with a purification capacity of $1187 \mathrm{~mL} \mathrm{~g}^{-1}$ at an ultralow concentration of $1000 \mathrm{ppm}$.

In 2018, Yang et al. further reported the one-step purification of $\mathrm{C}_{3} \mathrm{H}_{6}$ from multicomponent gases (propyne and propadiene) using a single material NbOFFIVE-2-Cu-i (also termed as ZU-62, NbOFFIVE $=\mathrm{NbOF}_{5}{ }^{2-}, \mathrm{i}=$ interpenetrated). ${ }^{111}$ The adoption of the asymmetric anion pillar $\mathrm{NbOF}_{5}{ }^{2-}$ as well as the interpenetrated structure successfully customized the separate energy favorable binding sites/space for the propyne and propadiene molecules within ZU-62 so that it can simultaneously adsorb them. ZU-62 features asymmetric $\mathrm{O} / \mathrm{F}$ node coordination, which leads to the formation of three types of nanopores bearing aperture sizes of $6.75 \AA$ (Site I), $6.94 \AA$ (Site II), $7.20 \AA$ (Site III), respectively. First-principles DFT-D calculated results show that propyne will be preferentially adsorbed on site III, while propadiene is more inclined to site I, leading to the introduced propyne and propadiene are able to target the corresponding suitable residence without mutual interference, revealing an interesting "classified storage" phenomenon. The propylene uptake at $298 \mathrm{~K}$ under $5000 \mathrm{ppm}$ was only $0.05 \mathrm{mmol} \mathrm{g}^{-1}$, almost negligible and the selectivity via the IAST calculation of the binary gases, propyne/ propylene and propadiene/propylene (0.5/99.5) was up to 48 and 34. This work provides some clues for the one-step purification from multicomponent mixtures.

Although the three above-described materials exhibit high $\mathrm{C}_{3} \mathrm{H}_{4}$ adsorption capacities, they only exhibit moderately high gas-separation performances because of their comparatively large pores capable of including both $\mathrm{C}_{3} \mathrm{H}_{4}$ and $\mathrm{C}_{3} \mathrm{H}_{6}$ molecules, thus limiting the throughput of the desired $\mathrm{C}_{3} \mathrm{H}_{6}$ product. In 2018, Li et al. conducted a comprehensive screening of a series of MOFs with a broad range of structures, pore sizes, and functionalities (Fig. 16a). Among them, the ultramicroporous UTSA-200 ([Cu(azpy $\left.)_{2}\left(\mathrm{SiF}_{6}\right)\right]_{n}$; azpy $=4,4^{\prime}$-azopyridine $)$ was identified as the best-performing material to remove trace amounts of $\mathrm{C}_{3} \mathrm{H}_{4}$ from $\mathrm{C}_{3} \mathrm{H}_{4} / \mathrm{C}_{3} \mathrm{H}_{6}$ mixtures. ${ }^{112}$ The static pore size of UTSA-200 is about $3.4 \AA$, which is much smaller than the dimensions of $\mathrm{C}_{3} \mathrm{H}_{4}(4.2 \AA)$ and $\mathrm{C}_{3} \mathrm{H}_{6}(4.6 \AA)$. A first-principles dispersion-corrected DFT study of UTSA-200 indicated that, after the adsorption of $\mathrm{C}_{3} \mathrm{H}_{4}$ molecules, the $\mathrm{N}=\mathrm{N}$ bond and pyridine rings of azpy exhibit obvious rotation and distortion, which enlarges the pores to about $4.2 \AA$, thereby allowing the passage of a $\mathrm{C}_{3} \mathrm{H}_{4}$ molecule, but blocking $\mathrm{C}_{3} \mathrm{H}_{6}$ in the lowpressure region ( $<0.2$ bar). In addition, each adsorbed $\mathrm{C}_{3} \mathrm{H}_{4}$ molecule is bound by two $\mathrm{SiF}_{6}{ }^{2-}$ sites from different nets through cooperative $\mathrm{C}-\mathrm{H} \cdots \mathrm{F}$ and $\mathrm{C} \equiv \mathrm{H} \cdots \mathrm{F}$ hydrogen bonding. UTSA-200 shows unprecedentedly high $\mathrm{C}_{3} \mathrm{H}_{4}$ adsorption capacity (95 $\mathrm{cm}^{3} \mathrm{~cm}^{-3}$ at 0.01 bar and $298 \mathrm{~K}$ ) and $\mathrm{C}_{3} \mathrm{H}_{4} / \mathrm{C}_{3} \mathrm{H}_{6}$ selectivity (over 20000 ) (Fig. 16b). Breakthrough experiments showed that UTSA-200 can remove trace $\mathrm{C}_{3} \mathrm{H}_{4}$ from mixtures of compositions 1 : 99 and 0.1 : 99.9 , producing $\mathrm{C}_{3} \mathrm{H}_{6}$ with a purity of $99.9999 \%$, in yields of 62.0 and $142.8 \mathrm{mmol} \mathrm{g}^{-1}$, respectively.

\section{Critical factors for industrial applications}

A wide range of promising porous MOF materials have been reported to date, and their potential use in the separation of light olefins was reviewed in the previous subsections. However, before they can be used in real industrial applications, there are some critical factors that need to be addressed. Fortunately, in recent years, more academic research groups and commercial companies have stepped up their efforts towards producing MOFs that meet the requirements, even though this can be a challenging task. 


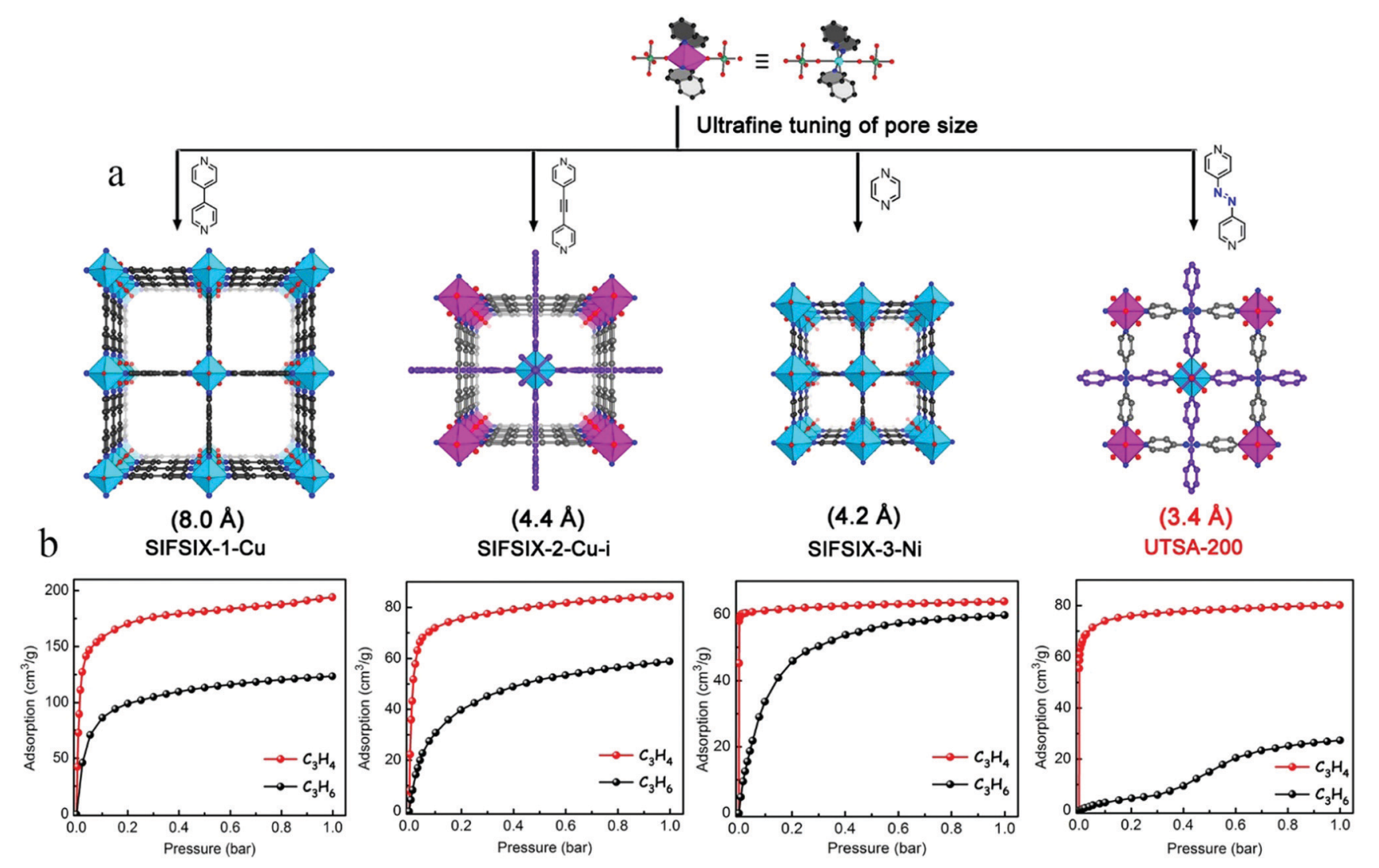

Fig. 16 (a) Pore apertures and pore chemistry of a series of SIFSIX materials. (b) $\mathrm{C}_{3} \mathrm{H}_{4}$ and $\mathrm{C}_{3} \mathrm{H}_{6}$ adsorption isotherms of the corresponding SIFSIX materials at $298 \mathrm{~K}$.

\subsection{Stability}

MOFs are connected by organic ligands and inorganic metal ions, and hence show low stability compared with traditional adsorbents (zeolites, activated carbon, or silica). This has been recognized as a major barrier that limits their practical applications.

3.1.1 Moisture/water resistance. Most MOFs with weak metal-ligand coordination bonds are somewhat susceptible to hydrolysis in the ambient atmospheric environment. For example, the well-known Mg-MOF-74 will gradually lose its structural integrity under moist conditions, incurring a sharp decrease in Brunauer-Emmett-Teller (BET) surface area from 1775 to $<20 \mathrm{~m}^{2} \mathrm{~g}^{-1}$ after one day in $40 \%$ relative humidity. The main reason for this is the unsaturated metal sites in Mg-MOF-74, which cause the clustering of water molecules in its pores, resulting in degradation of its framework.

In 2011, Yang et al. found that the water stability of MOFs can be improved by methyl modification. ${ }^{113}$ The authors used 2-methylterephthalic acid and 2,5-dimethylterephthalic acid to synthesize $\mathrm{CH}_{3} \mathrm{MOF}-5$ and $\mathrm{DiCH}_{3} \mathrm{MOF}-5$, respectively. PXRD experiments showed that the structures of these two materials did not collapse after they were exposed to ambient air with humidity $32-37 \%$ for 4 days (the PXRD pattern of pure MOF-5 is lost after exposure to air for $45 \mathrm{~min}$ ). These results strongly imply that introducing hydrophobic methyl groups enhances the structural stability of the MOF-5-type framework. For the adsorption of $\mathrm{H}_{2}$ ( 1 bar, $77 \mathrm{~K}$ ), $\mathrm{CH}_{3} \mathrm{MOF}-5$ (1.42 wt\%) was basically as effective as MOF-5 (1.44 wt\%), whereas DiCH $_{3}$ MOF-5 (1.29 wt\%) showed only a slightly lower uptake. After exposure to air for 4 days, the adsorption capacity of $\mathrm{DiCH}_{3} \mathrm{MOF}-5$ remained unchanged, whereas that of $\mathrm{CH}_{3} \mathrm{MOF}-5$ decreased due to partial decomposition. This work provides a good strategy for enhancing the water stability of MOF materials, but the introduction of a large number of methyl groups into the pores will inevitably lead to a reduction in porosity.

In 2012, Decoste et al. introduced a plasma-enhanced chemical vapor deposition (PECVD) method to improve the water stability of MOFs. ${ }^{114}$ Depositing perfluorohexane (PFH) on the surface of Cu-BTC by PECVD was found to successfully prevent the formation of water clusters and hydrolysis. The PXRD results confirmed that the structure of Cu-BTC-plasma showed no obvious changes compared with that of Cu-BTC (Fig. 17a). After immersion in water at room temperature for $24 \mathrm{~h}$, the structure of Cu-BTC-plasma remained intact, demonstrating its excellent water stability. It has been found that water molecules first coordinate at copper atoms of site I in Cu-BTC. Secondary binding of water occurs at sites I' (the large cage interior), which occurs through hydrogen-bonding with water molecules adsorbed at sites I (Fig. 17b). According to GCMC and thermogravimetric analyses, $\mathrm{PFH}$ preferentially adsorbs at sites I'. The binding of PFH away from site I allows water molecules to still coordinate to the $\mathrm{Cu}$ atoms in $\mathrm{Cu}-\mathrm{BTC}$, 

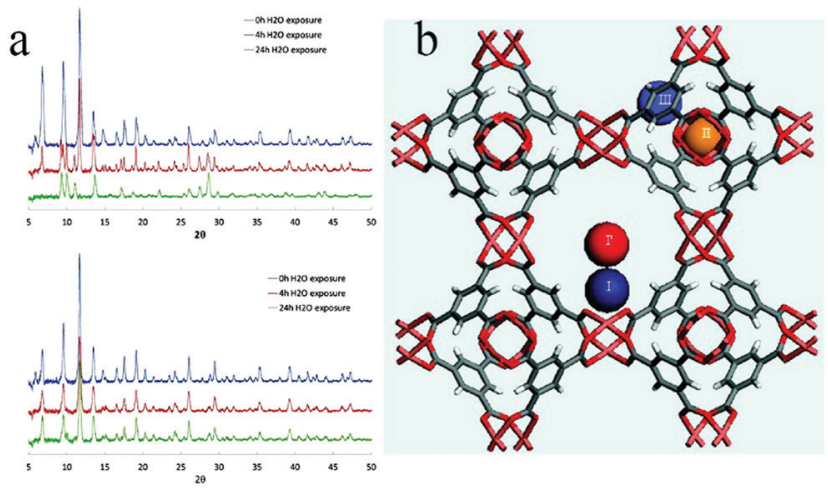

Fig. 17 (a) PXRD patterns for Cu-BTC and Cu-BTC-plasma after immersion in water at room temperature for 0,4 , and $24 \mathrm{~h}$. (b) Representation of sorption sites I, I', II, and III in Cu-BTC viewed along the [100] direction.

but the hydrophobic nature of $\mathrm{PFH}$ in the pores prevents the formation of water clusters at higher humidity levels. This work provides a new way of enhancing the water stability of MOFs. However, the method is rather complex, only suitable for specific MOFs, and the porosity and specific surface area are decreased by about $30 \%$ after modification.

Around the same time, Yang et al. proposed a new method for improving the water stability of MOFs without using additional solvents or chemicals. ${ }^{115}$ They placed IRMOF-1 in a tube furnace, and carbonized it at a target temperature under nitrogen so as to transform the organic ligands on its surface into an amorphous carbon coating. Through precisely controlling the temperature and gas flow, they basically maintained the crystal structure and pore size distribution of the material. Due to the hydrophobicity of carbon, this method effectively avoids direct exposure of the MOF to moisture, thereby preventing hydrolysis. PXRD analysis showed that the structure of the carbon coating on IRMOF-1 remained intact after being exposed to air of $34 \%$ humidity for 14 days. After heat treatment at $510{ }^{\circ} \mathrm{C}$, the crystal structure of the material was still maintained after soaking in water for $2 \mathrm{~h}$. This work demonstrated that the amorphous carbon surface formed during heat treatment hindered hydrolysis of the MOF, even upon submersion in water.

To develop a more facile method, in 2014 Zhang et al. also used a vapor deposition technique to apply hydrophobic polydimethylsiloxane (PDMS) on the surface of MOF materials ${ }^{116}$ (Fig. 18a). MOF-5, HKUST-1, and ZnBT were successfully coated with PDMS and their stabilities were tested. MOF- 5 and coated MOF-5 were placed in air of $55 \%$ humidity for 2 days, whereupon the coated MOF-5 maintained the same morphology and smooth surface before and after the treatment, and its structure and porosity were largely preserved, as verified by powder XRD patterns and $\mathrm{N}_{2}$ adsorption isotherms (Fig. 18b and c). In the case of coated HKUST-1, its BET surface area was unchanged after soaking in water for three months. This method is simple and easy to operate, and the MOFs coated with PDMS not only show superhydrophobicity and excellent water stability, but also retain their inherent porosities and high specific surface areas.

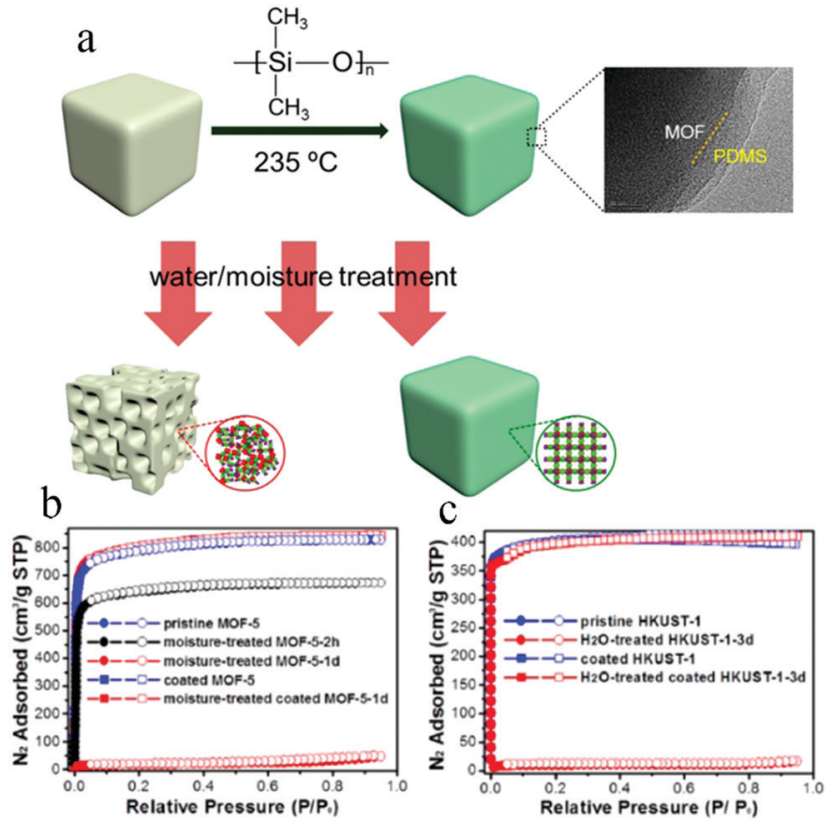

Fig. 18 (a) Illustration of PDMS-coating on the surface of MOFs with improvement of their moisture/water resistance. $\mathrm{N}_{2}$ sorption isotherms for pristine and PDMS-coated MOF-5 (b) and HKUST-1 (c) before and after moisture/water treatment (MOF-5 was treated in air at $55 \%$ relative humidity for $1 \mathrm{~d}$; HKUST-1 was treated in water for $3 \mathrm{~d}$ ).

Optical sensing and adsorption-based methods are considered as very promising separation methods for the removal of organic pollutants from wastewater. However, a precondition of applying MOFs for the detection and removal of pollutants is water stability of their frameworks. To synthesize MOFs with highly stable structures, in 2016, Wang et al. reported the use of zirconium ions for the preparation of a variety of MOF materials for the purification of wastewater, including BUT-12 $\left[\mathrm{Zr}_{6} \mathrm{O}_{4}(\mathrm{OH})_{8^{-}}\right.$ $\left(\mathrm{H}_{2} \mathrm{O}\right)_{4}(\mathrm{CTTA})_{8 / 3} ; \mathrm{H}_{3} \mathrm{CTTA}=5^{\prime}$-(4-carboxyphenyl)-2', $4^{\prime}, 6^{\prime}$-trimethyl$\left[1,1^{\prime}: 3^{\prime}, 1^{\prime \prime}\right.$-terphenyl]-4,4"-dicarboxylic acid $]$ and BUT-13 $\left[\mathrm{Zr}_{6} \mathrm{O}_{4^{-}}\right.$ $(\mathrm{OH})_{8}\left(\mathrm{H}_{2} \mathrm{O}\right)_{4}(\mathrm{TTNA})_{8 / 3} ; \mathrm{H}_{3}$ TTNA $=6,6^{\prime}, 6^{\prime \prime}$-(2,4,6-trimethylbenzene1,3,5-triyl)tris(2-naphthoic acid)]. ${ }^{117}$ In BUT-12, the carboxylate ligand CTTA $^{3-}$ is functionalized with three methyl groups. These three methyl groups increase the hydrophobicity of the framework, so that the material exhibits excellent water stability. The material was soaked in water, $\mathrm{HCl}$ solutions, and $\mathrm{NaOH}$ solution $(\mathrm{pH}=10)$ both at room temperature and boiling temperature. After $24 \mathrm{~h}$, the PXRD patterns showed that the crystallinity and structure of the material had not changed, which confirmed its excellent stability.

To further enhance the coordination bond between the metal and the ligand, modification of the configuration of the ligand would seem to be a good choice. In 2019, Wang et al. demonstrated that fixing the flexible arms of core-shared ligands enhanced the stability of their $\mathrm{Zr}(\mathrm{Iv})-\mathrm{MOFs}{ }^{118}$ by blocking the rotation of ligand rotamers. Four kinds of MOFs were synthesized (Fig. 19), two of which had the same pyrene core (BUT-72, BUT-73), while the other two had the same carbazole core (BUT-74, BUT-63). The difference between each pair lies in whether the side arm is flexible styrene or rigid naphthalene. 


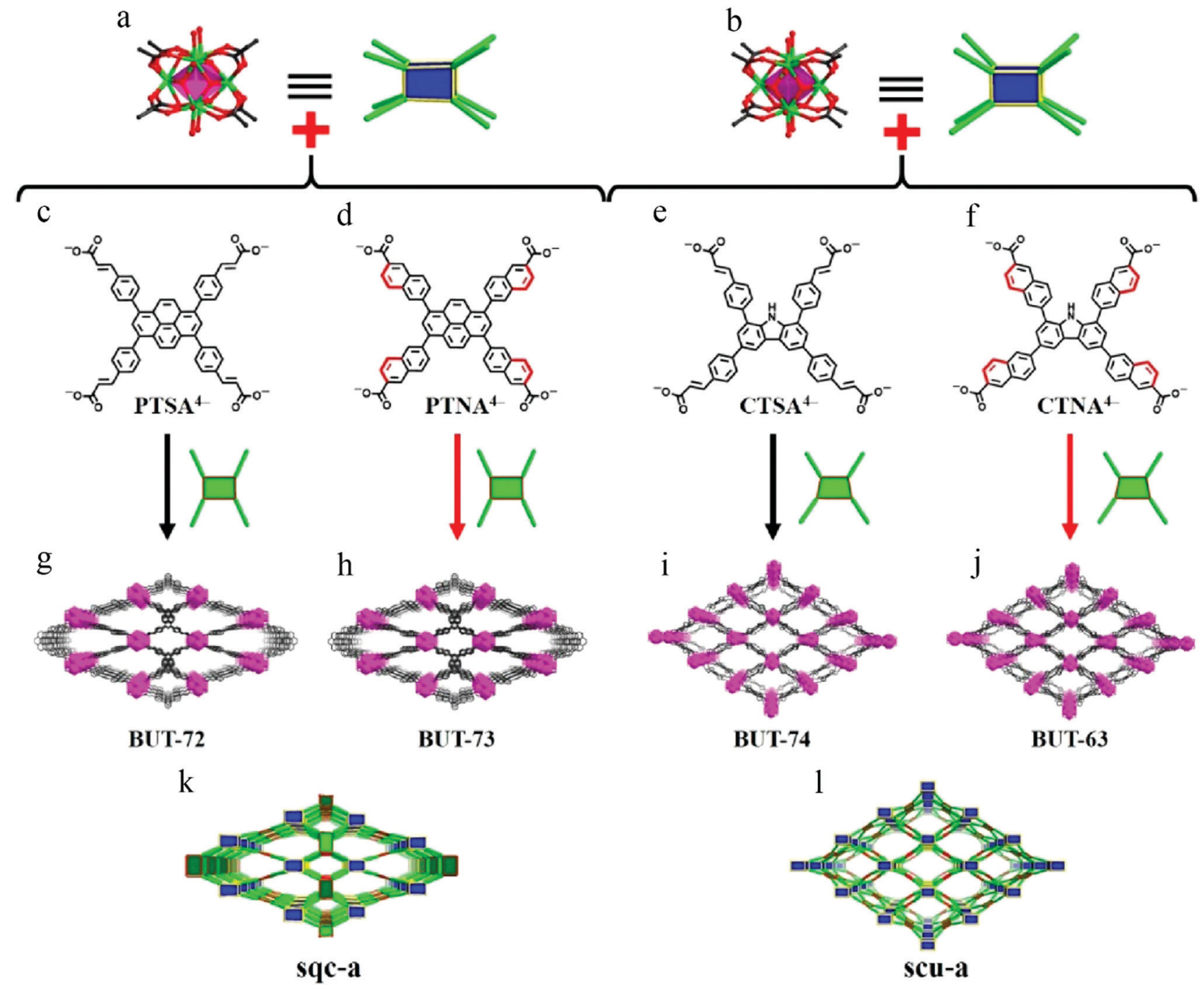

Fig. 19 Construction and structures of BUT-72, -73, -74, and -63: ligands (c) PTSA ${ }^{4-}$, (d) PTNA ${ }^{4-}$, (e) CTSA ${ }^{4-}$, and (f) CTNA ${ }^{4-}$ constructed with (a and b) $\mathrm{Zr}_{6}$ clusters to generate ( $\mathrm{g}$ and $\left.\mathrm{h}\right)$ BUT-72 and -73 with an sqc-a topological structure (k), and (i and j) BUT-74 and -63 with an scu-a structure (l), respectively.

After soaking in $\mathrm{HCl}, \mathrm{NaOH}$, or water for $24 \mathrm{~h}$, the PXRD peaks of all treated BUT-72 and BUT-74 samples had disappeared, indicating collapse of the framework, but the structures of BUT-73 and BUT-63 were still intact after the same treatment. This was because the destruction of MOFs is usually induced by disrupting the coordination moieties of ligands, and rigid ligands usually require a higher activation energy, such that the original configuration of ligands with rigid arms is easier to maintain.

3.1.2 Thermal stability. In the desorption or cycling process, vacuum and heat have often been utilized to regenerate the adsorbent for the adsorption process. For this purpose, thermal stability of MOFs is usually required under heat and vacuum or dry $\mathrm{N}_{2}$ atmosphere. In most cases, the thermal degradation of MOFs is the result of breakage of the connecting bonds between the nodes, accompanied by burning of the joints. Therefore, the thermal stability of an MOF generally depends on the bond strength and the number of node bonds. ${ }^{119}$ The thermal degradation of MOFs can also take the form of amorphization, melting, node cluster dehydration, (anaerobic) joint dehydrogenation, or graphitization.

In 2008, Cavka et al. reported the rigid MOF UiO-66, which contains highly stable secondary structural units. ${ }^{47}$ It is composed of six $\mathrm{Zr}(\mathrm{I})$ ions forming an octahedral cage structure, and each $\mathrm{Zr}(\mathrm{I})$ ion is connected with $12 \mathrm{H}_{2}$ BDC ligands, which is the highest coordination number reported for an MOF. In addition, Zr has a high oxygen affinity, and thus forms strong $\mathrm{Zr}-\mathrm{O}$ bonds. The high affinity of $\mathrm{Zr}$ for $\mathrm{O}$ and its compact structure endow UiO-66 with outstanding thermal stability. Its crystal structure is stable at $500{ }^{\circ} \mathrm{C}$, and its framework can withstand a mechanical pressure of $1 \mathrm{MPa}$. Its powder XRD pattern remained virtually unaltered after soaking samples in solvents such as water, DMF, benzene, and acetone for $24 \mathrm{~h}$.

The concept of MIXMOF provides us with an effective method for adjusting the structure and characteristics of pores. 
In 2010, Marx et al. applied this strategy in the synthesis of MIL-53(Al). ${ }^{120}$ They used benzene-1,4-dicarboxylate (BDC) and 2-aminobenzene-1,4-dicarboxylate (ABDC) to synthesize a series of MOFs of the general formula $\mathrm{Al}(\mathrm{OH})(\mathrm{BDC})_{1-x}(\mathrm{ABDC})_{x}$ $(x=0.1,0.5,0.9)$ with mixed ligands, whereby the content of amine groups was controlled by adjusting the ratio of the two ligands. PXRD patterns proved that both ligands were incorporated into the framework. The thermal stability of the material was tested by thermogravimetry and differential thermogravimetry. The temperature of maximum decomposition rate was shifted from $593{ }^{\circ} \mathrm{C}$ for the MIXMOF with $10 \%$ ABDC to $537{ }^{\circ} \mathrm{C}$ for that with $50 \% \mathrm{ABDC}$ and $494{ }^{\circ} \mathrm{C}$ for that with $90 \% \mathrm{ABDC}$. The results show that adjusting the ratio of the two ligands can significantly change the thermal stability of the MIXMOF.

3.1.3 Chemical stability. In traditional light-olefin production processes (mostly steam-cracking or thermal decomposition of the corresponding paraffins), certain amounts of common hazardous molecules, $\mathrm{CO}_{x}, \mathrm{NO}_{x}, \mathrm{SO}_{x}$, and $\mathrm{H}_{2} \mathrm{~S}$, are present in the products. Although a high proportion of these molecules can be removed at the alkali-washing stage, ppm or ppb levels of acid molecules persist in the gas flows, which requires that MOF adsorbents have high chemical stability to maintain their structures and separation performance over a long operation time (usually at least 3 years).

In 2011, Colombo et al. first proposed that the $\mathrm{p} K_{\mathrm{a}}$ value of a coordinating atom on a ligand can be regarded as an approximate indicator of the bond strength between a metal and the ligand. ${ }^{121}$ This is because the assembly of MOFs is controlled by Lewis acid-base theory. From this perspective, these authors synthesized a series of MOFs with high stability by searching for ligands with high $\mathrm{p} K_{\mathrm{a}}$ values, as exemplified by pyrazolate [1,3,5-tris(1H-pyrazol-4-yl)benzene] $\left(\mathrm{H}_{3} \mathrm{BTP}\right)$, with $\mathrm{p} K_{\mathrm{a}} 19.8$. Results showed $\mathrm{M}_{3}(\mathrm{BTP})_{2}$ systems $(\mathrm{M}=\mathrm{Co}, \mathrm{Ni}, \mathrm{Cu}, \mathrm{Zn})$ to have high thermal and chemical stability, especially $\mathrm{Ni}_{3}(\mathrm{BTP})_{2}$, which maintained its structure whether heated to $410{ }^{\circ} \mathrm{C}$ in air or soaked with boiling aqueous solutions of $\mathrm{pH}$ 2-14 for two weeks. Thus, this stability parallels, or even surpasses, that of zeolites.

In 2011, Kang et al. ${ }^{122}$ carried out an extensive investigation of the stability differences of isotypic MOFs with different central metal ions. They selected an $\mathrm{M}$-BDC $(\mathrm{M}=\mathrm{Al}, \mathrm{Cr}, \mathrm{V})$ series of MOFs and tested their stabilities. Firstly, the three respective materials were placed in a basic solution $(7.0 \times$ $\left.10^{-2} \mathrm{M} \mathrm{NaOH}\right)$ at room temperature. It was found that the XRD peaks and BET surface area of Al-BDC and V-BDC decreased sharply with the contact time. However, Cr-BDC proved to be very stable in the basic solution and showed no change in BET surface area or XRD pattern. Similar results were observed in acidic solution $\left(7.0 \times 10^{-2} \mathrm{M} \mathrm{HCl}\right)$ and deionized water ( $\mathrm{pH}$ 6.7). Therefore, the chemical and moisture stabilities of these three materials follow the order $\mathrm{Cr}-\mathrm{BDC}>\mathrm{Al}-\mathrm{BDC}>$ V-BDC. The results show that the chemical and moisture stabilities of the materials are related to the inertness or lability of the metal ions. In other words, the chemical stability of isotypic MOFs increases with increasing inertness (or decreasing lability) of the central metal ions. The thermal stabilities of these
MOFs were also tested by TGA, and follow the order Al-BDC > Cr-BDC > V-BDC, mirroring the strengths of the metal-oxygen bonds in the common oxides $\left(\mathrm{Al}_{2} \mathrm{O}_{3}, 514 \mathrm{~kJ} \mathrm{~mol}^{-1}, \mathrm{Cr}_{2} \mathrm{O}_{3}\right.$, $447 \mathrm{~kJ} \mathrm{~mol}^{-1}$, and $\mathrm{V}_{2} \mathrm{O}_{5}, 383 \mathrm{~kJ} \mathrm{~mol}^{-1}$ ). Finally, we note that the stability of a purified MOF may be lower than that of an MOF filled with an uncoordinated linker.

According to the hard-soft-acid-base theory (HSAB), soft-acid metal cations (such as $\mathrm{Zn}$ (II) and $\mathrm{Cu}$ (II) ions) can form a strong coordination bond with soft-base $\mathrm{N}$ donor ligands, which is conducive to enhancing the stability of an MOF, whereas weak bonding with a hard-base (acid ligand) is conducive to improving the crystallinity of a material so as to facilitate structural analysis. Based on this, in 2016, Hu et al. used $4^{\prime}$-(1H-tetrazol-5-yl)-[1,1'biphenyl]-3,5-dicarboxylic acid ( $\mathrm{H}_{3}$ TZBPDC), which contains both soft-base (nitrogen) and hard-base (carboxylic acid) coordination sites, to synthesize the ultrastable $\mathrm{Zn}$ (II)-organic framework USTC-7 with soft acid (Zn(II) ions) ${ }^{123}$ (Fig. 20a and b). Stability tests showed that USTC-7 could not only retain its crystallinity in diverse boiling solvents (ethanol, ethyl acetate, toluene, hexane) for $12 \mathrm{~h}$, but also in aqueous solutions at pH 2-12 (Fig. 20c and d).

\subsection{Balance of diffusion rate and selectivity}

Generally, the trade-off between physical adsorption selectivity and diffusion dynamics of porous materials is a major barrier for efficient gas separation and purification through physisorption. Some ultramicropore MOFs exhibits very high adsorption selectivity for the certain gas molecule with its tailor-made pore cavity, but its separation performance usually restricted by the low diffusion rate. While, the construction of hierarchicallyporous MOFs (HP-MOF) can solve this problem ideally. On the other hand, if the MOF materials have large pore size, it may not be suitable for effectively recognize for some small molecules, because a large pore space usually leads to low adsorption selectivity. For small-molecule gases, separation performance can be improved by adjusting the density of host-guest interactions and adsorption sites in the small pore space. In this context, the concept of pore space partition (PSP) has been introduced. ${ }^{44,124-128}$

3.2.1 Low diffusion rate. In 2012, Feng et al. reported the preparation of PCN-222, which was synthesized with $\mathrm{H}_{2}$ TCPP (TCPP $=$ tetrakis(4-carboxyphenyl)porphyrin) and $\left[\mathrm{Zr}_{6}\right]$ metal clusters as binders and metal nodes. ${ }^{129} \mathrm{PCN}-222$ contains large 1D hexagonal mesochannels $(3.7 \mathrm{~nm})$ and small triangular microchannels $(0.8 \mathrm{~nm})$, indicating its hierarchically porous structure. This MOF exhibits excellent catalytic performance due to its large pore size, higher catalytic center density and faster diffusion rate of the substrates. However, the direct synthesis method is not easy for expand to the synthesis of other materials.

In 2015, after considering the disadvantages of the traditional method for preparing large porous MOFs such as expensive ligands and difficulty in accurate control, Huang et al. proposed a new strategy for preparation of stable hierarchicalpore MOFs by in situ self-assembled template method with low cost, simple and general use (Fig. 21) ${ }^{130}$ Different from the traditional hard template and soft template methods, acid-sensitive 
a

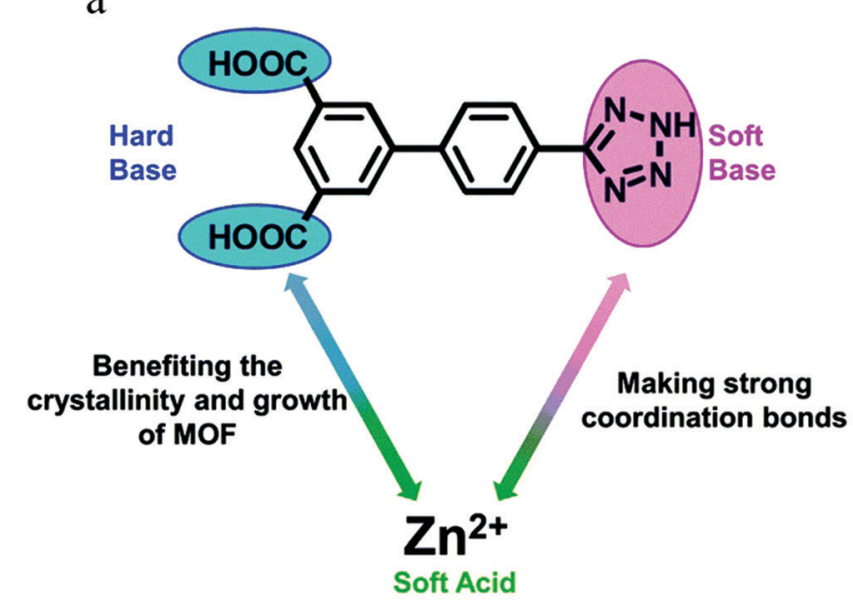

C

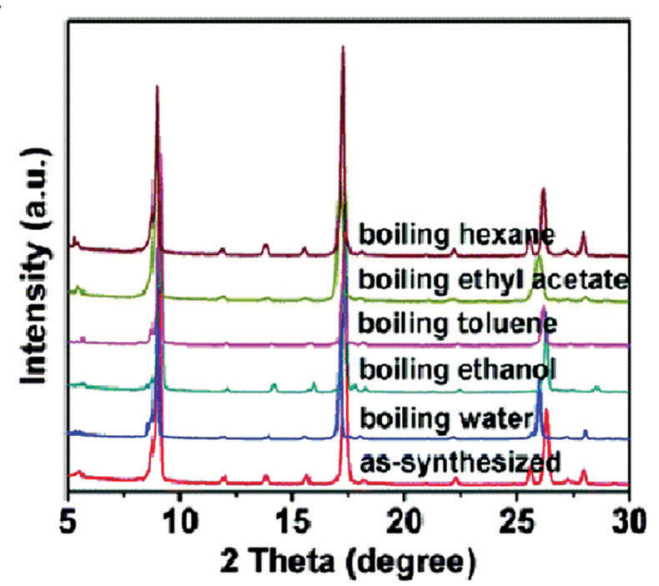

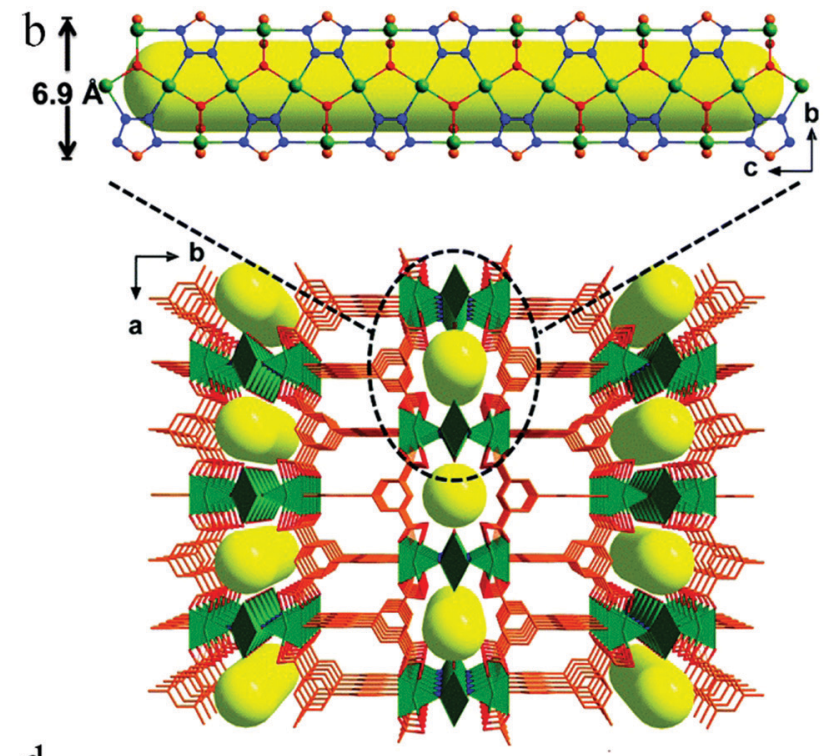

$\mathrm{d}$

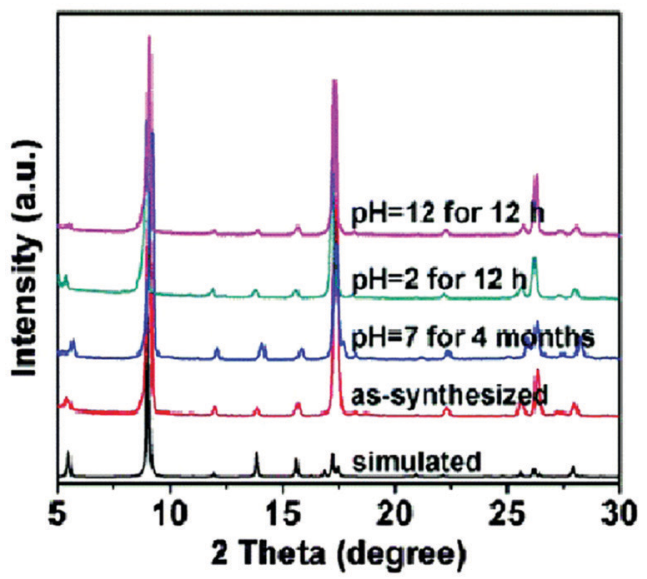

Fig. 20 (a) Illustration of the rational design of stable MOFs based on $\mathrm{Zn}(\mathrm{II})$ ions and a ligand bearing carboxylate and tetrazole groups. (b) View of the 3D network of USTC-7. The $\mathrm{ZnO}_{3}$ and $\mathrm{ZnO}_{4}$ polyhedra are shaded in olive-green for clarity. Powder XRD profiles of USTC-7 (c) after being soaked in various boiling solvents for $12 \mathrm{~h}$ or (d) after being soaked in neutral, acidic, and basic aqueous solutions for different durations.

metal-organic assemblies (MOAs) were used as a template to synthesize stable HP-MOF. The MOAs not only have a good interaction and affinity with the reaction precursor, but also can be easily removed, so as to maintain the structural integrity of the target porous materials. In this study, 19 kinds of stable HPMOFs were successfully prepared, and the mesoporous size could be controlled by the dosage of template, which provided a solid foundation for adsorption/separation of large molecules, heterogeneous catalysis and drug release on MOFs.

In 2018, Feng et al. reported a common synthesis strategy called linker thermolysis for constructing ultra-stable hierarchicalpore MOFs using thermal-sensitive linkers that are easily cracked. ${ }^{131}$ After thermal decomposition, the linkers of the multivariate MOF crystal breaks to generate a crystal defect, and the mesoporous are produced while the high crystallinity and stability of the original MOF are still retained. Its pore size distribution can be precisely controlled by adjusting the proportion of thermalsensitive ligands, heating time and heating temperature. The synthetic $\mathrm{ZrO}_{2}$ @HP-UiO-66 (UiO-66- $\mathrm{NH}_{2}-26 \%-350{ }^{\circ} \mathrm{C}-2 \mathrm{~h}$ ) by linker thermolysis in this work not only possesses $5.5 \mathrm{~nm}$ mesoporous, but also promotes the formation of ultrasmall metal oxide nanoparticles and exposure of more functional sites, showing high catalytic activity in Lewis acid-catalysed reactions.

3.2.2 Low density. The separation of $\mathrm{C}_{2} \mathrm{H}_{2} / \mathrm{C}_{2} \mathrm{H}_{4}$ mixtures by MOFs has been proved to be an effective method, albeit with the challenge of developing materials with high $\mathrm{C}_{2} \mathrm{H}_{2} / \mathrm{C}_{2} \mathrm{H}_{4}$ selectivity and $\mathrm{C}_{2} \mathrm{H}_{2}$ capacity. For example, the series M'MOF possesses good selectivity for $\mathrm{C}_{2} \mathrm{H}_{2} / \mathrm{C}_{2} \mathrm{H}_{4}$ but with low capacity. In 2017, Hong et al. designed and synthesized a pillar-layered MOF $\left\{\left[\mathrm{Cd}_{5}(\mathrm{MPCZ})_{2}(\mathrm{BDC})_{3}\left(\mathrm{NO}_{3}\right)_{2}\left(\mathrm{H}_{2} \mathrm{O}\right)_{4}\right] \cdot \mathrm{G}\right\}_{n}$ (EMCS-5) using the method of $\mathrm{PSP}^{132}$ (Fig. 22). It not only inherits the sieving effects of the M'MOF series to limit the adsorption of $\mathrm{C}_{2} \mathrm{H}_{4}$, but also shows an expanded space in the 2D layer so that it can capture more $\mathrm{C}_{2} \mathrm{H}_{2}$, and the pore-partition group provides abundant adsorption sites to simultaneously ensure high $\mathrm{C}_{2} \mathrm{H}_{2} / \mathrm{C}_{2} \mathrm{H}_{4}$ selectivity (12.6-17.5) and $\mathrm{C}_{2} \mathrm{H}_{2}$ adsorption capacity $\left(125.5 \mathrm{~cm}^{3} \mathrm{~g}^{-1}\right.$ at $273 \mathrm{~K}$ and $\left.1 \mathrm{bar}\right)$. 


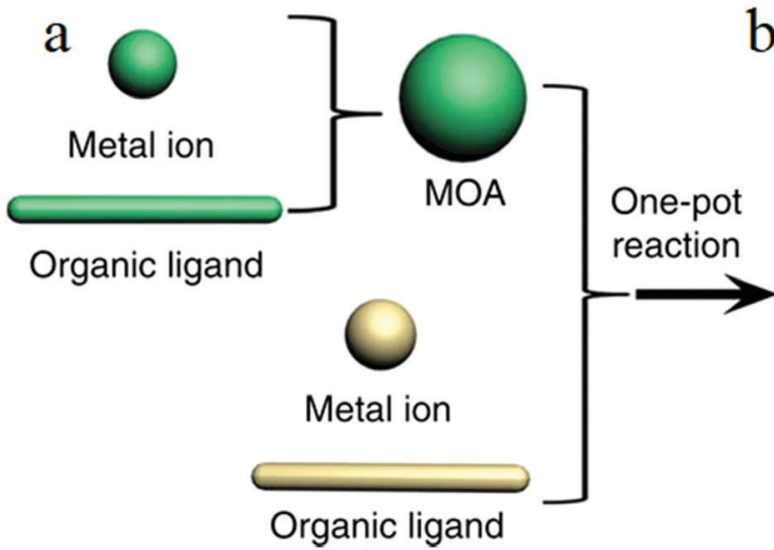

$\mathrm{b}$

C
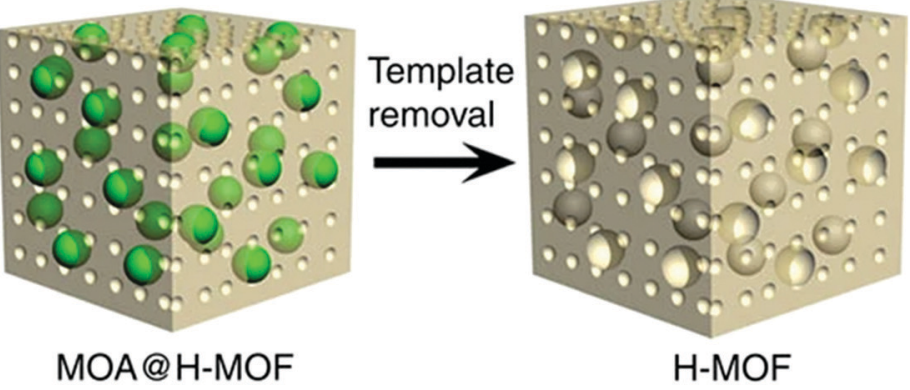

Fig. 21 Schematic representation for the preparation of H-MOF. (a) In situ self-assembly of MOA through the reaction between metal ion and organic ligand. (b) MOACH-MOF composite formed by one-pot self-assembly reaction. (c) H-MOF formed through removing MOA template.

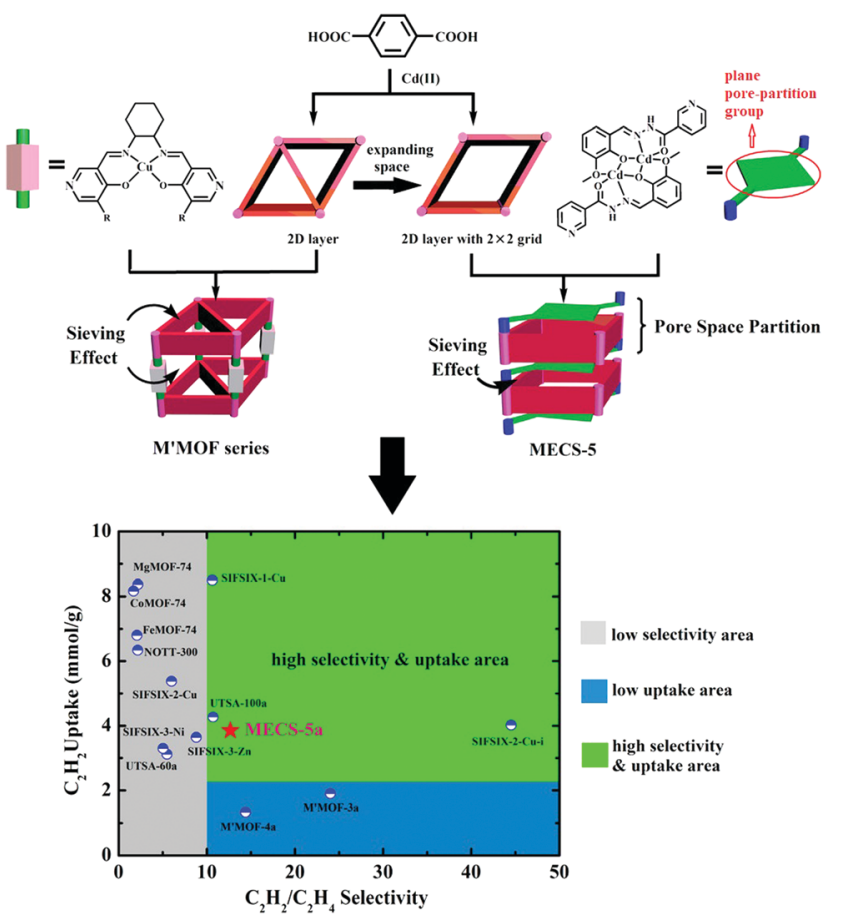

Fig. 22 Imitating M'MOF to design an MOF with high $\mathrm{C}_{2} \mathrm{H}_{2} / \mathrm{C}_{2} \mathrm{H}_{4}$ selectivity and $\mathrm{C}_{2} \mathrm{H}_{2}$ uptake.

In 2019, Ye et al. successfully modified FJU-88 with a triangular ligand [Tripp $=2,4,6$-tris(4-pyridyl)pyridine] by the PSP method to realize a novel porous MOF (FJU-90) with dual functionalities for the challenging $\mathrm{C}_{2} \mathrm{H}_{2} / \mathrm{CO}_{2}$ separation. ${ }^{133}$ The pore dimensions of FJU-90 decreased from $12.0 \times 9.4 \AA^{2}$ to $5.4 \times 5.1 \AA^{2}$, which greatly improved the separation performance for $\mathrm{C}_{2} \mathrm{H}_{2} / \mathrm{CO}_{2}$. The optimized pore size and the hydrogen bond between $\mathrm{C}_{2} \mathrm{H}_{2}$ and an $\mathrm{O}$ atom on the pore surface raise the adsorption capacity of $\mathrm{C}_{2} \mathrm{H}_{2}$ to $180 \mathrm{~cm}^{3} \mathrm{~g}^{-1}$, while that of $\mathrm{CO}_{2}$ is reduced to $103 \mathrm{~cm}^{3} \mathrm{~g}^{-1}$ at $298 \mathrm{~K}$ and 1 bar. Although the IAST selectivity (4.3) of FJU-90 is lower than that of UTSA-74a (8.2) and those of other excellent materials, due to the combination of its high absorption capacity and moderate selectivity for
$\mathrm{C}_{2} \mathrm{H}_{2} / \mathrm{CO}_{2}$, FJU-90 exhibits the highest gravimetric productivity with a value of $5.10 \mathrm{~mol} \mathrm{~kg}{ }^{-1}$, which is much higher than that for UTSA-74a. It is worth noting that the stability of FJU-90 is much higher than that of FJU-88, which can be ascribed to the introduction of the Tripp ligand. This work represents an outstanding example of application of the PSP strategy for rationally designing microporous MOF materials for challenging gas separations.

\subsection{Scale-up synthesis}

Central to the translation of these new materials into industrial separation processes is the ability to manufacture MOFs at the required scale, purity, and price for implementation. Depending on the final purpose, diverse MOFs may be prepared by employing several distinct synthetic methodologies. Processes that are faster, with lower energy consumption, are clearly more attractive for industrial purposes. ${ }^{134-137}$ Often, the feasibility of preparing the desired materials on a large scale, a difficult but important task, is the factor that determines the method that is ultimately selected.

In 2005, BASF Aktiengesellschaft first synthesized HKUST-1 by an electrochemical approach. ${ }^{138}$ The method involved immersion of a copper plate in a solution containing the organic linker 1,3,5-benzenetricarboxylic acid (BTC) and an electrolyte. When a certain potential was applied, the copper electrode released $\mathrm{Cu}(\mathrm{II})$ ions into the solution, which could react with the dissolved linker. During a period of $150 \mathrm{~min}$ at a potential of $12-19 \mathrm{~V}$, the current was $1.3 \mathrm{~A}$, and a greenish-blue precipitate was formed. This product had a specific surface area of $1820 \mathrm{~m}^{2} \mathrm{~g}^{-1}$, which was higher than that of the corresponding material synthesized by a solvothermal method.

In 2016, Campagnol et al. studied the mechanism of HKUST-1 synthesis by anodic deposition. ${ }^{139}$ They divided the electrochemical synthesis of this MOF into four stages: (I) initial nucleation; (II) growth of HKUST-1 islands; (III) intergrowth; and (IV) crystal detachment. In the initial stage, the metal substrate starts dissolving anodically in the solution containing the linker, and the first crystals nucleate on the electrode surface. After the first nuclei are formed, new crystals tend to nucleate next to them, forming islands of intergrown MOF. At the same time, those already nucleated grow to dimensions of several microns, eventually 
forming a compact layer. In the last stage, the crystals detach from the surface and expose empty spots of bare metal.

To date, MOFs have mainly been synthesized under hydrothermal/solvothermal conditions. This method requires long reaction times and incurs heavy energy consumption. In recent years, microwave irradiation has been used to synthesize various inorganic nanomaterials, such as zeolites and MOFs. The method is based on the interaction of electromagnetic waves with any material containing mobile electric charges, which can greatly shorten the reaction time and improve the product yields.

In 2005, Jhung et al. carried out pioneering work on the microwave-assisted synthesis of MOFs. A water-based synthesis of MIL-100 in the presence of hydrofluoric acid was reported. ${ }^{140}$ Materials were synthesized in a microwave oven at $220^{\circ} \mathrm{C}$ for 1 , 2 , or $4 \mathrm{~h}$, respectively, in a sealed Teflon autoclave. The results showed that unreacted chromium was consumed in about $2 \mathrm{~h}$. After $4 \mathrm{~h}$, the obtained yield of the crystals was $44 \%$, akin to the $45 \%$ achieved by conventional synthesis after 4 days. Thus, it can be seen that the microwave-assisted synthesis is about 20 times faster than the conventional synthesis.

In 2015 , in a study by Bag et al., nine isostructural microporous lanthanide MOFs were synthesized on a large scale by microwave-assisted solvothermal reaction within 5 min. ${ }^{141}$ At the same temperature, conventional solvothermal reactions required a longer reaction time ( 2 days) and slow evaporation (5 days) to produce these compounds in similar yields. Moreover, only $10 \mathrm{mg}$ of high-quality material could be obtained by the solvothermal method, whereas up to $2 \mathrm{~g}$ of the MOF could be produced by the microwave-assisted synthesis. This work not only demonstrated a great reduction in reaction time, but also a successful large-scale laboratory synthesis. It highlights that microwave-assisted synthesis is of great significance in the production of MOFs.

For most chemical syntheses, reactions are carried out in solution, whereas mechanochemical synthesis relies on mechanical forces and essentially does not require solvents or only a small amount of solvent. It has the advantages of low energy consumption, fast throughput, and the ability to quantitatively synthesize the targeted materials. In 2015, Crawford et al. proposed the use of twin-screw extrusion (TSE) and singlescrew extrusion (SSE) for the continuous synthesis of various metal complexes, and to provide high yields of high purity products at a specific temperature and shear force without a solvent or with only a small amount of solvent ${ }^{142}$ (Fig. 23). Using this method, the commercially important MOFs HKUST-1, ZIF-8, and MAF-4 were successfully prepared. These authors synthesized $\mathrm{Cu}_{3}(\mathrm{BTC})_{2}$ from $\mathrm{Cu}(\mathrm{II})$ hydroxide and benzene1,3,5-tricarboxylic acid at the appropriate $3: 2$ molar ratio by solvent-assisted TSE employing screw speeds in the range 55-250 rpm. The space time yield was $144000 \mathrm{~kg}$ per $\mathrm{m}^{3}$ per day. The high yield can be attributed to the near absence of solvent in the synthetic process, which usually occupies most of the reactor volume, together with the high reaction rates possible between such highly concentrated (or even neat) reactants under these conditions.

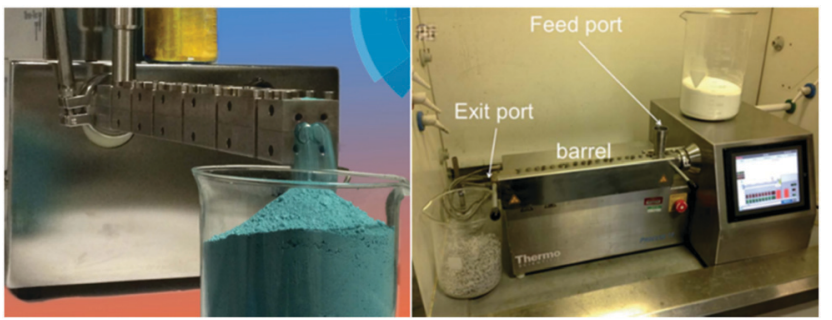

Fig. 23 Twin-screw extruder with key parts highlighted. The two screws which convey and knead the reactants are housed in the barrel.

\subsection{Shaping}

For industrial separation processes, adsorbents often need to be shaped or packed into given morphologies, such as granules, ${ }^{143-146}$ pellets, ${ }^{143,147,148}$ thin films, ${ }^{149-153}$ and so on, ${ }^{154-157}$ so as to reduce the pressure drop across the adsorbent bed as well as to provide gas diffusion channels and to enhance the mechanical stability. However, mechanical issues (e.g., stability and phase integrity) related to the use of MOFs remain largely unexplored in the literature. Typically, these compounds are obtained as loose powders (composed of small crystallites) with low packing densities. For this reason, MOFs should be shaped into suitable geometries before loading into the adsorption bed, in order to resist attrition and avoid disintegration into a powder, which could contaminate tanks, pipes, or other apparatus.

Fortunately, both companies (mainly BASF) and some academic research groups have already realized this high industrial importance, and hundreds of patents relating to the industrial properties of MOFs have been submitted to the European Patent Office.

In 2016, Chen et al. used a continuous-phase transformation processing strategy to convert MOFs into processable fluids, shaped bodies, and even MOF foams that could be reversibly interconverted between these states ${ }^{158}$ (Fig. 24). They introduced HKUST-1@ $\mathrm{Fe}_{3} \mathrm{O}_{4}$ core-shell nanoparticles into carboxymethylcellulose solution to obtain a high particle content (25.0-45.4 wt\%) magnetic fluid (HKUST-1@Fe $\mathrm{O}_{4}-\mathrm{MF}$ ). A cup reactor was manufactured by a solvent-induced hardening process. The excellent catalytic ability (conversion $76 \%$ and selectivity $93 \%$ ) was also verified by catalytic tests. In order to further improve the catalytic efficiency and develop a more practical catalyst form for industrial application, a light yet robust foam with hierarchical porosity was obtained by freeze-drying of HKUST-1@ $\mathrm{Fe}_{3} \mathrm{O}_{4}$-MF. Based on the adsorption isotherm of $\mathrm{N}_{2}$ at $77 \mathrm{~K}$, the surface area of the foam was $196 \mathrm{~m}^{2} \mathrm{~g}^{-1}$, and its pore volume was $0.65 \mathrm{~m}^{3} \mathrm{~g}^{-1}$. Robustness is one of the key prerequisites for practical application. Weight pressing, tape tests, and collision experiments proved that the foam had extraordinary mechanical stability. The loading capacity of this MOF could even reach $80 \mathrm{wt} \%$ without reducing its mechanical stability. Moreover, this MOF foam presented high permeability with a low pressure drop $\left(<20 \mathrm{~Pa}, 500 \mathrm{~mL} \mathrm{~min}^{-1}\right)$ because of its hierarchical porous structure and uniform distribution, making it potentially useful as a membrane reactor for various important catalytic and separation processes. 
a

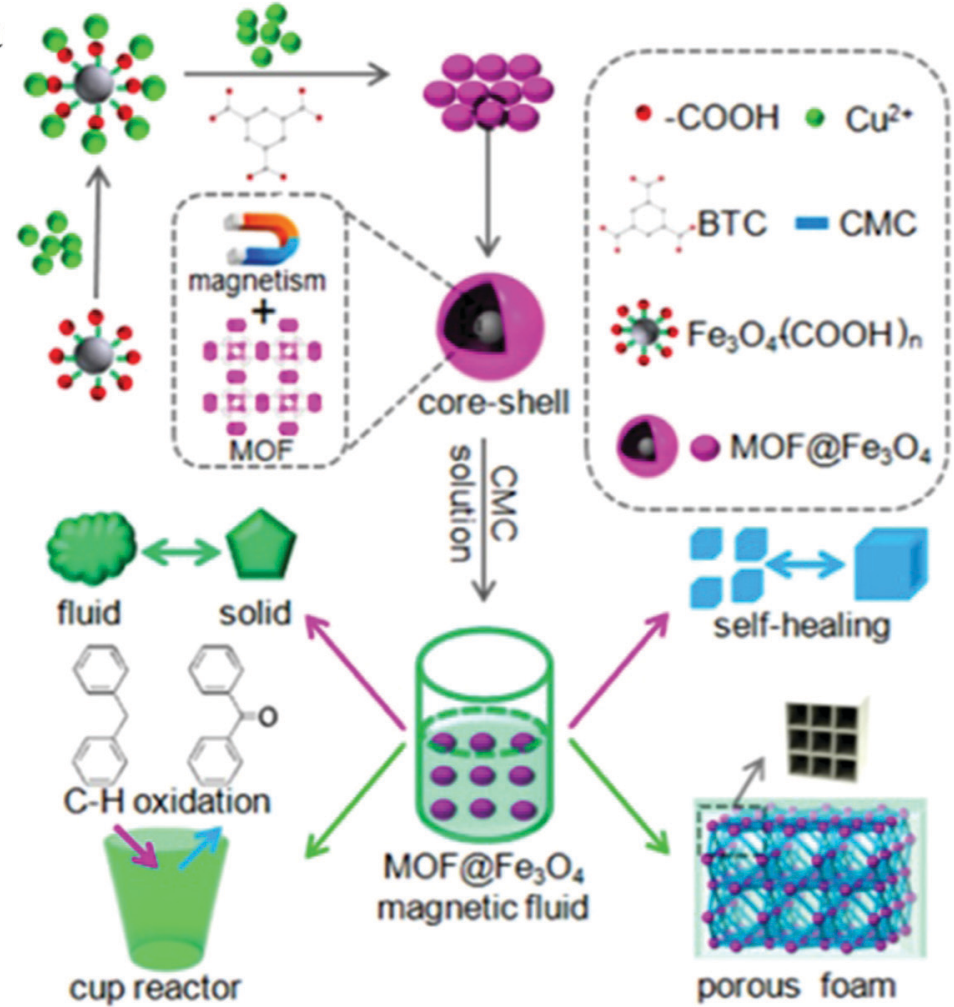

b

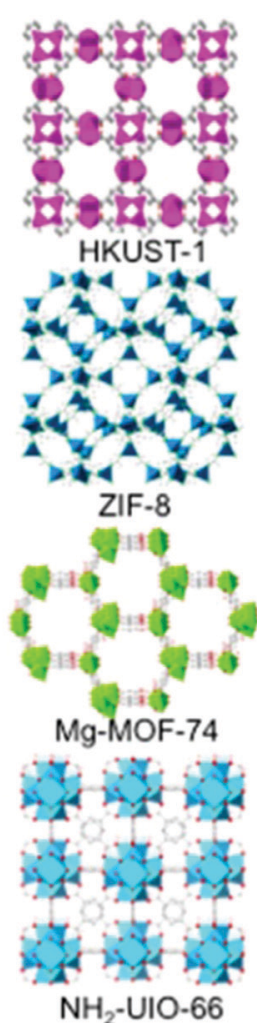

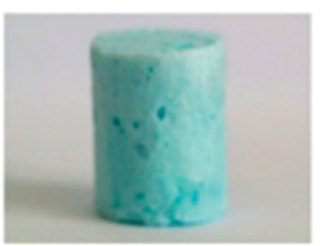
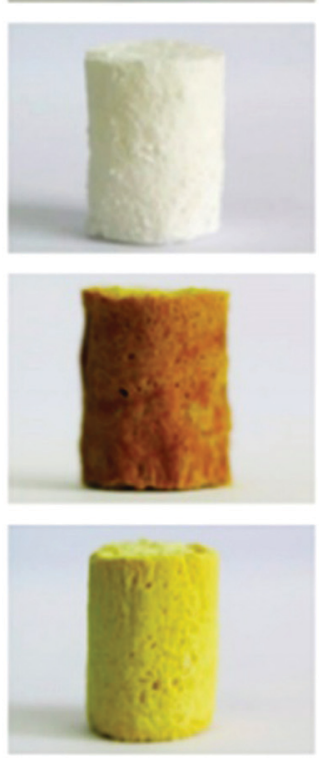

Fig. 24 (a) Schematic procedure for producing HKUST-1@ $\mathrm{FF}_{3} \mathrm{O}_{4}-\mathrm{MF}$ and its transformation from magnetic fluid to gel, shaped bodies, and a porous foam. (b) Other foams derived from representative MOFs through this strategy.

The bottleneck that prevents natural gas from becoming a transportation fuel is the development of materials that can store it in a sufficiently compact form at ambient temperature. In 2017, Tian et al. used a sol-gel method to synthesize a porous monolithic MOF without using additional binders or high pressure. ${ }^{159}$ The capacity of their product was $259 \mathrm{~cm}^{3} \mathrm{~cm}^{-3}$ after successful packing and densification at 65 bar. This is the highest value for methane storage in a porous solid reported to date, representing an increase of $50 \%$ on any previously reported experimental value. The article also pointed out that the drying conditions of the MOF play a key role in its shaping (Fig. 25a). Only a dense monolith was obtained when the dense gel was dried under mild conditions, whereas a powder was obtained when the dense gel was dried at high temperature. Nanoindentation tests on the monolithic MOF (Fig. 25b) showed robust mechanical properties, and its hardness was found to be at least $130 \%$ greater than those of previously studied conventional MOF counterparts. This discovery represents a substantial step forward in the use of MOFs in high-capacity energy storage and other industrial applications.

At present, the most common and simple shaping method is pelletization and extrusion. However, this method always causes a significant reduction in the surface area of MOFs. An ideal shaping strategy would enhance the stability of an MOF without significantly changing its internal structure. Another common technique is to add a binder to an MOF. In 2018, Mallick et al. successfully improved the mechanical properties of an MOF after shaping it using a polymer as a binder, and minimized the impact of the shaping process on the structure and adsorption performance of the MOF. ${ }^{160}$ They selected two distinct polymers, namely a rubbery polymer (polyethylene glycol; PEG) and a glassy polymer (poly(methyl methacrylate); PMMA), as binders for NbOFFIVE-1-Ni shaping, and compared the shaping effects. Through some simple processing, the MOF powder was shaped into cubic beads with a side length of about $1 \mathrm{~cm}$. The amount of binder could be adjusted according to the target hardness of the MOF. Various tests showed that PMMA as a binder performs better than PEG in terms of material hardness, surface area, and adsorption performance. The hardness and adsorption performance of NbOFFIVE-1-Ni beads with 10\% PMMA proved to be the best. In addition, this shaping strategy has been successfully applied to ZIF-8, UiO-66, and HKUST-1, whereby the reduction of surface area was less than $15 \%$, and the mechanical strength was greatly improved. It can be concluded that the PMMA binder technique offers great promise for the requisite shaping on a large industrial scale.

\section{Summary and prospects}

Light olefins are fundamental chemical industry feedstocks. As they are obtained through traditional steam cracking or 
a

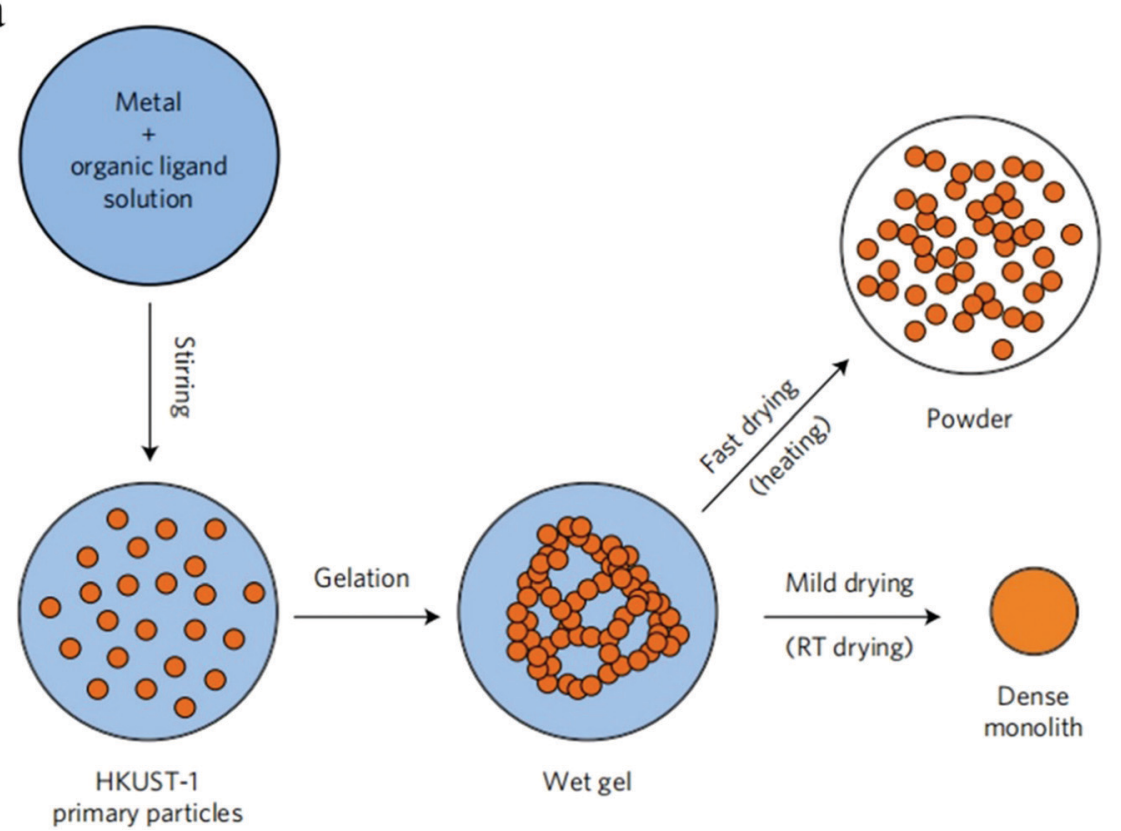

$\mathrm{b}$

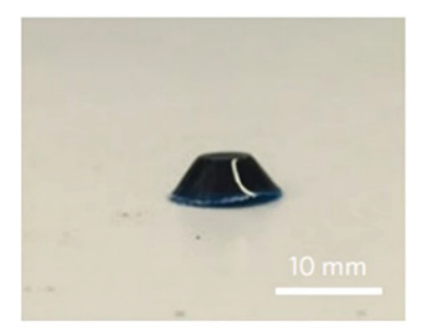

c

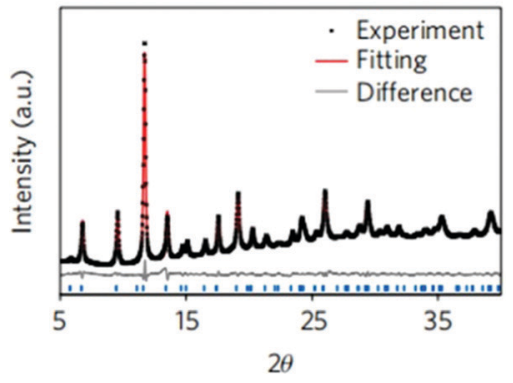

Fig. 25 Schematic representation of monolithic and powder MOF synthesis. (a) The synthesis follows a sol-gel process, whereby a dense monolith is obtained under mild drying conditions whereas powders are obtained when the wet gel is dried at higher temperature or under vacuum. (b) Optical image of the monolithic MOF, mono HKUST-1, showing that it maintains the shape of the mold in which it was prepared. (c) Comparison of PXRD patterns of mono HKUST-1: observed (black symbols), Pawley fitting (red line), and difference (gray line), confirming its successful synthesis.

thermal decomposition of paraffins, they are obtained as mixtures, but must be separated or highly purified for further use. Due to their very similar physical properties, their separation processes are difficult, as can be seen from the various rectification columns in petrochemical industry factories all around the world. Indeed, $10-15 \%$ of global energy production has hitherto been used for the separation and purification of such industrial commodities through cryogenic distillation. Adsorptive separation based on porous materials is a promising technology to lower energy expenditure. Compared to conventional porous materials (activated carbon and zeolites), MOFs represent a unique class of materials, with exceptional porosity and diverse functionalities, which allow the establishment of different relationships between such structures and their final properties, thus showing great promise in addressing the important issue of the separation of light olefins. In this progress report, we have summarized recent advances in exploiting MOF materials for the efficient separation and purification of several typical light-olefin mixtures. It is noted that, although extensive research has been carried out, the development of MOFs as a class of new absorbing materials for the separation and purification of light olefins is still at an early stage, and some underdeveloped issues still need to be considered and addressed.

Fortunately, and as clearly shown in the present review, much progress has been made, and several visionary companies have already brought some MOFs from the laboratory to the real commodity market in recent years. Although we are still not sure as to whether MOFs can replace all of today's wellknown industrial compounds (such as zeolites, silicas, or active carbons), we are rather close to answering this question. It is time for researchers engaged in MOF studies to prove that MOF materials are vital to our modern lifestyle and, therefore, can establish their technological and industrial importance. This shift in direction has already started, with a large number of patents having been filed to date. Future challenges concern the preparation of MOFs as well as MOF-based devices in a simple, easy, green, and low-cost way, and in large amounts capable of meeting the relevant demands.

\section{Conflicts of interest}

There are no conflicts to declare.

\section{Acknowledgements}

This work was financially supported by the National Natural Science Foundation of China (No. 21922810, 21908153, 21908155 and 21878205), Coal Bed Methane Joint Foundation of Shanxi (2016012006), and program of Innovative Talents of Higher Education Institutions of Shanxi.

\section{Notes and references}

1 S. Chu, Y. Cui and N. Liu, The path towards sustainable energy, Nat. Mater., 2016, 16, 16-22.

2 D. S. Sholl and R. P. Lively, Seven chemical separations to change the world, Nature, 2016, 532, 435-437. 
3 T. Ren, M. Patel and K. Blok, Olefins from conventional and heavy feedstocks: Energy use in steam cracking and alternative processes, Energy, 2006, 31, 425-451.

4 M. Rungta, L. Xu and W. J. Koros, Carbon molecular sieve dense film membranes derived from Matrimid ${ }^{\mathbb{R}}$ for ethylene/ ethane separation, Carbon, 2012, 50, 1488-1502.

5 P. J. Bereciartua, Á. Cantín, A. Corma, J. L. Jordá, M. Palomino, F. Rey, S. Valencia, E. W. Corcoran Jr., P. Kortunov and P. I. Ravikovitch, et al., Control of zeolite framework flexibility and pore topology for separation of ethane and ethylene, Science, 2017, 358, 1068-1071.

6 L. Li, R. B. Lin, R. Krishna, H. Li, S. Xiang, H. Wu, J. Li, W. Zhou and B. Chen, Ethane/ethylene separation in a metal-organic framework with iron-peroxo sites, Science, 2018, 362, 443-446.

7 S. Kitagawa, R. Kitaura and S.-i. Noro, Functional Porous Coordination Polymers, Angew. Chem., Int. Ed., 2004, 43, 2334-2375.

8 H. Furukawa, K. E. Cordova, M. O'Keeffe and O. M. Yaghi, The Chemistry and Applications of Metal-Organic Frameworks, Science, 2013, 341, 1230444.

9 H. C. Zhou, J. R. Long and O. M. Yaghi, Introduction to Metal-Organic Frameworks, Chem. Rev., 2012, 112, 673-674.

10 G. Maurin, C. Serre, A. Cooper and G. Ferey, The new age of MOFs and of their porous-related solids, Chem. Soc. Rev., 2017, 46, 3104-3107.

11 M. Peplow, Materials science: The hole story, Nature, 2015, 520, 148-150.

12 Y. He, W. Zhou, G. Qian and B. Chen, Methane storage in metal-organic frameworks, Chem. Soc. Rev., 2014, 43, 5657-5678.

13 B. Li, H.-M. Wen, H. Wang, H. Wu, M. Tyagi, T. Yildirim, W. Zhou and B. Chen, A porous metal-organic framework with dynamic pyrimidine groups exhibiting record high methane storage working capacity, J. Am. Chem. Soc., 2014, 136, 6207-6210.

14 B. Li, H.-M. Wen, W. Zhou, J. Q. Xu and B. Chen, Porous metal-organic frameworks: promising materials for methane storage, Chem, 2016, 1, 557-580.

15 M. K. Taylor, T. e. Runčevski, J. Oktawiec, M. I. Gonzalez, R. L. Siegelman, J. A. Mason, J. Ye, C. M. Brown and J. R. Long, Tuning the Adsorption-Induced Phase Change in the Flexible Metal- Organic Framework Co(bdp), J. Am. Chem. Soc., 2016, 138, 15019-15026.

16 R. B. Getman, Y.-S. Bae, C. E. Wilmer and R. Q. Snurr, Review and analysis of molecular simulations of methane, hydrogen, and acetylene storage in metal-organic frameworks, Chem. Rev., 2012, 112, 703-723.

17 R. Vaidhyanathan, S. S. Iremonger, G. K. Shimizu, P. G. Boyd, S. Alavi and T. K. Woo, Direct observation and quantification of $\mathrm{CO}_{2}$ binding within an amine-functionalized nanoporous solid, Science, 2010, 330, 650-653.

18 R. Banerjee, A. Phan, B. Wang, C. Knobler, H. Furukawa, M. O'Keeffe and O. M. Yaghi, High-Throughput Synthesis of Zeolitic Imidazolate Frameworks and Application to $\mathrm{CO}_{2}$ Capture, Science, 2008, 319, 939-943.
19 P. Nugent, Y. Belmabkhout, S. D. Burd, A. J. Cairns, R. Luebke, K. Forrest, T. Pham and S. Ma, B. Space and L. Wojtas, Porous materials with optimal adsorption thermodynamics and kinetics for $\mathrm{CO}_{2}$ separation, Nature, 2013, 495, 80-84.

20 Y. Peng, Y. Li, Y. Ban, H. Jin, W. Jiao, X. Liu and W. Yang, Metal-corganic framework nanosheets as building blocks for molecular sieving membranes, Science, 2014, 346, 1356-1359.

21 J. An, C. M. Shade, D. A. Chengelis-Czegan, S. Petoud and N. L. Rosi, Zinc-adeninate metal-organic framework for aqueous encapsulation and sensitization of near-infrared and visible emitting lanthanide cations, J. Am. Chem. Soc., 2011, 133, 1220-1223.

22 R. B. Lin, F. Li, S. Y. Liu, X. L. Qi, J. P. Zhang and X. M. Chen, A Noble-Metal-Free Porous Coordination Framework with Exceptional Sensing Efficiency for Oxygen, Angew. Chem., Int. Ed., 2013, 52, 13429-13433.

23 Y. Cui, B. Chen and G. Qian, Lanthanide metal-organic frameworks for luminescent sensing and light-emitting applications, Coord. Chem. Rev., 2014, 273, 76-86.

24 Z. Hu, B. J. Deibert and J. Li, Luminescent metal-organic frameworks for chemical sensing and explosive detection, Chem. Soc. Rev., 2014, 43, 5815-5840.

25 R. B. Lin, S. Y. Liu, J. W. Ye, X. Y. Li and J. P. Zhang, Photoluminescent metal-organic frameworks for gas sensing, Adv. Sci., 2016, 3, 1500434.

26 M. Zhao, K. Yuan, Y. Wang, G. Li, J. Guo, L. Gu, W. Hu, H. Zhao and Z. Tang, Metal-organic frameworks as selectivity regulators for hydrogenation reactions, Nature, 2016, 539, 76-80.

27 Q.-L. Zhu, J. Li and Q. Xu, Immobilizing metal nanoparticles to metal-organic frameworks with size and location control for optimizing catalytic performance, J. Am. Chem. Soc., 2013, 135, 10210-10213.

28 B. Li, K. Leng, Y. Zhang, J. J. Dynes, J. Wang, Y. Hu, D. Ma, Z. Shi, L. Zhu, D. Zhang, Y. Sun, M. Chrzanowski and S. Ma, Metal-organic framework based upon the synergy of a Brønsted acid framework and Lewis acid centers as a highly efficient heterogeneous catalyst for fixed-bed reactions, J. Am. Chem. Soc., 2015, 137, 4243-4248.

29 H. Noh, Y. Cui, A. W. Peters, D. R. Pahls, M. A. Ortuño, N. A. Vermeulen, C. J. Cramer, L. Gagliardi, J. T. Hupp and O. K. Farha, An exceptionally stable metal-organic framework supported molybdenum (VI) oxide catalyst for cyclohexene epoxidation, J. Am. Chem. Soc., 2016, 138, 14720-14726.

30 Y.-T. Xu, X. Xiao, Z.-M. Ye, S. Zhao, R. Shen, C.-T. He, J.-P. Zhang, Y. Li and X.-M. Chen, Cage-confinement pyrolysis route to ultrasmall tungsten carbide nanoparticles for efficient electrocatalytic hydrogen evolution, J. Am. Chem. Soc., 2017, 139, 5285-5288.

31 Q. Yang, Q. Xu and H.-L. Jiang, Metal-organic frameworks meet metal nanoparticles: synergistic effect for enhanced catalysis, Chem. Soc. Rev., 2017, 46, 4774-4808.

32 M. C. Das, Q. Guo, Y. He, J. Kim, C.-G. Zhao, K. Hong, S. Xiang, Z. Zhang, K. M. Thomas and R. Krishna, Interplay 
of metalloligand and organic ligand to tune micropores within isostructural mixed-metal organic frameworks (M'MOFs) for their highly selective separation of chiral and achiral small molecules, J. Am. Chem. Soc., 2012, 134, 8703-8710.

33 M. M. Wanderley, C. Wang, C.-D. Wu and W. Lin, A chiral porous metal-organic framework for highly sensitive and enantioselective fluorescence sensing of amino alcohols, J. Am. Chem. Soc., 2012, 134, 9050-9053.

34 Y. Inokuma, S. Yoshioka, J. Ariyoshi, T. Arai, Y. Hitora, K. Takada, S. Matsunaga, K. Rissanen and M. Fujita, X-ray analysis on the nanogram to microgram scale using porous complexes, Nature, 2013, 495, 461-466.

35 Z. Hu, W. P. Lustig, J. Zhang, C. Zheng, H. Wang, S. J. Teat, Q. Gong, N. D. Rudd and J. Li, Effective detection of mycotoxins by a highly luminescent metal-organic framework, J. Am. Chem. Soc., 2015, 137, 16209-16215.

36 Z. Hasan and S. H. Jhung, Removal of hazardous organics from water using metal-organic frameworks (MOFs): plausible mechanisms for selective adsorptions, J. Hazard. Mater., 2015, 283, 329-339.

37 S. Y. Moon, Y. Liu, J. T. Hupp and O. K. Farha, Instantaneous Hydrolysis of Nerve-Agent Simulants with a SixConnected Zirconium-Based Metal-Organic Framework, Angew. Chem., Int. Ed., 2015, 54, 6795-6799.

38 J. E. Mondloch, M. J. Katz, W. C. Isley III, P. Ghosh, P. Liao, W. Bury, G. W. Wagner, M. G. Hall, J. B. DeCoste and G. W. Peterson, Destruction of chemical warfare agents using metal-organic frameworks, Nat. Mater., 2015, 14, 512-516.

39 A. Schoedel, Z. Ji and O. M. Yaghi, The role of metalorganic frameworks in a carbon-neutral energy cycle, Nat. Energy, 2016, 1, 1-13.

40 H. Li, K. Wang, Y. Sun, C. T. Lollar, J. Li and H.-C. Zhou, Recent advances in gas storage and separation using metal-organic, Mater. Today, 2018, 21, 108-121.

41 B. Li, H. M. Wen, Y. Cui, W. Zhou, G. Qian and B. Chen, Emerging Multifunctional Metal-Organic Framework Materials, Adv. Mater., 2016, 28, 8819-8860.

42 W. G. Cui, T. L. Hu and X. H. Bu, Metal-Organic Framework Materials for the Separation and Purification of Light Hydrocarbons, Adv. Mater., 2020, 32, 1806445.

43 A. U. Czaja, N. Trukhan and U. Müller, Industrial applications of metal-organic frameworks, Chem. Soc. Rev., 2009, 38, 1284-1293.

44 M. Gaab, N. Trukhan, S. Maurer, R. Gummaraju and U. Müller, The progression of Al-based metal-organic frameworks - From academic research to industrial production and applications, Microporous Mesoporous Mater., 2012, 157, 131-136.

45 M. Rubio-Martinez, C. Avci-Camur, A. W. Thornton, I. Imaz, D. Maspoch and M. R. Hill, New synthetic routes towards MOF production at scale, Chem. Soc. Rev., 2017, 46, 3453-3480.

46 B. Yilmaz, N. Trukhan and U. Müller, Industrial Outlook on Zeolites and Metal Organic Frameworks, Chin. J. Catal., 2012, 33, 3-10.
47 J. H. Cavka, S. Jakobsen, U. Olsbye, N. Guillou, C. Lamberti, S. Bordiga and K. P. Lillerud, A new zirconium inorganic building brick forming metal organic frameworks with exceptional stability, J. Am. Chem. Soc., 2008, 130, 13850-13851.

48 K. S. Park, Z. Ni, A. P. Cote, J. Y. Choi, R. Huang, F. J. UribeRomo, H. K. Chae, M. O'Keeffe and O. M. Yaghi, Exceptional chemical and thermal stability of zeolitic imidazolate frameworks, Proc. Natl. Acad. Sci. U. S. A., 2006, 103, 10186-10191.

49 M. Bosch, M. Zhang and H.-C. Zhou, Increasing the Stability of Metal-Organic Frameworks, Adv. Chem., 2014, 2014, 1-8.

50 N. C. Burtch, H. Jasuja and K. S. Walton, Water stability and adsorption in metal-organic frameworks, Chem. Rev., 2014, 114, 10575-10612.

51 J. Canivet, A. Fateeva, Y. Guo, B. Coasne and D. Farrusseng, Water adsorption in MOFs: fundamentals and applications, Chem. Soc. Rev., 2014, 43, 5594-5617.

52 M. Kim, J. F. Cahill, H. Fei, K. A. Prather and S. M. Cohen, Postsynthetic ligand and cation exchange in robust metal-organic frameworks, J. Am. Chem. Soc., 2012, 134, 18082-18088.

53 T. C. Wang, W. Bury, D. A. Gomez-Gualdron, N. A. Vermeulen, J. E. Mondloch, P. Deria, K. Zhang, P. Z. Moghadam, A. A. Sarjeant, R. Q. Snurr, J. F. Stoddart, J. T. Hupp and O. K. Farha, Ultrahigh surface area zirconium MOFs and insights into the applicability of the BET theory, J. Am. Chem. Soc., 2015, 137, 3585-3591.

54 S. Hermes, F. Schröder, R. Chelmowski, C. Wöll and R. A. Fischer, Selective Nucleation and Growth of MetalOrganic Open Framework Thin Films on Patterned $\mathrm{COOH} /$ $\mathrm{CF}_{3}$-Terminated Self-Assembled Monolayers on $\mathrm{Au}(111)$, J. Am. Chem. Soc., 2005, 127, 13744-13745.

55 M. Rubio-Martinez, C. Avci-Camur, A. W. Thornton, I. Imaz, D. Maspoch and M. R. Hill, New synthetic routes towards MOF production at scale, Chem. Soc. Rev., 2017, 46, 3453-3480.

56 D. Zacher, O. Shekhah, C. Wöll and R. A. Fischer, Thin films of metal-organic frameworks, Chem. Soc. Rev., 2009, 38, 1418-1429.

57 Z. Bao, G. Chang, H. Xing, R. Krishna, Q. Ren and B. Chen, Potential of microporous metal-organic frameworks for separation of hydrocarbon mixtures, Energy Environ. Sci., 2016, 9, 3612-3641.

58 Z. R. Herm, E. D. Bloch and J. R. Long, Hydrocarbon Separations in Metal-Organic Frameworks, Chem. Mater., 2013, 26, 323-338.

59 J. R. Li, R. J. Kuppler and H. C. Zhou, Selective gas adsorption and separation in metal-organic frameworks, Chem. Soc. Rev., 2009, 38, 1477-1504.

60 R. B. Lin, S. Xiang, H. Xing, W. Zhou and B. Chen, Exploration of porous metal-organic frameworks for gas separation and purification, Coord. Chem. Rev., 2019, 378, 87-103.

61 S. Mukherjee, A. V. Desai and S. K. Ghosh, Potential of metal-organic frameworks for adsorptive separation of industrially and environmentally relevant liquid mixtures, Coord. Chem. Rev., 2018, 367, 82-126. 
62 S. Seifzadeh Haghighi, M. R. Rahimpour, S. Raeissi and O. Dehghani, Investigation of ethylene production in naphtha thermal cracking plant in presence of steam and carbon dioxide, Chem. Eng. J., 2013, 228, 1158-1167.

63 S. Aguado, G. Bergeret, C. Daniel and D. Farrusseng, Absolute Molecular Sieve Separation of Ethylene/Ethane Mixtures with Silver Zeolite A, J. Am. Chem. Soc., 2012, 134, 14635-14637.

64 P. J. Bereciartua, A. Cantin, A. Corma, J. L. Jorda, M. Palomino, F. Rey, S. Valencia, E. W. Corcoran, P. Kortunov, P. I. Ravikovitch, A. Burton, C. Yoon, Y. Wang, C. Paur, J. Guzman, A. R. Bishop and G. L. Casty, Control of zeolite framework flexibility and pore topology for separation of ethane and ethylene, Science, 2017, 358, 1068-1071.

65 Q. M. Wang, D. Shen, M. Bülow, M. L. Lau, S. Deng, F. R. Fitch, N. O. Lemcoff and J. Semanscin, Metalloorganic molecular sieve for gas separation and purification, Microporous Mesoporous Mater., 2002, 55, 217-230.

66 S. Wang, Q. Yang and C. Zhong, Adsorption and separation of binary mixtures in a metal-organic framework Cu-BTC: A computational study, Sep. Purif. Technol., 2008, 60, 30-35.

67 Z. Bao, S. Alnemrat, L. Yu, I. Vasiliev, Q. Ren, X. Lu and S. Deng, Adsorption of ethane, ethylene, propane, and propylene on a magnesium-based metal-organic framework, Langmuir, 2011, 27, 13554-13562.

68 E. D. Bloch, W. L. Queen, R. Krishna, J. M. Zadrozny, C. M. Brown and J. R. Long, Hydrocarbon separations in a metal-organic framework with open iron(II) coordination sites, Science, 2012, 335, 1606-1610.

69 S. Yang, A. J. Ramirez-Cuesta, R. Newby, V. Garcia-Sakai, P. Manuel, S. K. Callear, S. I. Campbell, C. C. Tang and M. Schroder, Supramolecular binding and separation of hydrocarbons within a functionalized porous metalorganic framework, Nat. Chem., 2014, 7, 121-129.

70 J. E. Bachman, M. T. Kapelewski, D. A. Reed, M. I. Gonzalez and J. R. Long, $\mathrm{M}_{2}$ (m-dobdc) ( $\mathrm{M}=\mathrm{Mn}$, Fe, Co, Ni) MetalOrganic Frameworks as Highly Selective, High-Capacity Adsorbents for Olefin/Paraffin Separations, J. Am. Chem. Soc., 2017, 139, 15363-15370.

71 Z. Bao, J. Wang, Z. Zhang, H. Xing, Q. Yang, Y. Yang, H. Wu, R. Krishna, W. Zhou, B. Chen and Q. Ren, Molecular Sieving of Ethane from Ethylene through the Molecular Cross-Section Size Differentiation in Gallate-based MetalOrganic Frameworks, Angew. Chem., Int. Ed., 2018, 57, 16020-16025.

72 R. B. Lin, L. Li, H. L. Zhou, H. Wu, C. He, S. Li, R. Krishna, J. Li, W. Zhou and B. Chen, Molecular sieving of ethylene from ethane using a rigid metal-organic framework, Nat. Mater., 2018, 17, 1128-1133.

73 B. Li, Y. Zhang, R. Krishna, K. Yao, Y. Han, Z. Wu, D. Ma, Z. Shi, T. Pham, B. Space, J. Liu, P. K. Thallapally, J. Liu, M. Chrzanowski and S. Ma, Introduction of picomplexation into porous aromatic framework for highly selective adsorption of ethylene over ethane, J. Am. Chem. Soc., 2014, 136, 8654-8660.
74 M. H. Mohamed, Y. Yang, L. Li, S. Zhang, J. P. Ruffley, A. G. Jarvi, S. Saxena, G. Veser, J. K. Johnson and N. L. Rosi, Designing Open Metal Sites in Metal-Organic Frameworks for Paraffin/Olefin Separations, J. Am. Chem. Soc., 2019, 141, 13003-13007.

75 L. Zhang, L. Li, E. Hu, L. Yang, K. Shao, L. Yao, K. Jiang, Y. Cui, Y. Yang, B. Li, B. Chen and G. Qian, Boosting Ethylene/Ethane Separation within Copper(I)-Chelated Metal-Organic Frameworks through Tailor-Made Aperture and Specific pi-Complexation, Adv. Sci., 2020, 7, 1901918.

76 C. Gu, N. Hosono, J. J. Zheng, Y. Sato, S. Kusaka, S. Sakaki and S. Kitagawa, Design and control of gas diffusion process in a nanoporous soft crystal, Science, 2019, 363, 387-391.

77 J. Kim, L. C. Lin, R. L. Martin, J. A. Swisher, M. Haranczyk and B. Smit, Large-Scale Computational Screening of Zeolites for Ethane/Ethene Separation, Langmuir, 2012, 28, 11914-11919.

78 X. Wang, Y. Wu, J. Peng, Y. Wu, J. Xiao, Q. Xia and Z. Li, Novel glucosamine-based carbon adsorbents with high capacity and its enhanced mechanism of preferential adsorption of $\mathrm{C}_{2} \mathrm{H}_{6}$ over $\mathrm{C}_{2} \mathrm{H}_{4}$, Chem. Eng. J., 2019, 358, 1114-1125.

79 C. Gucuyener, J. van den Bergh, J. Gascon and F. Kapteijn, Ethane/Ethene Separation Turned on Its Head: Selective Ethane Adsorption on the Metal-Organic Framework ZIF-7 through a Gate-Opening Mechanism, J. Am. Chem. Soc., 2010, 132, 17704-17706.

80 J. Pires, M. L. Pinto and V. K. Saini, Ethane selective IRMOF-8 and its significance in ethane-ethylene separation by adsorption, ACS Appl. Mater. Interfaces, 2014, 6, 12093-12099.

81 R. B. Lin, H. Wu, L. Li, X. L. Tang, Z. Li, J. Gao, H. Cui, W. Zhou and B. Chen, Boosting Ethane/Ethylene Separation within Isoreticular Ultramicroporous Metal-Organic Frameworks, J. Am. Chem. Soc., 2018, 140, 12940-12946.

82 F. Z. Sun, S. Q. Yang, R. Krishna, Y. H. Zhang, Y. P. Xia and T. L. Hu, Microporous Metal-Organic Framework with a Completely Reversed Adsorption Relationship for C2 Hydrocarbons at Room Temperature, ACS Appl. Mater. Interfaces, 2020, 12, 6105-6111.

83 P. Q. Liao, W. X. Zhang, J. P. Zhang and X. M. Chen, Efficient purification of ethene by an ethane-trapping metal-organic framework, Nat. Commun., 2015, 6, 8697.

84 W. Liang, F. Xu, X. Zhou, J. Xiao, Q. Xia, Y. Li and Z. Li, Ethane selective adsorbent $\mathrm{Ni}(\mathrm{bdc})(\mathrm{ted})_{0.5}$ with high uptake and its significance in adsorption separation of ethane and ethylene, Chem. Eng. Sci., 2016, 148, 275-281.

85 Y. Chen, Z. Qiao, H. Wu, D. Lv, R. Shi, Q. Xia, J. Zhou and $\mathrm{Z}$. Li, An ethane-trapping MOF PCN-250 for highly selective adsorption of ethane over ethylene, Chem. Eng. Sci., 2018, 175, 110-117.

86 L. Yang, W. Zhou, H. Li, A. Alsalme, L. Jia, J. Yang, J. Li, L. Li and B. Chen, Reversed ethane/ethylene adsorption in a metal-organic framework via introduction of oxygen, Chin. J. Chem. Eng., 2020, 28, 593-597. 
87 O. T. Qazvini, R. Babarao, Z. L. Shi, Y. B. Zhang and S. G. Telfer, A Robust Ethane-Trapping Metal-Organic Framework with a High Capacity for Ethylene Purification, J. Am. Chem. Soc., 2019, 141, 5014-5020.

88 L. Yang, Y. Wang, Y. Chen, J. Yang, X. Wang, L. Li and J. Li, Microporous metal-organic framework with specific functional sites for efficient removal of ethane from ethane/ ethylene mixtures, Chem. Eng. J., 2020, 387, 124137.

89 K. J. Chen, D. G. Madden, S. Mukherjee, T. Pham, K. A. Forrest, A. Kumar, B. Space, J. Kong, Q. Y. Zhang and M. J. Zaworotko, Synergistic sorbent separation for one-step ethylene purification from a four-component mixture, Science, 2019, 366, 241-246.

90 N. Lamia, M. Jorge, M. A. Granato, F. A. Almeida Paz, H. Chevreau and A. E. Rodrigues, Adsorption of propane, propylene and isobutane on a metal-organic framework: Molecular simulation and experiment, Chem. Eng. Sci., 2009, 64, 3246-3259.

91 J. W. Yoon, Y. K. Seo, Y. K. Hwang, J. S. Chang, H. Leclerc, S. Wuttke, P. Bazin, A. Vimont, M. Daturi, E. Bloch, P. L. Llewellyn, C. Serre, P. Horcajada, J. M. Greneche, A. E. Rodrigues and G. Ferey, Controlled reducibility of a metal-organic framework with coordinatively unsaturated sites for preferential gas sorption, Angew. Chem., Int. Ed., 2010, 49, 5949-5952.

92 Y. S. Bae, C. Y. Lee, K. C. Kim, O. K. Farha, P. Nickias, J. T. Hupp, S. T. Nguyen and R. Q. Snurr, High propene/ propane selectivity in isostructural metal-organic frameworks with high densities of open metal sites, Angew. Chem., Int. Ed., 2012, 51, 1857-1860.

93 K. Li, D. H. Olson, J. Seidel, T. J. Emge, H. Gong, H. Zeng and J. Li, Zeolitic imidazolate frameworks for kinetic separation of propane and propene, J. Am. Chem. Soc., 2009, 131, 10368-10369.

94 C. Y. Lee, Y. S. Bae, N. C. Jeong, O. K. Farha, A. A. Sarjeant, C. L. Stern, P. Nickias, R. Q. Snurr, J. T. Hupp and S. T. Nguyen, Kinetic separation of propene and propane in metal-organic frameworks: controlling diffusion rates in plate-shaped crystals via tuning of pore apertures and crystallite aspect ratios, J. Am. Chem. Soc., 2011, 133, 5228-5231.

95 J. Peng, H. Wang, D. H. Olson, Z. Li and J. Li, Efficient kinetic separation of propene and propane using two microporous metal organic frameworks, Chem. Commun., 2017, 53, 9332-9335.

96 L. Li, R.-B. Lin, X. Wang, W. Zhou, L. Jia, J. Li and B. Chen, Kinetic separation of propylene over propane in a microporous metal-organic framework, Chem. Eng. J., 2018, 354, 977-982.

97 A. Cadiau, K. Adil, P. Bhatt, Y. Belmabkhout and M. Eddaoudi, A metal-organic framework-based splitter for separating propylene from propane, Science, 2016, 353, 137-140.

98 H. Wang, X. Dong, V. Colombo, Q. Wang, Y. Liu, W. Liu, X. L. Wang, X. Y. Huang, D. M. Proserpio, A. Sironi, Y. Han and J. Li, Tailor-Made Microporous Metal-Organic Frameworks for the Full Separation of Propane from Propylene Through Selective Size Exclusion, Adv. Mater., 2018, 30, e1805088.

99 X. Wang, R. Krishna, L. Li, B. Wang, T. He, Y.-Z. Zhang, J.-R. Li and J. Li, Guest-dependent pressure induced gate-opening effect enables effective separation of propene and propane in a flexible MOF, Chem. Eng. J., 2018, 346, 489-496.

100 M. H. Yu, B. Space, D. Franz, W. Zhou, C. He, L. Li, R. Krishna, Z. Chang, W. Li, T. L. Hu and X. H. Bu, Enhanced Gas Uptake in a Microporous Metal-Organic Framework via a Sorbate Induced-Fit Mechanism, J. Am. Chem. Soc., 2019, 141, 17703-17712.

101 U. Bohme, B. Barth, C. Paula, A. Kuhnt, W. Schwieger, A. Mundstock, J. Caro and M. Hartmann, Ethene/ethane and propene/propane separation via the olefin and paraffin selective metal-organic framework adsorbents CPO-27 and ZIF-8, Langmuir, 2013, 29, 8592-8600.

102 L. Yang, X. Cui, Q. Ding, Q. Wang, A. Jin, L. Ge and H. Xing, Polycatenated Molecular Cage-Based Propane Trap for Propylene Purification with Recorded Selectivity, ACS Appl. Mater. Interfaces, 2020, 12, 2525-2530.

103 Z. Zhang, Q. Yang, X. Cui, L. Yang, Z. Bao, Q. Ren and H. Xing, Sorting of C4 Olefins with Interpenetrated Hybrid Ultramicroporous Materials by Combining Molecular Recognition and Size-Sieving, Angew. Chem., Int. Ed., 2017, 56, 16282-16287.

104 P. Q. Liao, N. Y. Huang, W. X. Zhang, J. P. Zhang and X. M. Chen, Controlling guest conformation for efficient purification of butadiene, Science, 2017, 356, 1193-1196.

105 S. C. Xiang, Z. Zhang, C. G. Zhao, K. Hong, X. Zhao, D. R. Ding, M. H. Xie, C. D. Wu, M. C. Das, R. Gill, K. M. Thomas and B. Chen, Rationally tuned micropores within enantiopure metal-organic frameworks for highly selective separation of acetylene and ethylene, Nat. Commun., 2011, 2, 204.

106 T. L. Hu, H. Wang, B. Li, R. Krishna, H. Wu, W. Zhou, Y. Zhao, Y. Han, X. Wang, W. Zhu, Z. Yao, S. Xiang and B. Chen, Microporous metal-organic framework with dual functionalities for highly efficient removal of acetylene from ethylene/acetylene mixtures, Nat. Commun., 2015, 6, 7328.

107 X. Cui, K. Chen, H. Xing, Q. Yang, R. Krishna, Z. Bao, H. Wu, W. Zhou, X. Dong, Y. Han, B. Li, Q. Ren, M. J. Zaworotko and B. Chen, Pore chemistry and size control in hybrid porous materials for acetylene capture from ethylene, Science, 2016, 353, 141-144.

108 B. Li, X. Cui, D. O’Nolan, H. M. Wen, M. Jiang, R. Krishna, H. Wu, R. B. Lin, Y. S. Chen, D. Yuan, H. Xing, W. Zhou, Q. Ren, G. Qian, M. J. Zaworotko and B. Chen, An Ideal Molecular Sieve for Acetylene Removal from Ethylene with Record Selectivity and Productivity, Adv. Mater., 2017, 29, 1704210.

109 L. Li, R. B. Lin, R. Krishna, X. Wang, B. Li, H. Wu, J. Li, W. Zhou and B. Chen, Flexible-Robust Metal-Organic Framework for Efficient Removal of Propyne from Propylene, J. Am. Chem. Soc., 2017, 139, 7733-7736. 
110 L. Yang, X. Cui, Q. Yang, S. Qian, H. Wu, Z. Bao, Z. Zhang, Q. Ren, W. Zhou, B. Chen and H. Xing, A Single-Molecule Propyne Trap: Highly Efficient Removal of Propyne from Propylene with Anion-Pillared Ultramicroporous Materials, Adv. Mater., 2018, 30, 1705374.

111 L. Yang, X. Cui, Z. Zhang, Q. Yang, Z. Bao, Q. Ren and H. Xing, An Asymmetric Anion-Pillared Metal-Organic Framework as a Multisite Adsorbent Enables Simultaneous Removal of Propyne and Propadiene from Propylene, Angew. Chem., Int. Ed., 2018, 57, 13145-13149.

112 L. Li, H. M. Wen, C. He, R. B. Lin, R. Krishna, H. Wu, W. Zhou, J. Li, B. Li and B. Chen, A Metal-Organic Framework with Suitable Pore Size and Specific Functional Sites for the Removal of Trace Propyne from Propylene, Angew. Chem., Int. Ed., 2018, 57, 15183-15188.

113 J. Yang, A. Grzech, F. M. Mulder and T. J. Dingemans, Methyl modified MOF-5: a water stable hydrogen storage material, Chem. Commun., 2011, 47, 5244-5246.

114 J. B. Decoste, G. W. Peterson, M. W. Smith, C. A. Stone and C. R. Willis, Enhanced stability of Cu-BTC MOF via perfluorohexane plasma-enhanced chemical vapor deposition, J. Am. Chem. Soc., 2012, 134, 1486-1489.

115 S. J. Yang and C. R. Park, Preparation of highly moistureresistant black-colored metal organic frameworks, $A d v$. Mater., 2012, 24, 4010-4013.

116 W. Zhang, Y. Hu, J. Ge, H. L. Jiang and S. H. Yu, A facile and general coating approach to moisture/water-resistant metal-organic frameworks with intact porosity, J. Am. Chem. Soc., 2014, 136, 16978-16981.

117 B. Wang, X. L. Lv, D. Feng, L. H. Xie, J. Zhang, M. Li, Y. Xie, J. R. Li and H. C. Zhou, Highly Stable Zr(Iv)-Based MetalOrganic Frameworks for the Detection and Removal of Antibiotics and Organic Explosives in Water, J. Am. Chem. Soc., 2016, 138, 6204-6216.

118 C. Dong, J. Bai, X. L. Lv, W. Wu, J. Lv and J. R. Li, Fixing Flexible Arms of Core-Shared Ligands to Enhance the Stability of Metal-Organic Frameworks, Inorg. Chem., 2019, 58, 15909-15916.

119 N. Li, J. Xu, R. Feng, T. L. Hu and X. H. Bu, Governing metal-organic frameworks towards high stability, Chem. Commun., 2016, 52, 8501-8513.

120 S. Marx, W. Kleist, J. Huang, M. Maciejewski and A. Baiker, Tuning functional sites and thermal stability of mixedlinker MOFs based on MIL-53(Al), Dalton Trans., 2010, 39, 3795-3798.

121 V. Colombo, S. Galli, H. J. Choi, G. D. Han, A. Maspero, G. Palmisano, N. Masciocchi and J. R. Long, High thermal and chemical stability in pyrazolate-bridged metal-organic frameworks with exposed metal sites, Chem. Sci., 2011, 2, 1311-1319.

122 I. J. Kang, N. A. Khan, E. Haque and S. H. Jhung, Chemical and thermal stability of isotypic metal-organic frameworks: effect of metal ions, Chemistry, 2011, 17, 6437-6442.

123 Y. Hu, M. Ding, X. Q. Liu, L. B. Sun and H. L. Jiang, Rational synthesis of an exceptionally stable $\mathrm{Zn}$ (II) metal-organic framework for the highly selective and sensitive detection of picric acid, Chem. Commun., 2016, 52, 5734-5737.

124 S. Chen, J. Zhang, T. Wu, P. Feng and X. Bu, Multiroute synthesis of porous anionic frameworks and size-tunable extraframework organic cation-controlled gas sorption properties, J. Am. Chem. Soc., 2009, 131, 16027-16029.

125 S. T. Zheng, J. T. Bu, Y. Li, T. Wu, F. Zuo, P. Feng and X. Bu, Pore space partition and charge separation in cage-withincage indium-organic frameworks with high $\mathrm{CO}_{2}$ uptake, J. Am. Chem. Soc., 2010, 132, 17062-17064.

126 X. Zhao, X. Bu, Q. G. Zhai, H. Tran and P. Feng, Pore space partition by symmetry-matching regulated ligand insertion and dramatic tuning on carbon dioxide uptake, J. Am. Chem. Soc., 2015, 137, 1396-1399.

127 S. T. Zheng, T. Wu, B. Irfanoglu, F. Zuo, P. Feng and X. Bu, Multicomponent self-assembly of a nested $\mathrm{Co}_{24} @ \mathrm{Co}_{48}$ metal-organic polyhedral framework, Angew. Chem., Int. Ed., 2011, 50, 8034-8037.

128 S. T. Zheng, T. Wu, F. Zuo, C. Chou, P. Feng and X. Bu, Mimicking zeolite to its core: porous sodalite cages as hangers for pendant trimeric $\mathrm{M}_{3}(\mathrm{OH})$ clusters $(\mathrm{M}=\mathrm{Mg}$, Mn, Co, Ni, Cd), J. Am. Chem. Soc., 2012, 134, 1934-1937.

129 D. Feng, Z. Y. Gu, J. R. Li, H. L. Jiang, Z. Wei and H. C. Zhou, Zirconium-Metalloporphyrin PCN-222: Mesoporous Metal-Organic Frameworks with Ultrahigh Stability as Biomimetic Catalysts, Angew. Chem., Int. Ed., 2012, 51, 10307-10310.

130 H. Huang, J. R. Li, K. Wang, T. Han, M. Tong, L. Li, Y. Xie, Q. Yang, D. Liu and C. Zhong, An in situ self-assembly template strategy for the preparation of hierarchical-pore metal-organic frameworks, Nat. Commun., 2015, 6, 8847.

131 L. Feng, S. Yuan, L. L. Zhang, K. Tan, J. L. Li, A. Kirchon, L. M. Liu, P. Zhang, Y. Han, Y. J. Chabal and H. C. Zhou, Creating Hierarchical Pores by Controlled Linker Thermolysis in Multivariate Metal-Organic Frameworks, J. Am. Chem. Soc., 2018, 140, 2363-2372.

132 X. J. Hong, Q. Wei, Y. P. Cai, B. B. Wu, H. X. Feng, Y. Yu and R. F. Dong, Pillar-Layered Metal-Organic Framework with Sieving Effect and Pore Space Partition for Effective Separation of Mixed Gas $\mathrm{C}_{2} \mathrm{H}_{2} / \mathrm{C}_{2} \mathrm{H}_{4}$, ACS Appl. Mater. Interfaces, 2017, 9, 29374-29379.

133 Y. Ye, Z. Ma, R. B. Lin, R. Krishna, W. Zhou, Q. Lin, Z. Zhang, S. Xiang and B. Chen, Pore Space Partition within a Metal-Organic Framework for Highly Efficient $\mathrm{C}_{2} \mathrm{H}_{2} / \mathrm{CO}_{2}$ Separation, J. Am. Chem. Soc., 2019, 141, 4130-4136.

134 M. D. Allendorf, C. A. Bauer, R. K. Bhakta and R. J. Houk, Luminescent metal-organic frameworks, Chem. Soc. Rev., 2009, 38, 1330-1352.

135 D. Farrusseng, S. Aguado and C. Pinel, Metal-organic frameworks: opportunities for catalysis, Angew. Chem., Int. Ed., 2009, 48, 7502-7513.

136 P. Horcajada, R. Gref, T. Baati, P. K. Allan, G. Maurin, P. Couvreur, G. Ferey, R. E. Morris and C. Serre, Metalorganic frameworks in biomedicine, Chem. Rev., 2012, 112, 1232-1268. 
137 K. Sumida, D. L. Rogow, J. A. Mason, T. M. McDonald, E. D. Bloch, Z. R. Herm, T. H. Bae and J. R. Long, Carbon dioxide capture in metal-organic frameworks, Chem. Rev., 2012, 112, 724-781.

138 U. Mueller, M. Schubert, F. Teich, H. Puetter, K. SchierleArndt and J. Pastré, Metal-organic frameworks-prospective industrial applications, J. Mater. Chem., 2006, 16, 626-636.

139 N. Campagnol, T. R. C. Van Assche, M. Li, L. Stappers, M. Dincă, J. F. M. Denayer, K. Binnemans, D. E. De Vos and J. Fransaer, On the electrochemical deposition of metalorganic frameworks, J. Mater. Chem. A, 2016, 4, 3914-3925.

140 S. H. Jhung, J. H. Lee and J. S. Chang, Microwave synthesis of a nanoporous hybrid material, chromium trimesate, Bull. Korean Chem. Soc., 2005, 26, 880-881.

141 P. P. Bag, X. S. Wang and R. Cao, Microwave-assisted large scale synthesis of lanthanide metal-organic frameworks (Ln-MOFs), having a preferred conformation and photoluminescence properties, Dalton Trans., 2015, 44, 11954-11962.

142 D. Crawford, J. Casaban, R. Haydon, N. Giri, T. McNally and S. L. James, Synthesis by extrusion: continuous, largescale preparation of MOFs using little or no solvent, Chem. Sci., 2015, 6, 1645-1649.

143 D. Bazer-Bachi, L. Assié, V. Lecocq, B. Harbuzaru and V. Falk, Towards industrial use of metal-organic framework: Impact of shaping on the MOF properties, Powder Technol., 2014, 255, 52-59.

144 J. Kim, S.-H. Kim, S.-T. Yang and W.-S. Ahn, Bench-scale preparation of $\mathrm{Cu}_{3}(\mathrm{BTC})_{2}$ by ethanol reflux: Synthesis optimization and adsorption/catalytic applications, Microporous Mesoporous Mater., 2012, 161, 48-55.

145 P.-J. Kim, Y.-W. You, H. Park, J.-S. Chang, Y.-S. Bae, C.-H. Lee and J.-K. Suh, Separation of $\mathrm{SF}_{6}$ from $\mathrm{SF}_{6} / \mathrm{N}_{2}$ mixture using metal-organic framework MIL-100(Fe) granule, Chem. Eng. J., 2015, 262, 683-690.

146 M. A. Moreira, J. C. Santos, A. F. Ferreira, J. M. Loureiro, F. Ragon, P. Horcajada, K. E. Shim, Y. K. Hwang, U. H. Lee, J. S. Chang, C. Serre and A. E. Rodrigues, Reverse shape selectivity in the liquid-phase adsorption of xylene isomers in zirconium terephthalate MOF UiO-66, Langmuir, 2012, 28, 5715-5723.

147 D. Liu, J. J. Purewal, J. Yang, A. Sudik, S. Maurer, U. Mueller, J. Ni and D. J. Siegel, MOF-5 composites exhibiting improved thermal conductivity, Int. J. Hydrogen Energy, 2012, 37, 6109-6117.

148 G. W. Peterson, J. B. DeCoste, T. G. Glover, Y. Huang, H. Jasuja and K. S. Walton, Effects of pelletization pressure on the physical and chemical properties of the metalorganic frameworks $\mathrm{Cu}_{3}(\mathrm{BTC})_{2}$ and UiO-66, Microporous Mesoporous Mater., 2013, 179, 48-53.

149 K. Eum, A. Rownaghi, D. Choi, R. R. Bhave, C. W. Jones and S. Nair, Fluidic Processing of High-Performance ZIF-8
Membranes on Polymeric Hollow Fibers: Mechanistic Insights and Microstructure Control, Adv. Funct. Mater., 2016, 26, 5011-5018.

150 H. Ji, S. Hwang, K. Kim, C. Kim and N. C. Jeong, Direct in Situ Conversion of Metals into Metal-Organic Frameworks: A Strategy for the Rapid Growth of MOF Films on Metal Substrates, ACS Appl. Mater. Interfaces, 2016, 8, 32414-32420.

151 W.-J. Li, J. Lü, S.-Y. Gao, Q.-H. Li and R. Cao, Electrochemical preparation of metal-organic framework films for fast detection of nitro explosives, J. Mater. Chem. A, 2014, 2, 19473-19478.

152 C. Scherb, A. Schodel and T. Bein, Directing the structure of metal-organic frameworks by oriented surface growth on an organic monolayer, Angew. Chem., Int. Ed., 2008, 47, 5777-5779.

153 E. Biemmi, C. Scherb and T. Bein, Oriented Growth of the Metal Organic Framework $\mathrm{Cu}_{3}(\mathrm{BTC})_{2}\left(\mathrm{H}_{2} \mathrm{O}\right)_{3} \cdot x \mathrm{H}_{2} \mathrm{O}$ Tunable with Functionalized Self-Assembled Monolayers, J. Am. Chem. Soc., 2007, 129, 8054-8055.

154 A. de la Pena Ruigomez, D. Rodriguez-San-Miguel, K. C. Stylianou, M. Cavallini, D. Gentili, F. Liscio, S. Milita and O. M. Roscioni, et al., Direct On-Surface Patterning of a Crystalline Laminar Covalent Organic Framework Synthesized at Room Temperature, Chemistry, 2015, 21, 10666-10670.

155 B. Garai, A. Mallick and R. Banerjee, Photochromic metalorganic frameworks for inkless and erasable printing, Chem. Sci., 2016, 7, 2195-2200.

156 H. Jiang, Q. Wang, H. Wang, Y. Chen and M. Zhang, MOF74 as an Efficient Catalyst for the Low-Temperature Selective Catalytic Reduction of $\mathrm{NO}_{\mathrm{x}}$ with $\mathrm{NH}_{3}$, ACS Appl. Mater. Interfaces, 2016, 8, 26817-26826.

157 J. Park and M. Oh, Construction of flexible metal-organic framework (MOF) papers through MOF growth on filter paper and their selective dye capture, Nanoscale, 2017, 9, 12850-12854.

158 Y. Chen, X. Huang, S. Zhang, S. Li, S. Cao, X. Pei, J. Zhou, $\mathrm{X}$. Feng and B. Wang, Shaping of Metal-Organic Frameworks: From Fluid to Shaped Bodies and Robust Foams, J. Am. Chem. Soc., 2016, 138, 10810-10813.

159 T. Tian, Z. Zeng, D. Vulpe, M. E. Casco, G. Divitini, P. A. Midgley, J. Silvestre-Albero, J. C. Tan, P. Z. Moghadam and D. Fairen-Jimenez, A sol-gel monolithic metal-organic framework with enhanced methane uptake, Nat. Mater., 2018, 17, 174-179.

160 A. Mallick, G. Mouchaham, P. M. Bhatt, W. Liang, Y. Belmabkhout, K. Adil, A. Jamal and M. Eddaoudi, Advances in Shaping of Metal-Organic Frameworks for $\mathrm{CO}_{2}$ Capture: Understanding the Effect of Rubbery and Glassy Polymeric Binders, Ind. Eng. Chem. Res., 2018, 57, 16897-16902. 